Portland State University

PDXScholar

$1-1-1982$

\title{
The effect of chronic post-natal protein deprivation on the social interaction of the rhesus macaque
}

Gertrude Alice Fogle

Portland State University

Follow this and additional works at: https://pdxscholar.library.pdx.edu/open_access_etds Let us know how access to this document benefits you.

\section{Recommended Citation}

Fogle, Gertrude Alice, "The effect of chronic post-natal protein deprivation on the social interaction of the rhesus macaque" (1982). Dissertations and Theses. Paper 473.

https://doi.org/10.15760/etd.473

This Thesis is brought to you for free and open access. It has been accepted for inclusion in Dissertations and Theses by an authorized administrator of PDXScholar. Please contact us if we can make this document more accessible: pdxscholar@pdx.edu. 
THE EFFECT OF CHRONIC POST-NATAL PROTEIN DEPRIVATION

ON THE SOCIAL INTERACTION OF THE

RHESUS MACAQUE

by
GERTRUDE (TRUDY) ALICE FOGLE

A thesis submitted in partial fulfillment of the requirements for the degree of

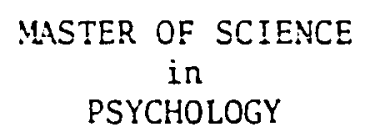

Portland State University

C) 1982 Gertrude (Trudy) Alice Fogle 
TO THE OFFICE OF GRADUATE STUDIES AND RESEARCH:

The members of the Committee approve the thesis of Gertrude (Trudy) Al ice Fogle presented June 2, 1982.

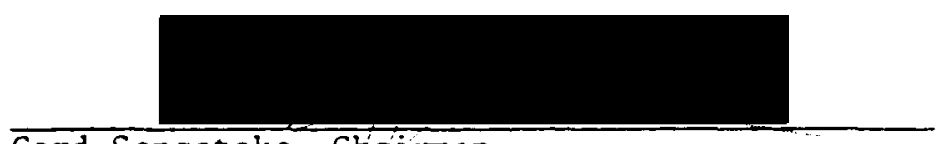

Cord Sengstake, Chatirman

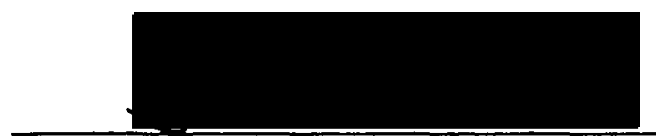

Jim Paulson

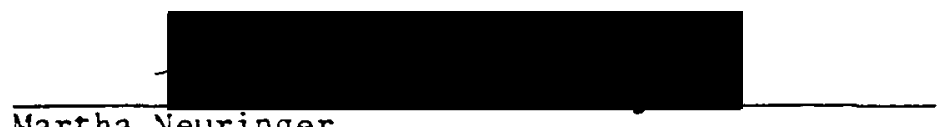

Martha Neuringer

APPROVED :

David Wrench, Head, Department of Psychology

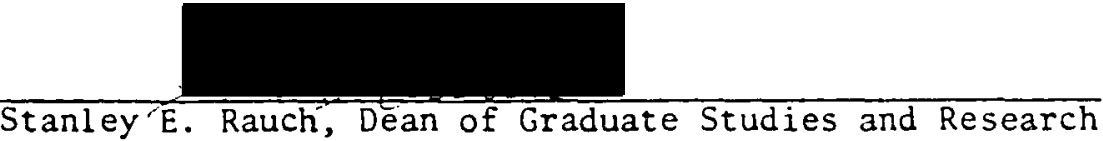


AN ABSTRACT OF THE THESIS OF Gertrude (Trudy) Alice Fogle for the Master of Science in Psychology degree presented June 2, 1982.

T1tle: The Effect of Chron1c Post-Natal Protein Deprivation on the Soctal Interaction of the Rhesus Macaque.

APPROVED BY MEMBERS OF THE THESIS COMMTTEE:

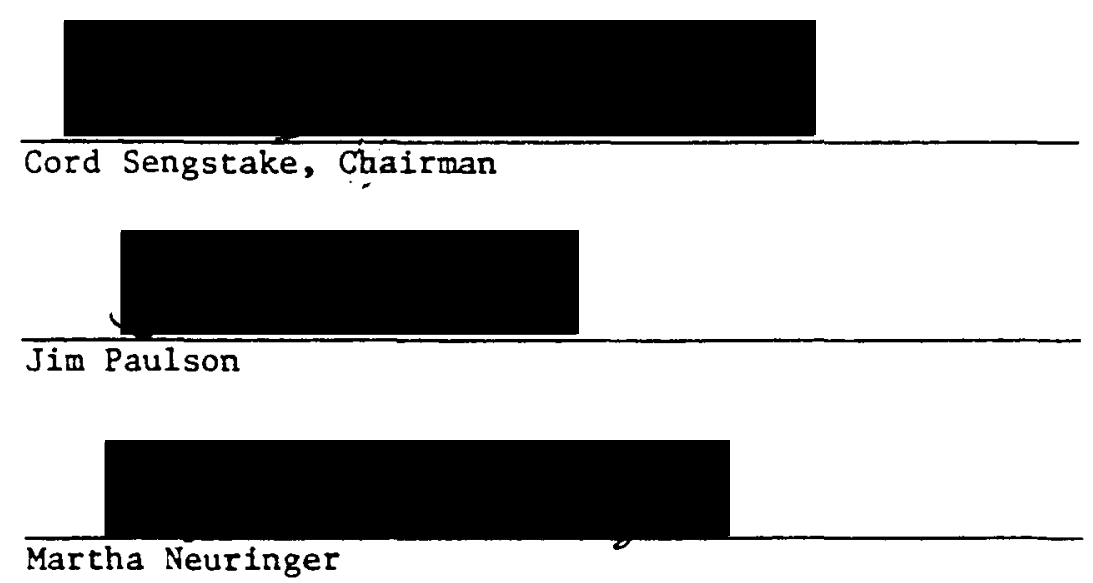

It has been well documented that protein calorie malnutrition (PCM) gives rise to phystological and behavioral deficits. These deficits include changes in emotional, exploratory and social behaviors of the malnourished organism. In particular, previous research has demonstrated that PCM from infancy results in avoidance of and fallure to initiate social interactions as well as decreased contact with the environment, which in turn, further disrupt emotional and social development. This study examined the effects of chronic protein malnutrition on the social behavior of adult rhesus macaques by experimentally testing the hypothesis that deficient monkeys, unlike 
normal well-fed ones, are more 11 kely to avoid social encounters than to seek them out. In addition, the animals' social interactions were recorded and analyzed.

Subjects consisted of eleven adult rhesus monkeys (Macaca mulatta). Five were fed a protein-deficient diet $(3.0 \%$ of total kilocalories) and six were fed adequate amounts of protein ( $14 \%$ of total kilocalories) from birth. After habituation to the test apparatus, subjects were trained to perform an operant response which opened a sliding door. During training, the response allowed access to food. In the final testing, opening the door allowed access to a social partner. If the subject performed the response and released a social partner, the social behaviors of the pair was recorded for ten minutes. Each subject was given three opportunities, on three separate occasions, to release every other subject.

Protein-deficient subjects habituated to the experimental apparatus and acquired a simple operant response at the same rate as the control subjects. The protein-deficient monkeys, however, failed to generalize this operant response as rapidly as the control monkeys. As predicted, protein-deficient monkeys performed an operant response allowing access to a social partner less frequently than did the control monkeys. For 1ike-diet pairings both the control and deficlent subjects released approximately $60 \%$ of their partiers; however, controls were far more likely to release a dissimilar diet partner (84\% probability) than were deficient subjects ( $39 \%$ probability). Diet condition of the releasor was 2 significant factor, whereas diet condition of the releasee was not. Vartables which could confound 
these findings were examined. It was found that: 1 . The difference between diet groups was not accounted for by proximity of home cages; 2. Sex of the animals was not a confounding factor; 3. Although body weight and diet condition were highly correlated, body weight alone did not exert an effect above and beyond that of diet condition; 4 . Dominance status, although correlated with both diet condition and body welght, showed only a weak correlation with the likelihood of one subject releasing another when the effect of diet condition was partialed out. In summary, diet condition played the major determining role in the frequency of release rates.

Social behavior data was collected throughout the final phase of the experiment. Both groups of animals exhibited minimal play and sexual behaviors. Protein-deficient monkeys were more submissive than their matched controls. Subjects deviated most dramatically from one another In two behavioral clusters: disturbed (defined as selfstimulatory, autistic-like behaviors) and exploratory behaviors. Deficient monkeys engaged in more disturbed behaviors, while control monkeys engaged in more exploratory behaviors. Results are discussed in terms of behavioral similarity to social isolate animals, and possible nutritional-environmental interaction leading to chronic or persistent deficits in soctal development. 


\section{ACKNOWLEDGMENTS}

I would like to thank all the members of my thesis cormittee: Dr. Neuringer, without her assistance and role model this thesis would never have been undertaken; Dr. Paulson, who is living proof of the necessity of a statistician; and Dr. Sengstake for his faith, humor and proddings. I would also like to thank my special and precious friends (Henry Rhone, Jr., Cheryl Jardine, Tina Bammes, and Karla Fiori) who insured my emotional survival throughout this project. 
TABLE OF CONTENTS

PAGE

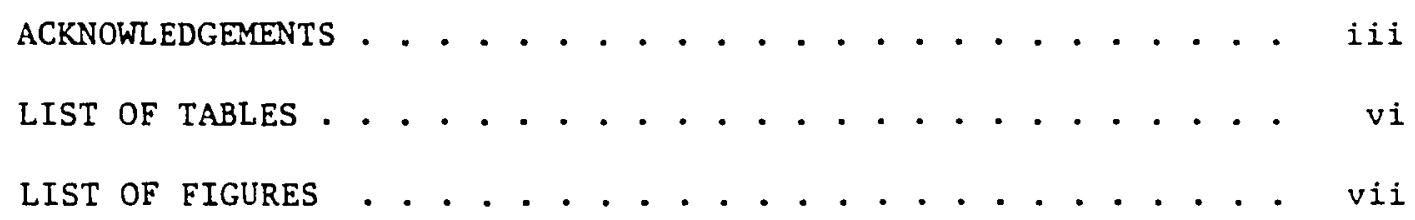

CHAPTER

I INTRODUCTION . . . . . . . . . . . . . . . . . . . 1

II REVIEW OF THE LITERATURE . . . . . . . . . . . . . . . . 5

Learning . . . . . . . . . . . . . . . 5

Emotional and Exploratory Behavior . . . . . . 6

Social Behavior . . . . . . . . . . . . . 9

The Modulating Influence of Environment . . . . . 10

Statement of the Problem . . . . . . . . . . 12

II MATERIALS AND METHODS . . . . . . . . . . . . . . . 14

Subjects . . . . . . . . . . . . . . . 14

Experimental Histories . . . . . . . . . . . 21

Housing . . . . . . . . . . . . . . . . . 23

Apparatus . . . . . . . . . . . . . . . 24

Phase I - Habituation to the Selection Chamber . . 29

Phase II - Habituation to the Selection . . . . .

Chamber Doors . . . . . . . . . . . . 29

Phase III - Shaping the Key Press . . . . . . . . 31

Phase IV - Generalization of the Keypressing 
Response . . . . . . . . . . . . . . 34

Phase V - Selection of a Social Partner . . . . . . 36

Definitions - Behavioral Observation Scoring

Sheet, Form A . . . . . . . . . . . . 38

Definitions - Behavioral Observation Scoring

Sheet, Form B . . . . . . . . . . . . 41

Definitions - Behavioral Observation Scoring

Sheet, Form C . . . . . . . . . . . . 44

IV RESULTS AND DISCUSSION . • . . . . . . . . . . . . . 51

Habituation: Phases I and II. . . . . . . . 51

Phase III: Shaping the Key Press . . . . . . . 53

Phase IV: Generalization of the Key Pressing

Response ................ . . 53

Phase V: Release Data . . . . . . . . . 54

Phase V: Social Behaviors . . . . . . . . 69

Conclusion . . . . . . . . . . . . . . 74

BIBLIOGRAPHY . . . . . . . . . . . . . . . . . . . . . 80

APPENDIX A: BLOOD BIOCHEMISTRY DATA . . . . . . . . . . . . . . 91

APPENDIX B: EXPERIMENTAL HISTORIES . . . . . . . . . . . . . 103 


\section{LIST OF TABLES}

TABLE

PAGE

I Infant Formulas for Deficient and Control Groups . . . 15

II Semipurified Diets for Deficient and Control Groups . . . 16

II Composition of Vitamin Mix for All Diets . . . . . . 17

IV Subjects Composing Social Groups SPARCE and SIMPL . . . . 22

V ANOVA Releasor-Releasee Diet Conditions . . . . . . 57

VI ANOVA Releasor-Releasee Diet Conditions (Control Diet

versus Protein-Deficlent Diet) with Home Cage

Partner Pairings Deleted ............ 60

VII ANOVA Three Factors (Diet $X$ Sex of Releasor $X$ Sex

of Releasee) with Repeated Measures on One Factor . . 63 
1. Average Body Weights for the Control and ProteinDeficient Groups ............. 19

2. Body Weights for Individual Animals . . . . . . 20

3. Schemata for Home Cage Partners .......... 25

4. The Selection Chamber............. 26

5. Floor Plan for the Selection Chamber . . . . . . 27

6. Data Collection Sheet for Phase I of training . . . 30

7. Data Collection Sheet for Phase II . . . . . . . 32

8. Data Collection Sheet for Phase III . . . . . . . 35

9. Data Collection Sheet for Phase IV . . . . . . . 37

10. Behavioral Observation Scoring Sheet, Form A . . . . 39

11. Behavioral observation Scoring Sheet, Form B . . . . 42

12. Behavioral observation Scoring Sheet, Form C . . . . 43

13. Figure Sequence of Pairings, Test Pairs SFARCE . . . . 48

14. Figure Sequence of Pairings, Test Pairs SIMPL . . . . 49

15. Habituation to the Selection Chamber, Phases I-IV

Trials to Criterion for Each Phase (Mean Plus and Minus S.E.) ............. 52

16. Effect of Diet Condition on Frequency of Release (Gean Plus and Minus S.E.) . . . . . . . . 55 17. Frequency of Release with Home Cage Partners Omitted 
(Mean Plus and Minus S.E.) . . . . . . . . . 59

18. Effect of Diet Condition and Sex on Frequency of

Release (Mean Plus and Minus S.E.)......... 61

19. Effect of Body Welght on Frequency of Release (Mean

Plus and Minus S.E.).............. 64

20. Effect of Dominance on Frequency of Release (Kean

Plus and Minus S.E.).............. 67

21. Effect of Diet Condition on Frequency of Dominant

and Submissive Behaviors (Mean Plus and Minus S.E.) • 71

22. Effect of Diet Condition on Frequency of Social

Contact, Play, and Sexual Behaviors (Mean Plus and

Minus S.E.) ................ 72

23. Effect of Diet Condition on Frequency of Disturbed and

Exploratory Behaviors (Mean Plus and Minus S.E.) . . 73

24. Effect of Diet Condition on Serum Protein Levels (Mean

Plus and Minus S.E.) .............. 94

25. Effect of Diet Condition on Serum Albumin Levels (Mean

Plus and Minus S.E.)............... 96

26. Effect of Diet Condition on Gama Globulin Levels

(Mean Plus and Minus S.E.)........... 98

27. Effect of Diet Condition on Blood Urea Nitrogen Levels

(Mean Plus and Minus S.E.)............. . 99

28. Effect of Diet Condition on Serum Glucose Levels (Mean

Plus and Minus S.E.).............. 101

29. Effect of Diet Condition on Hemoglobin Levels (Mean 
Plus and Minus S.E.) ............ 102 


\section{CHAPTER I}

\section{INTRODUCTION}

The developing countries' greatest health problem is the protein calorie malnutrition (PCM) of their infants and children. It is estimated that 60 to 70 percent of the world's pre-school age children experience PCM (Behar, 1968). Even in the U.S.A., pockets of poverty and ignorance exist in which some children suffer the severe debilitation of PCM (Chase and Martin, 1970). The prevalence of PCM has motivated research intended to define and delineate the consequences of nutritional deprivation.

Research with malnourished children has documented persistent physical, psysiological, and behavioral deficits. PCM results in growth retardation (Monckeberg, 1968; Cravioto, DeLicardie, and Birch, 1966), diminished head circumference (Monckeberg, 1967), retarded motor development (Scrimshaw and Behar, 1961; Stoch and Smythe, 1968; Waterlow, Cravioto and Stephen, 1960), and alterations in the development and function of the central nervous system (Chase, Dorsey and McKhann, 1967; Cheek, Holt, and Mellits, 1972; Dobbing and Path, 1968). Numerous studies have also reported delayed or impaired cognitive development as determined by I.Q. scores and developmental quotients (Brockman and Ricciuti, 1971; Cabak and Najdanvik, 1965; Champakan, Srikantia and Gopalan, 1968; Cobos and Guevara, 1973; Klein, et al., 1971; Pollitt, 1972; Stoch and Smythe, 1963; Sulzer, 
1969; Wiener, 1970; and Witkop, 1970). The extent of mental and physical impairment was highly correlated with both the duration of the nutritional insult as well as the earliness of onset (Chase and Martin, 1970). Behavioral abnormalities, such as apathy, distractibility, impaired concentration, and emotionality have also been noted (Gerber and Dean, 1956; Kallen, 1973; Klein, et al., 1969; Latham, 1969; McKay, McKay, and Sinisterra, 1972).

These findings support the contention that PCM represents a profound world health problem. One question in particular that needs to be investigated is the long-term impact that these physiological and behavioral changes exert on the social functioning of the malnourished individual. Ricciuti (1971) states:

It would be useful to know more about the manner in which the physical and behavioral consequences of malnutrition might limit the infant's capacity to respond socially to others... Such potential influences would have significant implications not only for the infant's social and personality development but also with regard to the nature of the environmental stimulation available to him as a facilitator of intellectual development.

Latham (1969) and Sussman (1972) speculate that the psychological characteristics of an afflicted population are so altered that adaptive functioning and social competency are imperiled. They further hypothesize that individuals suffering from PCM run a greater risk of inadequate socialization, are less competent at formulating interpersonal relations, and therefore may only attain a marginal social existence in the real world.

PCM does not appear in isolation but is one element in a constellation of associated or interactive factors. Unfortunately for research, human studies are confounded by many such variables in 
addition to nutritional deprivation. These variables include

1. genetic history;

2. impoverished socio-economic status;

3. inadequate or nonexistent health care;

4. possible parental neglect;

5. greater exposure to unsanitary conditions;

6. high susceptibility to infection resulting in more numerous childhood diseases;

7. an unstimulating or truncating environment in terms of educational, cultural, and experiential opportunities.

These factors may exaggerate or mask possible dietary effects on intelligence, learning, emotionality and social adjustment. In addition, in human studies, the independent variable (nutrition) cannot be adequately measured or controlled. It is the role of research to tease apart and isolate the consequences of nutritional deprivation per se, as separate from those of other contributing or attenuating variables. Because control of these factors is not possible with human infants and children, animal models are necessary to investigate the effects of PCM in systematic experiments in which variables can be individually and discretely manipulated.

Although studies with rats and other small mammals are essential in the early explorative stages of research, their results cannot easily be generalized to human children and are not comparable to findings from primate studies. The rat is developmentally very immature at birth in comparison to both nonhuman primates and human infants. This immaturity makes the rat far more susceptible to the effects of postnatal malnutrition. The rat also has a brief lifespan 
and its rapid growth rate necessitates a much higher requirement for protein than is found in primates. In addition, methodological problems are inherent in rat studies. It is almost impossible to rear newborn rat pups by hand. Therefore, malnutrition of newborn rats is achieved by restricting their access to the nursing mother, increasing the litter size, or modifying the mother's diet. Such interventions, however, also affect maternal behavior and the amount of social stimulation, thereby changing the early experience of the offspring (Frankova, 1971; Massaro, Levitsky and Barnes, 1972). Such changes in early experience by themselves are known to affect later behavior. Monkeys are far more similar to human infants in their pace and schedules of development, their nutritional requirements, and their behavioral repertoire. Therefore, a nonhuman primate such as the rhesus macaque (macaca mulatta) provides the best available animal model of human malnutrition. The research proposed here will use rhesus macaques to study the effects of protein malnutrition on social functioning. 
CHAPTER I I

REVIEW OF THE LITERATURE

This section will review research which has used animal models to study the effects of nutritional deprivation on learning, emotionality, and social behavior, and the relationship of these effects to early environmental experience.

\section{Learning}

The effect of PCM on learning was initial focus of animal research. Conflicting results were reported even for acquisition of simple discrimination problems. While some investigators found impaired maze learning by rats subjected to early malnutrition (Griffiths and Senter, 1954; Wells, et al., 1972; Zimmermann and Wells, 1971), others claimed equal or superior performance (Bernhardt, 1936; Caldwell and Churchill, 1967; Pilgrim, et al., 1951). Barnes, et al. (1973) hypothesized that food rewards had much greater saliency for protein-deprived subjects and consequently increased both their motivation and performance. Smart and Dobbing (1972) reported increased drive and superior learning for low protein subjects when a food reward was utilized. In learning studies, therefore, the nature of the reinforcer may be critical.

Although results form animal studies proved to be equivocal and failed to elucidate a simple direct relationship between malnutrition and learning, they served a vital purpose in that they redirected the 
focus of attention to other bahavioral changes in protein deprived organisims. Incidental observations during learning experiments suggested abnormalities of motivation, exploration and emotionality which turned out to be far more striking and consistent consequences of protein deprivation. These will be described in the next section.

Emotional and Exploratory Behavior

Several investigators have documented changes in emotional and exploratory behaviors of malnourished rats, both those previously malnourished in early life and those malnourished at the time of testing. Examples of such behavioral abnormalities are:

a. stereotyped behaviors, such as unadaptive, perseverative jumping regardless of environmental contingencies during conditioned avoidance training. The organism appeared unable to inhibit or suppress a behavior that in one setting was appropriate and functional but in another setting no longer was (Frankova and Barnes, 1968 b);

b. hyper-reactivity to environmental stressors, as measured by heightened startle response to a loud noise, increased defecation, trembling, pilo-errection, rapid respiration, suppression of movement in response to aversive stimuli, greater passive avoidance of electric shock (Cowley and Griesel, 1964; Barnes, et al., 1967; Levitsky and Barnes, 1969, 1970 and 1972);

c. alterations in exploratory patterns, such as increased latency to emerge from a home cage, decreased locomotion and decreased rearing responses (standing on hind legs) in an open field in both currently malnourished rats (Cowley and Griesel, 1964) and those previously malnourished in early life (Lat, widdowson and MicCance, 1960; Frankova and Barnes, 1968 b).

Some of these findings were confirmed and extended by studies of other species such as pigs (Barnes, Moore, and Pond, 1970), mice (Smart, 1971), and dogs (Platt, Heard and Stewart, 1964). Primate research has revealed similar behavioral abberations. 
Reduced exploration has been reported in protein-deficient rhesus monkeys as well as protein-and calorie-deprived cebus monkeys (Elias and Samonds, 1974; Geist, Wells, and Zimmermann, 1972; Kerr, et al., 1970). The deprived animals also engaged in abnormal self-stimulatory behaviors such as rocking, thumb- and toe-sucking, and head-banging (Elias and Samonds, 1974, 1977; Zimnermann, et al., 1972). Zimmermann and colleagues (1974 and 1975) described their protein-deficient rhesus monkeys as "neophobic", that is, fearful of novel stimuli and settings. A neophobic reaction consisted not only of avoidance but also entailed emotional responses such as shrieking, self-clasping, freezing, and defecating. The malnourished monkeys manipulated chains and novel objects placed in their home cages less frequently, solved fewer mechanical puzzle-board problems, and thereby displayed less curiosity and environmental interaction than did their matched controls. The institution of a food reward for manipulating mechanical puzzles in the home cage increased the manipulatory behavior of deficient animals to the level of controls. However, a food reward failed to overcome neophobic reactions in a shuttle apparatus in which the animals had to climb from the bottom of a wire mesh cylinder to the top to obtain the food reward. A novel object, introduced into the center of the cylinder once the animal had acquired the shuttle response, resulted in a significant reduction in performance. Ongoing behaviors and learning therefore can be disrupted by neophobic emotional reactions unless an extensive adaptation period is allowed.

An early hypothesis was that nutritional deprivation results in 
depressed environmental responsiveness because the organism is attempting to conserve energy by not moving. This hypothesis was not sustantiated by research, as protein-deficient monkeys showed impoverished environmental interaction despite equivalent or greater activity levels (Geist, Zimmermann and Strobel, 1972; Neuringer, (1977 and 1978).

Zimmermann, et al. (1972) assessed visual curiosity in malnourished monkeys. Subjects were placed in a "visual curiosity chamber" for one hour sessions. The low protein group had lower initial rates of visual exploration. These differences, however, did not persist over time and with repeated testing. Neuringer (1977and 1978) assessed visual curiosity and preferences in postnatally proteindeficient rhesus monkeys. Animals were placed in an experimental chamber which was entirely enclosed. Visual access to the outside room could only be gained by manually lifting and holding open a door on the front of the cage. Recordings were made of the number of times a monkey opened the door to look outside its cage and the length of time it engaged in looking. When the visual stimulus consisted only of a view of the laboratory room no differences were found between groups. When the stimulus consisted of visual access to familiar monkeys, both deficient and control animals increased their response rates. The deficient animals, however, showed significantly smaller increases.

Thus, nutritional deficiency appears consistently to give rise to neophobia and heightened emotionality which can only have a cumalatively detrimental effect on the developing organism. Deficient 
animals display increased negative reactions to changes in their environment. Such behavioral responses lead to maladaptive inflexibility and limit the animal's ability to learn from interacting with its environment.

\section{Social Behavior}

Nutritional insufficiency has also been shown to influence the development and expression of social behaviors. Postnatally deprived rats, observed while still nutritionally deprived, initiated social interaction with their littermates less frequently than did controls (Frankova, 1973). The deprived pups actually avoided social encounters and, when approached, displayed negative reactions (they stiffened, trembled, bristled and pushed the social partner away) which discouraged further contact. Whatson, Smart, and Dobbing (1974) noted a greater incidence of aggression among their previously malnourished rats. When placed in mixed social groups of control and low protein animals, the deprived subjects showed less aggression than among themselves, but generally initiated more social interactions than did the controls. However, the experimental subjects tended to submit more frequently to the control animals rather than the other way around. Social isolation, surprisingly, served to increase the deficient animal's social responsiveness.

Kerr, et al. (1970) described their low protein infant monkeys as "unresponsive, withdrawn and retarded in peer group social interactions." Zimmermann, et al. (1970) reported virtually non-existent or ineffectual sexual behaviors in protein malnourished monkeys. Geist, Zimmermann and Strobel (1972) found less 
play-approach behavior, less sexual activity and more aggression in like-diet groups of malnourished rhesus monkeys than in control groups of adequately fed monkeys. Deficient animals also established less stable social dominance hierarchies (Warren and Maroney, 1958). Another study examined social behavior in mixed groups of proteindeficient and well-fed rhesus monkeys and showed similar changes in the social repertoires of the deprived animals, including fewer dominant and aggressive bahaviors, more fearful and submissive behaviors, a paucity of play and almost no sexual activity when contrasted to their matched controls (Neuringer, 1977). A longitudinal study of these subjects indicates that these behavioral modifications not only persist but that the divergence between groups is amplified with time (Neuringer, 1978).

Thus nutritional insult leads to reduced social interactions as well as decreased contact with the environment, and thereby prevents normal social development.

The Modulating Influence of Environment

Protein-deficient organisms have been likened to socially isolated animals. Animals raised in social isolation also demonstrate profound behavioral and social maladjustments such as neophobia, reduced social interactions, inappropriate sexual activity, unstable dominance relationships, and decreased fear thresholds (Harlow, Mason and Green, 1962; Mason, et al., 1968; Melzack, 1954; Zimmermann, et al., 1970). Several studies have examined the interaction of social isolation and protein malnutrition. In both rats and monkeys, the behavioral consequences of these two factors appear to be 
additive, especially when they are both instituted during vulnerable developmental periods (Levitsky and Barnes, 1972; Geist, Wells and Zimmermann, 1972; Frankova, 1972; Elias and Samonds, 1974 and 1975). Conversely, environmental enrichment appears to reduce the effects of malnutrition, particularly if provided during developmental critical periods (Levitsky and Barnes, 1972; Kanwit, 1976).

An organism develops problem-solving and social skills by interacting with the stimuli of its external world. Enrichment in early life promotes interaction with the environment which subserves an adaptive function in later life, thereby enabling the animal to cope with its surroundings. Anything which impedes such interaction may retard developmental maturation. It has been hypothesized that malnutrition functionally isolates the organism from its environment and therefore mimics the effects of environmental isolation (Frankova and Barnes, 1968; Levitsky and Barnes, 1972). This self-induced isolation may result from obstructed reception and integration of sensory input, disrupted motivation and attention, or altered saliency of environmental cues, due perhaps in part to increased attention to food. Whatever the mechanism, the reduced environmental stimulation modifies the animal's early experience, thereby limiting emotional and social development.

Three interrelated fields of research have been presented and an overview of the findings and some experimental questions involved in each area have been provided. This review of the literature, although representative of the data and issues, is not intended to provide an exhaustive survey. It has suggested that cognative 
functioning is not significantly altered by PCM, as changes in attention, exploration, and emotionality explain most of the effects on learning. The most dramatic effects of PCM are on emotional and exploratory behaviors and social development. This review also suggests that the development of emotional and exploratory behaviors is closely related to the development of social behavior. This study will attempt to further define the effects of protein deprivation on social behavior.

\section{Statement of the Problem}

Protein-deficient animals have been depicted as socially apathetic and unresponsive. The findings cited in the literature review document aberrant social interactions such as avoidance of other animals, reduced play and approach behavior, a paucity of sexual activity and increased submissive and fearful behaviors. All of these previous measures of social behavior consisted of behavioral observations collected during peer-group interactions. The question of social motivation per se, however, has not been directly tested. Neuringer's (1977) visual exploration paradigm, in which animals had to perform a response in order to gain visual access to familiar monkeys, showed that malnourished subjects were less likely to look at other monkeys. This experiment suggested a more specific task to measure social behavior: giving monkeys the opportunity, after training, to perform an operant response to gain access to a social partner. This thesis will thereby experimentally test the assertion that deficient monkeys, unlike normal well-fed ones, are more likely to avoid social interactions than to seek them out. In view of 
previous studies, it is predicted that protein-deprived monkeys will perform the operant response less often, that is, they will release social partners with lower frequency than will the well-fed controls. This study will also examine the influence of the following factors for those animals who do release a social partner:
a. diet condition (for example, do animals release only like-diet partners?),
b. sex of the partner,
c. position in the dominance hierarchy (that is, do animals only release social mates who are lower in dominance rank?),
d. familiarity (for example, do animals tend to release partners from within previously established social groups more frequently than they do subjects outside this group?).

In addition, all social interactions will be observed and recorded so that any consistent differences between control and experimental animals can be determined. 
CHAPTER II I

MATERIALS AND METHODS

\section{Subjects}

All subjects were members of a longitudinal study investigating the behavioral and physiological consequences of chronic post-natal protein deficiency. This study was conducted at the Oregon Regional Primate Research Center under the direction of Dr. Neuringer.

Originally the subjects were twelve rhesus macaques. This experiment, however, involved eleven subjects as one monkey had died prior to the onset of this investigation. During the period of this experiment the subjects were young adults, six to seven years old.

All subjects were removed from their mothers within twenty-four hours of birth and placed in one of two conditions:

1. The experimental group consisted of five animals maintained on a protein-deficient infant formula diet with protein providing 3.0 per cent of total kilocalories (kcai) (Table I).

2. The control group consisted of six animals maintained on a control infant formula diet with protein providing 14.1 per cent of kcal (Table I).

At age 18 months, all animals were changed to solid semipurified diet (Table II). The deficient diet provided 3.0 per cent of kcal as protein compared to 14.0 per cent for the control diet. At age five years, the composition of the deficient diet was modified so that protein provided 3.8 percent of kcal (Table II).

The low protein subjects were fed more calories than the 
TABLE I

INEANT FORMULAS FOR DEFICIENT AND CONTROL GROUPS

\section{DEFICIENT DIET}

content $/ 250 \mathrm{ml}$

22 gm SIA

$16 \mathrm{gm}$ dextrose

16 gm lactose

12 gm SMA Fat Mix

$1.0 \mathrm{gm}$ Hegsted IV salt mix

1.0 gin water-soluble vitamin mix

$0.1 \mathrm{ml}$ vitamin $\mathrm{D}_{3}$ solution

$1.2 \mathrm{ml}$ Vidaslin-M

$210 \mathrm{ml}$ warm water

\section{CONTROL DIET}

content $/ 250 \mathrm{ml}$

\author{
$40 \mathrm{gm} \mathrm{SHA}$ \\ 3 gm casein hydrolysate \\ $1.2 \mathrm{ml}$ Vidaylin-M
}

$210 \mathrm{ml}$ warm water

$\begin{array}{llll}\text { Protein: } & 4.0 \% \text { by dry weight } & \text { Protein: } & 18.0 \% \text { by dry weight } \\ & 3.0 \% \text { of Kcal } & & 14.1 \% \text { of Kcal } \\ \text { Carbohydrate: } & 67.2 \% \text { by dry weight } & \text { Carbohydrate: } & 52.0 \% \text { by dry weight } \\ & 50.5 \% \text { of Kcal } & & 40.4 \% \text { of Kcal } \\ \text { Fat: } & 27.5 \% \text { by dry weight } & \text { Fat: } & 26.0 \% \text { by dry weight } \\ & 46.5 \% \text { of Kcal } & & 45.5 \% \text { of Kcal }\end{array}$


TABLE II

SEMIPURIFIED DIETS FOR DEFICIENT AND CONTROL GROUPS

\begin{tabular}{|c|c|c|}
\hline DEFICIENT DIET & DEFICIENT DIET & CONTROL DIET \\
\hline$\overline{\text { Ages } 11 / 2-5 \text { years }}$ & $\overline{\text { Ages } 5-7 \text { years }}$ & Ages $11 / 2-7$ years \\
\hline $610 \mathrm{gm}$ sucrose & $600 \mathrm{gm}$ sucrose & gm sucrose \\
\hline gm cornstarch & 153 gm cornstarch & gm cornstarch \\
\hline gm vitamin-free casein & gm vitamin-free casein & gm vitamin-free casein \\
\hline gm Alphacel & gm Alphacel & gm Alphacel \\
\hline gin corn oil & gm corn oil & gm corn oil \\
\hline gm Hegested IV salt mix & gm Hegested IV salt mix & gm Hegested IV salt mix \\
\hline gm vitamin mix & gm vitamin mix & gm vitamin mix \\
\hline $1.5 \mathrm{ml}$ vitamin $\mathrm{D}_{3}(2000 \mathrm{IU} / \mathrm{ml})$ & $1.5 \mathrm{ml}$ vitamin $\mathrm{D}_{3}(2000 \mathrm{IU} / \mathrm{ml})$ & $1.5 \mathrm{ml}$ vitamin $D_{3}(2000 \mathrm{IU} / \mathrm{ml})$ \\
\hline gm water & $200 \mathrm{gm}$ water & gm water \\
\hline
\end{tabular}

$\begin{array}{lll}\text { Protein: } & 2.8 \% \text { by weight } & 3.5 \% \text { by weight } \\ & 3.0 \% \text { of kcal. } & 3.8 \% \text { of kcal. } \\ \text { Carbohydrate: } & 56.7 \% \text { by weight } & 56.0 \% \text { by weight } \\ & 61.0 \% \text { of kcal. } & 60.2 \% \text { of kcal. } \\ \text { Fat: } & 14.9 \% \text { by weight } & 14.9 \% \text { by weight } \\ & 36.0 \% \text { of kcal. } & 36.0 \% \text { of kcal. }\end{array}$

$13.0 \%$ by weight

$14.0 \%$ of kcal.

$46.5 \%$ by weight

$50.0 \%$ of kcal.

$14.9 \%$ by weight

$36.0 \%$ of kcal. 
TABLE I I I

COMPOSITION OF VITAMIN MIX FOR ALL DIETS

\begin{tabular}{|c|c|c|c|c|c|c|c|c|c|c|c|c|c|c|}
\hline Vitamin A ace & etate & $(1$ & $\operatorname{mil}$ & i & on & un & & & & & & & 0.625 & $\mathrm{gm}$. \\
\hline Alpha Tocophe & erol & & . & - & - & - . & - & - & & & & & 5.0 & $\mathrm{gm}$. \\
\hline Ascorbic Acid & d. . & & . & . & . & . . & . & . & . & . & & & 25.0 & $\mathrm{gm}$. \\
\hline Inositol . & . . & & . & . & . & . & . & - & - & . & & & 50.0 & $\mathrm{gm}$. \\
\hline Choline $\mathrm{Cl}$ & . & & . & . & . & . & . & . & . & . & . & & 250.0 & $\mathrm{gm}$. \\
\hline Menadione . & . & . & . & . & . & . & . & . & . & - & . & & 2.0 & $\mathrm{gm}$. \\
\hline Niacin . & . & . & . & . & . & . & . & . & . & . & . & & 2.45 & $\mathrm{gm}$. \\
\hline Riboflavin & . & . & . & . & . & . & . & . & - & - & - & & 0.5 & $\mathrm{gm}$. \\
\hline Thiamine . & . & . & . & . & . & . & . & . & . & . & . & & 0.5 & $\mathrm{gm}$. \\
\hline Pyridoxine . & . . . & & . & . & . & . & . & - & . & . & . & & 0.5 & $\mathrm{gm}$. \\
\hline Calcium Panto & othenat & ite & . & . & . & & . & . & & & . & & 1.5 & $\mathrm{gm}$. \\
\hline Biotin & $\cdot \cdot \cdot$ & - . & - & - & . & & - & - & $\bullet$ & & - & & 10.0 & $g \mathrm{gm}$. \\
\hline Folic acid & - $\cdot$ & & . & & . & & - & - & $\cdot$ & & - & & 50.0 & $\mathrm{mg}$. \\
\hline Vitamin $B_{12}$ & . $\cdot$ & & & & & & & & & & & & 1.0 & \\
\hline
\end{tabular}


controls in an attempt to equalize body weight gains for both groups. This regime maintained body weight equality for the first two years. After this time the disparity in body weights could only have been prevented by significantly depriving the controls of calories, a step that was not adopted. At the time of this study, the control animals received $55 \mathrm{gm}$ and the deficient animals $90 \mathrm{gm}$ of their respective diets per feeding. The animals received two feedings per day at 8:00 AM and 4:00 PM. Water was provided ad libitum.

From the second to the fourth year of life deficient animals showed an average weight gain of 400 grams (from 2100 to 2500 grams), which is a growth rate of less than 20 per cent, whereas controls gained an average of 2500 grams (from approximately 2300 to 4800 grams) for a growth rate of 110 per cent. Figure 1 shows the average body weights for the two diet groups during the period of this study, and Figure 2 charts individual body weights for each subject.

Throughout the duration of the experiment blood biochemical determinations were also obtained. The blood data for the deficient group showed changes characteristic of protein deficiency, including reductions in blood urea nitrogen, total serum protein, serun albumin, and hemoglobin. Blood glucose levels, although quite variable, were generally lower in the deficient group. These biochemical determinants document the existence of a significant physiological impact on the organism as a result of protein deficiency. Appendix A provides a detailed analysis of the blood biochemistry data. 


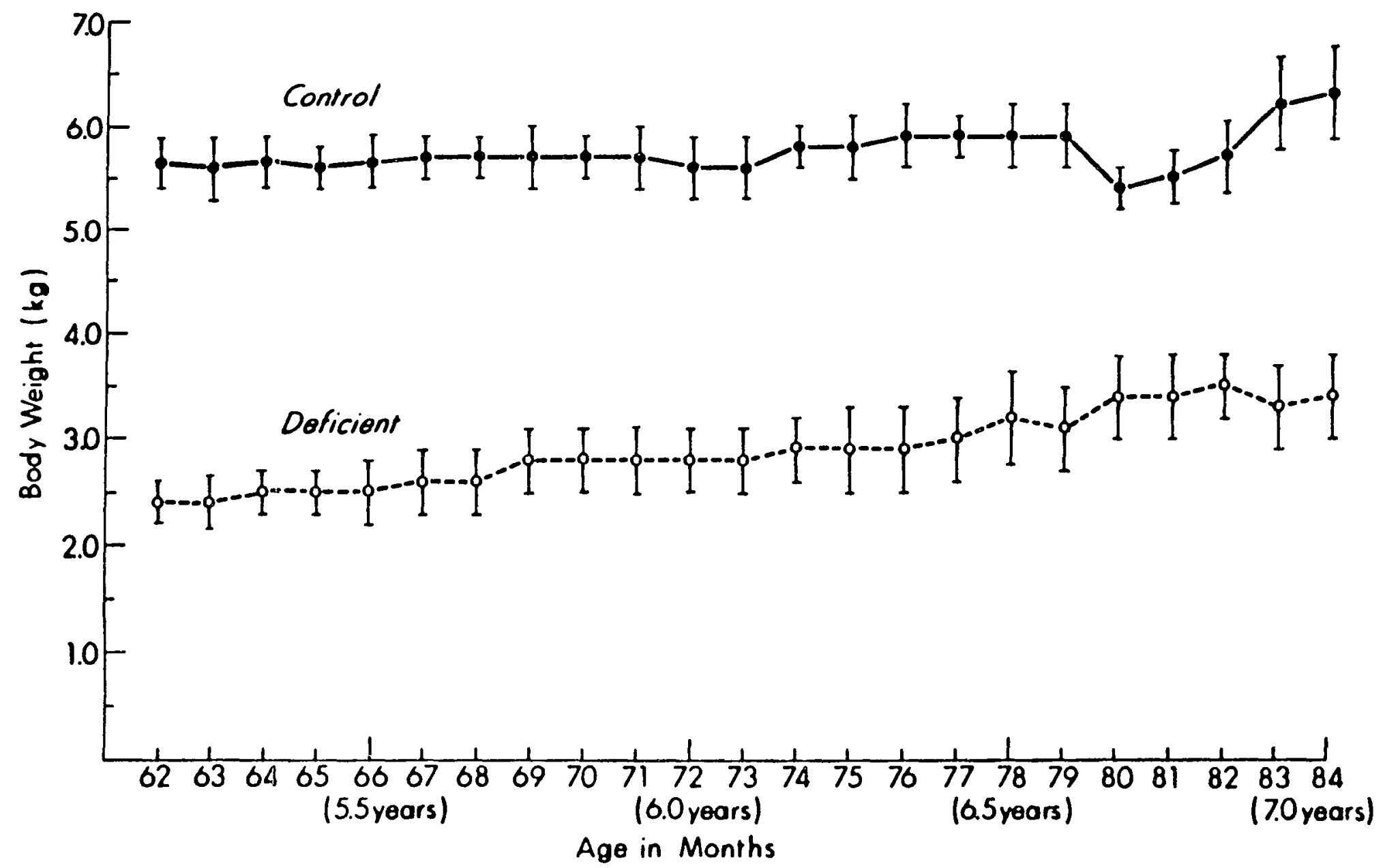

Flgure 1. Average Body Welghts for the Control and Protein-Deficient Groups. 


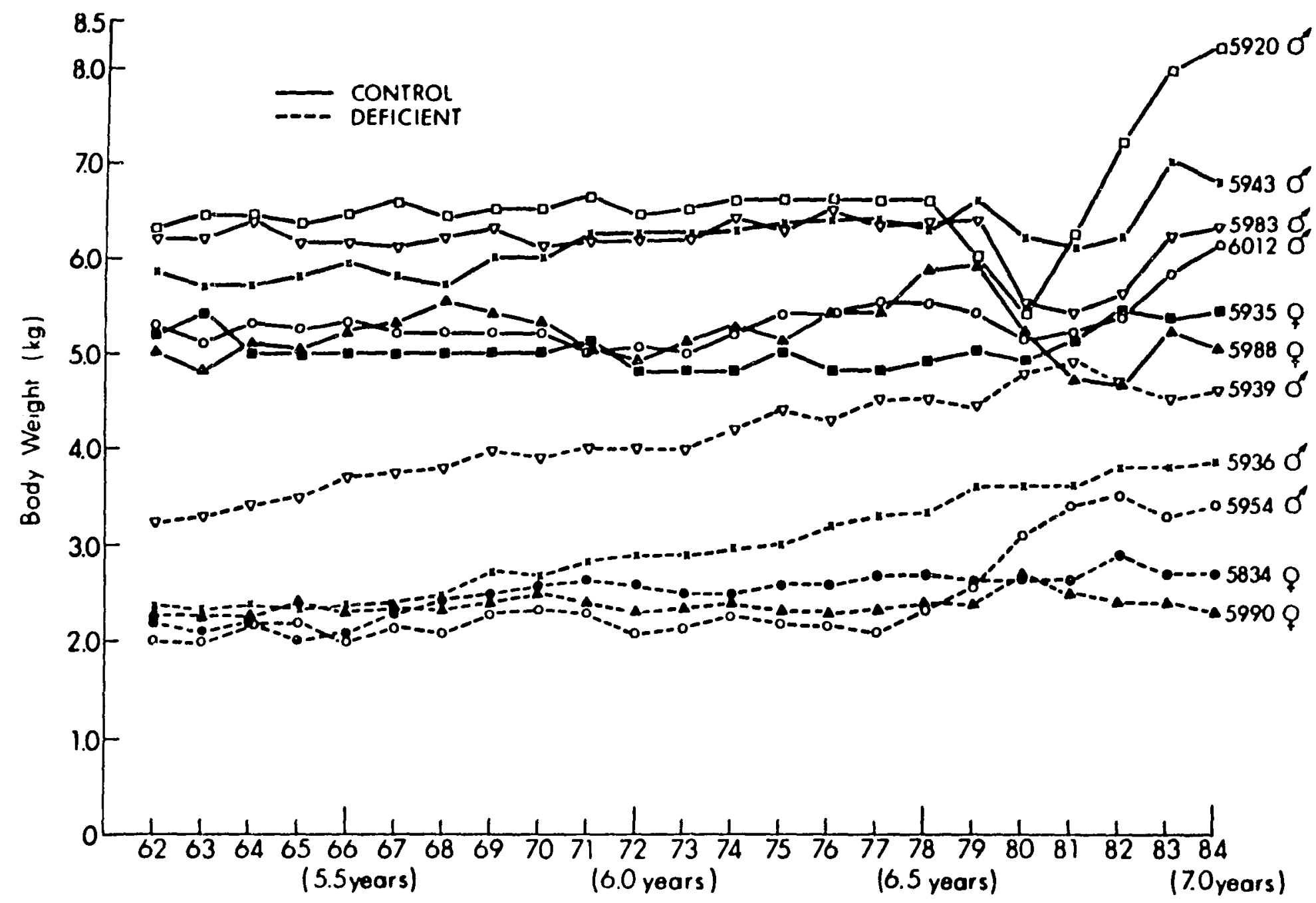

Figure 2. Body Welghts for Individual Animals.

Age in Months 
Experimental Histories

Because the subjects were members of a longitudinal study of postnatal protein deficiency, they had extensive experimental histories, which are summarized in Appendix B. Of particular relevance to the research presently undertaken is the fact that mixed groups of control and deficient animals were formed to observe and assess social behavior. Two social groups were formed and were identified by the acronyms SPARCE and SIMPL (Table IV). Each group initially consisted of two control males, two deficient males, one control female and one deficient female. Beginning at two months of age, each group received thirty minutes of daily social contact for 100 days. During this period their social behaviors and interactions were observed and scored. Control and protein deficient subjects demonstrated equal frequencies of aggressive, dominant, sexual and play behaviors. The only significant difference noted between experimentals and controls was the higher incidence of fearful and submissive behaviors found in the protein malnourished subjects. One protein-deficient male died at 13 months of age. Additional social group observations were conducted for 50 day periods at ages 10-13 months, 18-21 months, and 43-46 months. The groups also were placed together for additional social experience at irregular intervals between 21 and 43 months but without formal observation.

By 43 to 46 months of age, large discrepancies in body weight existed between the two groups, despite feeding increased calories to the deficient animals. The mean weight of control subjects was approximately twice that of the low protein subjects. The frequency 


\section{TABLE IV}

SUBJECTS COMPOSING SOCIAL GROUPS SPARCE AND SIMPL

$\begin{array}{lllll}\text { S } & \text { Sonya } & \# 5834 & \text { Low Protein } & \text { Female } \\ \mathrm{P} & \text { Peter } & \# 5943 & \text { Control } & \text { Male } \\ \mathrm{A} & \text { Alexis } & \# 5935 & \text { Control } & \text { Female } \\ \mathrm{R} & \text { Robert } & \# 5936 & \text { Low Protein } & \text { Male } \\ \mathrm{C} & \text { Charlie } & \# 5920 & \text { Control } & \text { Male } \\ \mathrm{E} & \text { Edgar } & \# 5939 & \text { Low Protein } & \text { Male }\end{array}$

$\begin{array}{cllll}\text { S } & \text { Stuart } & \# 5954 & \text { Low Protein } & \text { Male } \\ \text { I } & \text { Ilsa } & \# 5990 & \text { Low Protein } & \text { Female } \\ \text { M } & \text { Mark } & \# 5983 & \text { Control } & \text { Male } \\ \text { P } & \text { Petri } & \# 6012 & \text { Control } & \text { Male } \\ \text { L } & \text { Lisa } & \# 5988 & \text { Control } & \text { Female } \\ \text { (E } & \text { Evan } & \# 6013 & \text { Low Protein } & \text { Male }{ }^{\star} \text { ) }\end{array}$

* died at 13 months of age 
of submissive and fearful behaviors by deficient animals increased radically while their number of aggressive and dominant behaviors diminished. The protein-restricted monkeys avoided contact with their matched controls so that play and sexual encounters were virtually nonexistent. The malnourished animals manifested increasingly stereotyped and abnormal actions. These consisted of self-stimulatory or self-directed autistic behaviors such as huddling in a corner, self-clasping, rocking, and thumb- or toe-sucking.

Given an extensive experimental history, as well as preexisting, or established social groups, the following factors must be taken into consideration. Within each social group, previous social experience has established: alliances between animals, social rankings in a dominance hierarchy, and an already existent social structure with its unique internal rules in each group.

Consequently, it may be particularly informative to compare data from intra-group pairings to data from inter-group pairings, where no hierarchies or long lasting patterns of interaction have been established.

Housing

The eleven subjects were housed in the same animal colony in three four-unit cages. Each four-unit cage held four individually housed animals, two above and two below. These home cages were constructed of stainless steel sheet metal and wire mesh. Each individual unit was $60 \times 60 \times 86 \mathrm{~cm}$. Each unit had a wire mesh ceiling and floor, three wire mesh sides, and a glass divider which served as the interior side or partition between adjacent units. 
Subjects adjacent to one another therefore had close $v$ isual and auditory contact. These animals were referred to as "home cage partners" (Figure 3). The four-unit cages were also positioned to permit visual and auditory contact among all eleven animals.

\section{Apparatus}

The selection chamber (Figure 4) consisted of a long runway connected to five individually isolated rear holding compartments. The rear panel of each compartment had a solid metal vertically sliding door through which an animal could be introduced into the holding compartment. The front panel of each compartment was clear plexiglas with a vertically-sliding transparent plexiglas door. The front doors could be operated manually by the experimenter via a system of overhead pulleys.

The front doors for rear compartments zero through three (from left to right) opened into the runway which served as the test arena. Rear compartment number zero was designated as the start box. The test animal was placed in this chamber prior to release into the runway and was allowed to exit through this chamber upon completion of the experimental session. These doors were referred to as the rear holding compartment doors or the choice chamber doors. Beside each door was a response key with a keylight which darkened when the key was pressed. Under appropriate conditions, a key press produced the opening of the corresponding door (Figure 5).

The fifth and final compartment, together with its adjacent section of the runway, was sealed off visually and physically from the remainder of the apparatus. The front portion of this section 


\begin{tabular}{|c|c|}
\hline $\begin{array}{l}5983 \\
\text { MARX } \\
\text { Control } \\
\text { Male }\end{array}$ & $\begin{array}{l}5954 \\
\text { STUART } \\
\text { Deficient } \\
\text { Male }\end{array}$ \\
\hline $\begin{array}{l}5990 \\
\text { ILSA } \\
\text { Deficient } \\
\text { Female }\end{array}$ & $\begin{array}{l}5988 \\
\text { LISA } \\
\text { Control } \\
\text { Female }\end{array}$ \\
\hline
\end{tabular}

\begin{tabular}{|c|c|}
\hline $\begin{array}{l}5939 \\
\text { EDGAR } \\
\text { Deficient } \\
\text { Male }\end{array}$ & $\begin{array}{l}5936 \\
\text { ROBERT } \\
\text { Deficient } \\
\text { Male }\end{array}$ \\
\hline $\begin{array}{l}5943 \\
\text { PETER } \\
\text { Cont rol } \\
\text { Male }\end{array}$ & $\begin{array}{l}5920 \\
\text { CHARLIE } \\
\text { Control } \\
\text { Male }\end{array}$ \\
\hline
\end{tabular}

\begin{tabular}{|c|c|}
\hline $\begin{array}{l}5834 \\
\text { SONYA } \\
\text { Deficient } \\
\text { Female }\end{array}$ & $\begin{array}{l}5935 \\
\text { ALEXIS } \\
\text { Control } \\
\text { Female }\end{array}$ \\
\hline $\begin{array}{l}6012 \\
\text { PETRI } \\
\text { Control } \\
\text { Male }\end{array}$ & \\
\hline
\end{tabular}

Figure 3. Schemata for Home Cage Partners. 


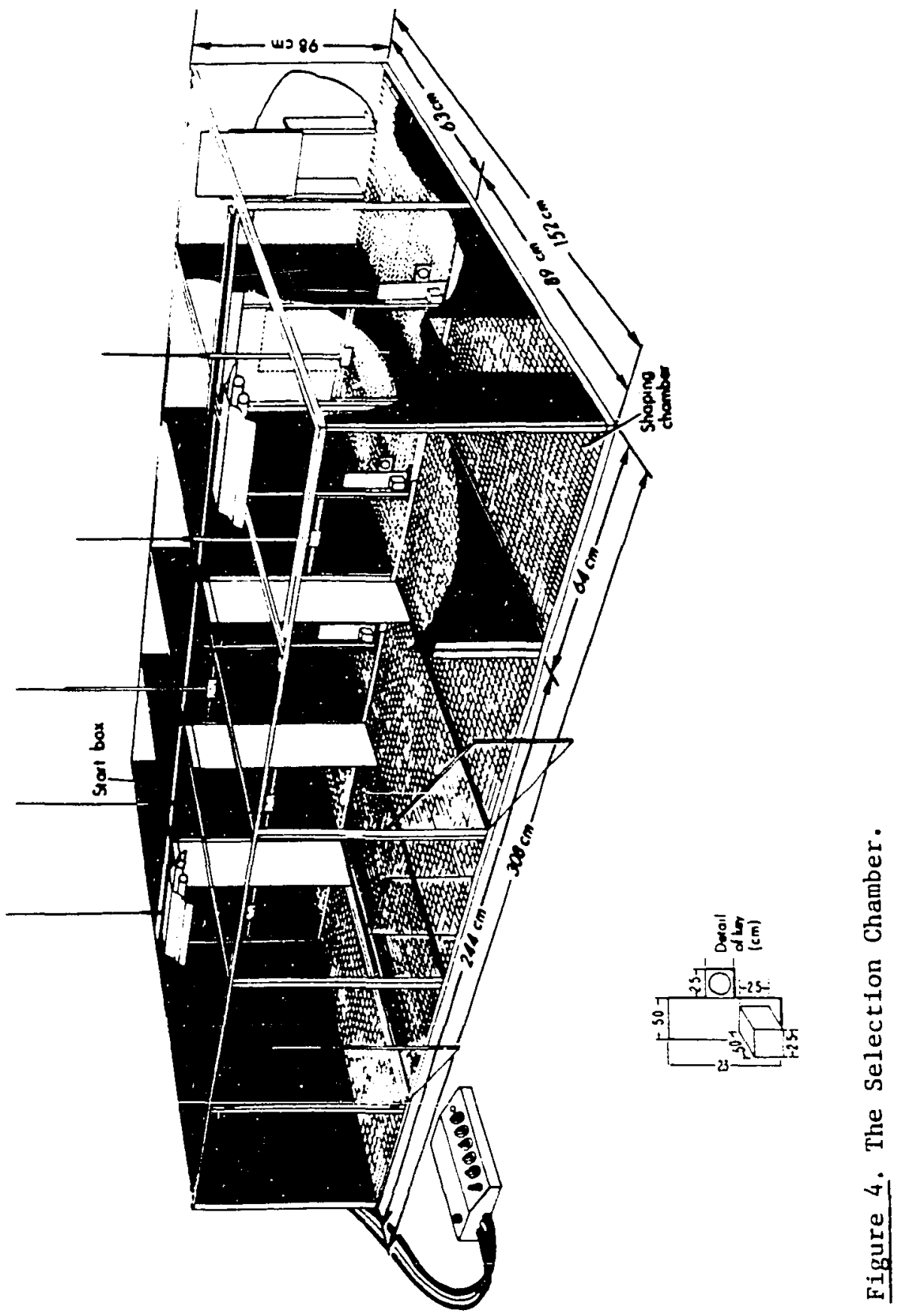




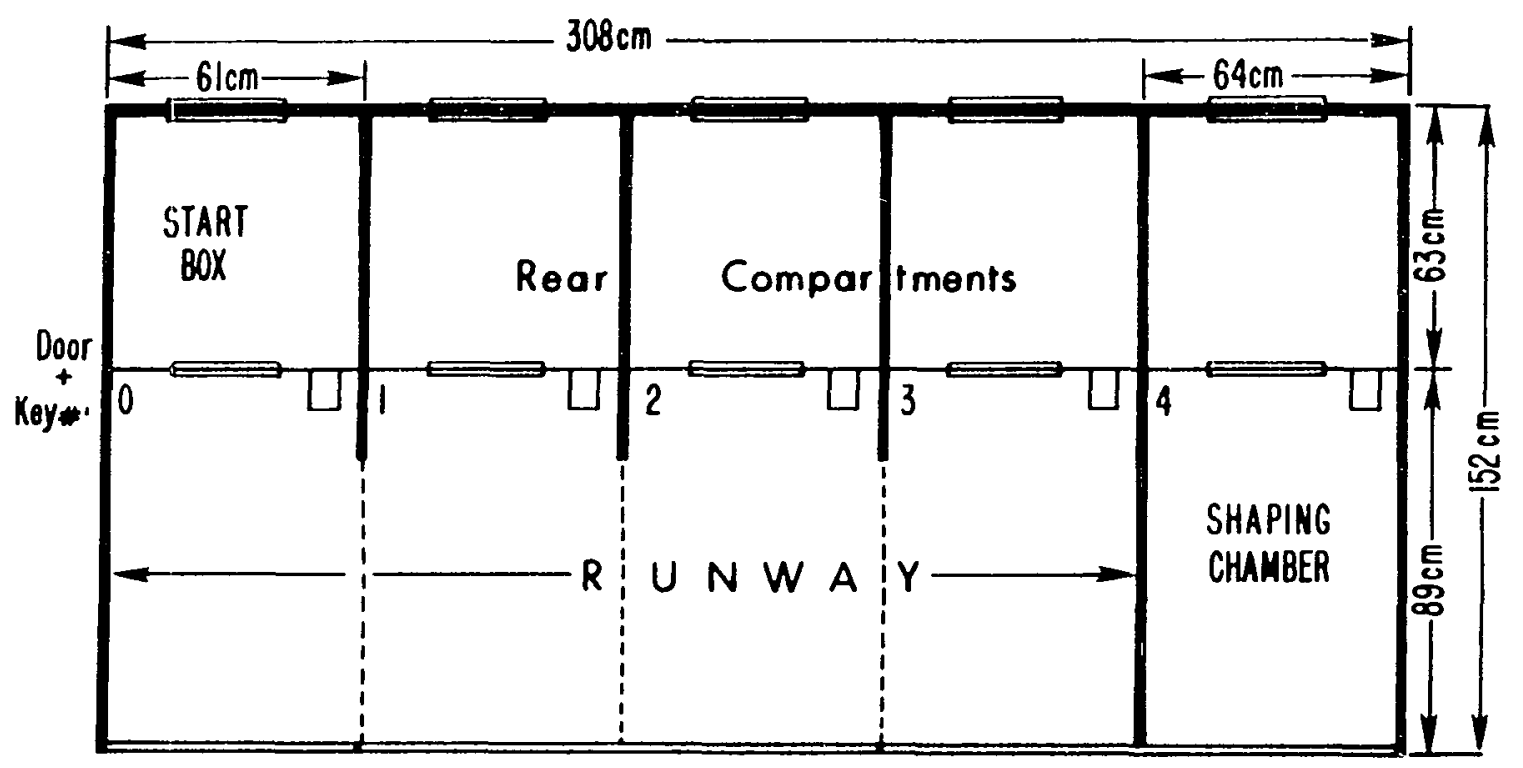

Figure 5. Floor Plan for the Selection Chamber. 
with its vertical sliding plexiglas door and response key functioned as the shaping chamber. The rear compartment had a metal vertical sliding door through which reinforcements could be loaded. The front compartment contained a metal sliding door on the side through which an animal could be introduced.

The ceiling and front wall of the runway, as well as the panels and doors separating the runway from the rear holding compartments, were constructed of transparent plexiglas. An animal in the runway could therefore see into each of the rear holding compartments, and the observers seated in front of the apparatus had a full unobstructed view of the animals in the runway as well as the rear compartments. The sides of the apparatus, as well as the backs and partitions between rear holding compartments, were constructed of masonite. The floor was stainless steel wire mesh. The entire apparatus was mounted on a metal stand with a stainless steel drop pan running the length of the apparatus.

Four shielded fluorescent light fixtures centrally mounted on the ceiling of the apparatus illuminated the interior structure. These are referred to as houselights. The houselights and each individual keylight were manually controlled by an externally located electronic control box (Figure 4).

The entire apparatus and all control devices were housed in a small sound-proofed room. During testing the room lights were off. The experimenters sat directly in front of the runway. The plexiglas front of the apparatus was coated with Solar- $X$, a one-way mirror film. With the houselights illuminated and the room otherwise dark, the 
experimenters could see into the apparatus, but the experimental subject could not see out.

Phase I - Habituation to the Selection Chamber

All subjects were food deprived for 20 hours prior to each habituation trial. A food reinforcer (Fruit Loop sugar-coated cereal) was placed on each of three trays which were positioned at various points in the runway. All plexiglas sliding doors for rear chambers zero through three remained closed and all keylights were darkened throughout this habituation phase.

Each subject was placed in the start box for one minute. The start box door was then held open until the animal exited into the runway. The amount of time it took the animal to enter the runway was recorded. The door to the start box was then closed, keeping the subject in the runway. The latency for the subject to take and eat each reinforcer was also recorded. A successful trial was scored if the subject found and ate the loops from all three trays within fifteen minutes. The session was terminated either by a successful trial or at the end of fifteen minutes, which ever came first. The animal was then allowed access back into the start box from which it was returned to its home cage. The criterion for Phase I was attained when the subject achieved five consecurive successful trials. The data collection sheet for this phase of training is shown in Figure 6.

Phase II - Habituation to Selection Chamber Doors

Phase II was an extension of Phase I and was designed to habituate the subjects to the operation of the plexiglas doors leading 
PROTEIN DEPRIVED MONKEYS:

HABITUATION TO THE SELECTION CHAMBER - PHASE I

\begin{tabular}{|c|c|c|c|c|c|}
\hline MONKEY & DATE & TIME & EXIT TIME & LATENCY TO EAT & CONMENTS \\
\hline \multicolumn{6}{|l|}{5834} \\
\hline \multicolumn{6}{|l|}{5936} \\
\hline \multicolumn{6}{|l|}{5939} \\
\hline \multicolumn{6}{|l|}{5954} \\
\hline 5990 & & & & & \\
\hline & & & & & \\
\hline
\end{tabular}

Figure 6. Data collection sheet for Phase I of training. 
into the rear compartments. As in Phase $I$, all the keylights remained off throughout the session, and all subjects were detained in the start box for one minute prior to being released into the runway. Delay to enter the runway was recorded. In contrast to Phase $I$, each of the three food trays (one loop per tray) was placed immediately behind one of the three rear holding compartment doors (1-3). Since the doors were transparent, the trays with their reinforcements were in full view of the animal in the runway. There was a one minute delay following the animal's entry into the runway before one of the rear holding compartment doors was opened by the experimenter, permitting access to the reinforcer. When the loop was taken, the door was promptly closed and the delay to retrieval was recorded. If the subject failed to retrieve the reinforcer within three minutes, that particular door was closed and remained closed for the duration of the session. In either case, a one minute interval preceded the operation of the next chamber door. One session consisted of three opportunities to retrieve a food reward. The order in which the three doors were opened was randomized over sessions.

The number of reinforcers retrieved was recorded for each session. A successful habituation session was scored if the subject took the reinforcer from behind all three doors in one session. Criterion for Phase II was attained when the subject achieved five consecutive successful sessions. The data sheet for Phase II is shown in Figure 7.

Phase III - Shaping the Key Press

The subject was placed in the shaping chamber. One minute 
HABITUATION TO SELECTION APPARATUS - PHASE II

MONKEY NO.

\begin{tabular}{|c|c|c|c|c|c|c|}
\hline SESSION & $\begin{array}{l}\text { DATE } \\
\text { and } \\
\text { TIME }\end{array}$ & $\begin{array}{l}\text { ORDER } \\
\text { of } \\
\text { DOORS }\end{array}$ & $\begin{array}{l}\text { DELAY } \\
\text { DOOR } 1 \\
\text { ATE ? }\end{array}$ & $\begin{array}{l}\text { DELAY } \\
\text { DOOR } 2 \\
\text { ATE ? }\end{array}$ & $\begin{array}{l}\text { DELAY } \\
\text { DOOR } 3 \\
\text { ATE ? }\end{array}$ & COMMENTS \\
\hline 1. & & & & & & \\
\hline 2. & & & & & & \\
\hline 3. & & & & & & \\
\hline 4. & & & & & & \\
\hline 5. & & & & & & \\
\hline 6. & & & & & & \\
\hline 7. & & & & & & \\
\hline & & & & & & \\
\hline
\end{tabular}

Figure 7. Data collection sheet for Phase II. 
later, the keylight was illuminated. The keylight served as a discriminative stimulus: when the light was on, successive approximations to a key press were reinforced. Three behavioral categories were scored:

1. Approach: Moving toward the response key;

2. Touch: Licking, sniffing, holding or in any other way contacting the key without sufficient force to activate it;

3. Press: Manipulating the key in such a manner as to depress the microswitch, thereby automatically turning off the keylight.

Initially, behavior in any one of the above three categories produced the following result: the keylight was darkened and the plexiglas door was raised to make the reinforcer available to the subject. The door was lowered after the reinforcer had been taken by the animal. After the tray was reloaded with a reinforcer, the keylight was illuminated to begin the next trial. The actual length of time between trials depended on the nature of the animal's intertrial activity. For instance, if the animal entered the rear compartment, the door could not be lowered until it re-entered the shaping chamber.

If necessary, the subject was gradually shaped through each successive stage. It was first reinforced simply for approaching the key, then only when it touched the key, and finally only when an effective keypress was achieved. Some animals contacted or pressed the key from the first shaping session, whereas others required considerable training at each stage. Each shaping session lasted either thirty minutes or until the animal made at least five consecutive key presses. The criterion for Phase III was attained 
when the subject pressed the key five or more consecutive times on three successive sessions. The data collection sheet for Phase III is shown in Figure 8.

Phase IV - Generalization of the Keypressing Response

The animal was allowed to enter the runway after 30 seconds in the startbox. As in Phase II, a food reinforcer was placed on the tray immediately behind each of the three plexiglas doors. One minute after an animal's entrance into the runway, all three keylights were illuminated simultaneously. The subject therefore had three discriminative stimuli to which it could respond. A response to a key produced the following sequence of events:

1. All keylights were darkened;

2. The corresponding door was raised, allowing access to the reinforcer;

3. Once the subject retrieved the reinforcer and exited from the rear chamber, that particular door was closed and its keylight remained off for the rest of the trial;

4. The remaining two keylights were then illuminated and the sequence repeated until responses had been made to all three keys and all three rewards had been retrieved.

On the first session only, an approach or touch to the key was counted as a response; all subsequent sessions required an actual keypress. Retrieval of all three reinforcers constituted one trial. A session consisted of five such trials, yielding a total of fifteen possible reinforcements. Upon completion of each trial the trays in the rear compartments were reloaded with Fruit Loops and the next trial was signalled by the re-illumination of all three keylights. 
SHAPING THE KEY PRESS - PHASE III

MONKEY \#

DATE

TIME

\section{SESSION \#}

\begin{tabular}{|c|c|c|c|}
\hline APPROACH & TOUCH & PRESS & COMMENTS \\
\hline \multicolumn{4}{|l|}{111} \\
\hline & 1 & & \\
\hline \multicolumn{4}{|l|}{$\pi \times 11$} \\
\hline & 1 & & \\
\hline \multicolumn{4}{|l|}{11} \\
\hline & 111 & & \\
\hline \multicolumn{4}{|l|}{111} \\
\hline & $\mathrm{NX} 11$ & & \\
\hline & & 111 & \\
\hline & 1111 & & \\
\hline & & $N \times 1$ & \\
\hline
\end{tabular}

The vertical slash mark(s) on the first line indicates the animal's initial mode of response (in this example it approached the key 3 times). Every time the subject changed response modes (from approach to touch, for instance) the experimenter moved down one line and marked a slash under the appropriate category. In this manner the animal's exact response sequence is recorded. The sample sheet informs the reader that this animal made 3 initial approaches to the key and then touched the key. Its 5 th-1lth responses were approaches once again and its 12 th response was a touch, etc.

Figure 8. Data collection sheet for Phase III. 
The response latency for each key, as well as the order in which the keys were pressed, was recorded for each trial. A successful session was scored when the subject pressed the key within fifteen seconds on every attempt for all five trials, and therefore received all fifteen reinforcements. Criterion was achieved when the subject performed successfully for four consecutive sessions, for a total of sixty consecutive reinforcements. Figure 9 is the data sheet for Phase IV.

Phase V - Selection of a Social Partner One subject -- the test animal -- was placed in the start box and another -- the stimulus animal -- was placed in one of the three possible rear holding compartments. A food reinforcer was placed in each of the other two compartments. All test animals were food deprived for 20 hours prior to testing. At the end of 30 seconds, the test animal in the start box was released into the runway. The keylights were illuminated after the test animal was in the runway for one minute. If the test animal then pressed a key, the keylight darkened and the corresponding door was opened, allowing access to that rear compartment. The key number and the response latency were recorded. If a key associated with a food reinforcer was pressed, the test subject was allowed to take the food reinforcer and the door to that compartment was then closed and remained closed for the duration of the test session. The keylight associated with this compartment also remained off. If the test animal pressed the key associated with the stimulus animal, the stimulus animal was allowed access to the runway. Once the stimulus animal entered the runway the door to the 
GENERAL IZATION OF THE KEY PRESSING RESPCNSE - PHASE IV

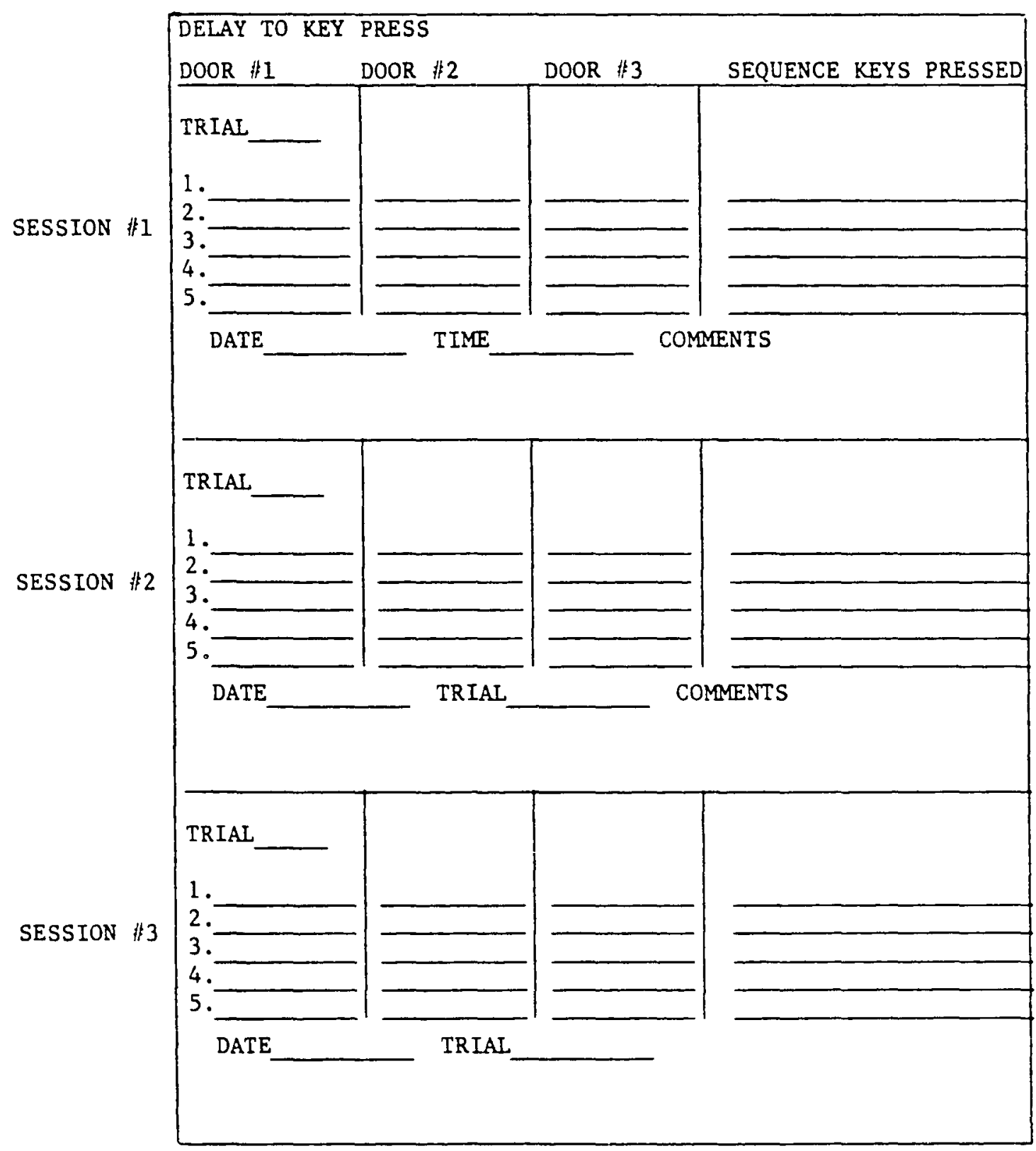

MONKEY if

Figure 9. Data collection sheet for Phase IV. 
rear compartment was closed for the duration of the test. Any keys not pressed before the release of the stimulus animal were then inactivated and all keylights remained darkened. The social behaviors of the pair were then recorded for ten minutes.

The test session was terminated if the test subject did not release the stimulus animal within seven minutes. The stimulus animal was then removed from the apparatus and the test animal was allowed to respond to obtain Fruit Loops if it had not already done so at least once. This procedure was adopted in order to preserve the key pressing response.

Two observers recorded the behaviors of both test and stimulus animal throughout Phase $V$. While the two animals were separated, that is, while the stimulus animal remained in the rear compartment, behavioral observation scoring sheet, Form A, (Figure 10) was used. Social behavior categories are taken from those of Hansen (1966). The behaviors and their definitions are listed below:

Test Animal Only

1. PROX Approaching and remaining within $60 \mathrm{~cm}$ of the compartment housing the stimulus animal.

2. PROX DOOR Approaching and remaining within $30 \mathrm{~cm}$ of the holding compartment door.

3. LOOK Orienting the head and directing the eyes towards the stimulus animal.

4. CGEX DOOR Cage exploration (biting, manipulating, or picking) restricted solely to the door behind which the stimulus animal was housed.

5. KEYX Key exploration, licking, touching, sniffing, holding, picking or manipulating a key without actually pressing it.

6. PRESS Pressing the key sufficiently hard to close 


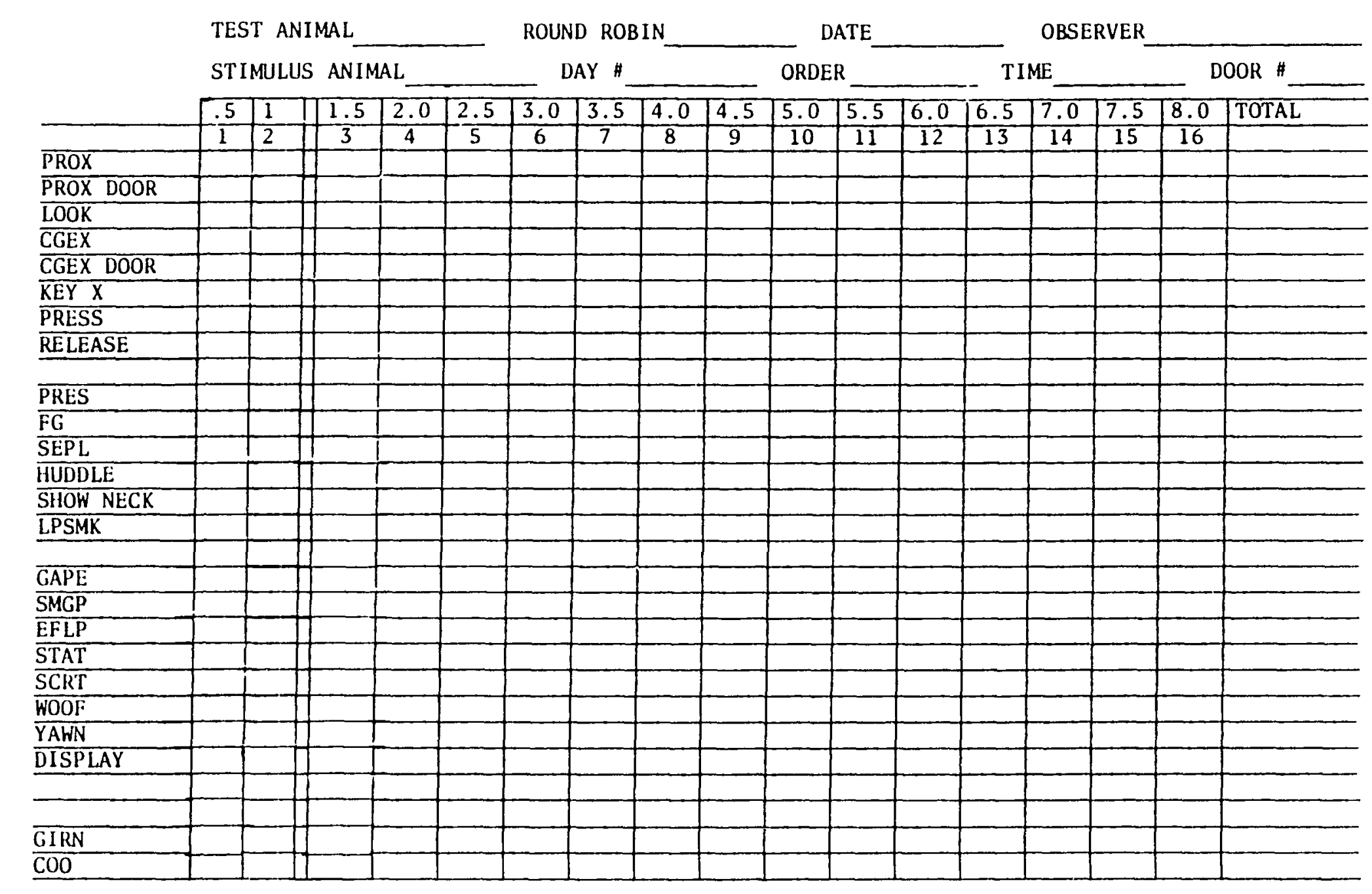

Figure 10. Behavioral observation scoring sheet, form A. 
its microswitch. Presses made when the keylight was on led to opening of the corresponding door and were counted as effective presses. Those made when the keylight was dark had no effect and were counted as ineffective presses.

7. RELEASE An effective press of the key associated with the rear compartment containing the stimulus animal.

Both Test and Stimulus Arimals

8. CGEX Cage exploration: biting, manipulating, or picking at any part of the cage.

9. PRES Present: a sexually receptive or submissive posture, with rear legs straight and perineum oriented toward the social partner.

10. F.G. Fear grimace: retracting the lips and corners of the mouth to bare clenched teeth. A submissive expression.

11. SEPL Self-play: masturbation.

12. HUDDLE Animal sitting with its arms and legs drawn up close to its torso.

13. SHOW NECK Tilting the head back in such a manner as to expose the underside of the throat. A submissive gesture.

14. LPSMK Lipsmack: smacking the lips together. The tongue may move rapidly in and out of the mouth. A conciliatory gesture.

15. GAPE

A stare with wide open mouth: a threat behavior.

16. SMGP

Smali mouth gape, or small open mouth threat: a stare with partially-open mouth. (A milder threat behavior.)

17. EFLP

Earflip: rapidly flattening the ears against the head. A threatening gesture; sometimes, especially in younger animals, as an invitation to rough-and-tumble play.

18. STAT

Stare threat: a concentrated, directed stare at another animal, accompanied by 
lowering of the brow. A threatening facial expression.

19. SCRT

Screech threat: a loud high-pitched vocalization made with teeth exposed but mouth open. A mixture of threat and fear. An approach-avoidance behavior.

20. WOOF Similar to a bark, a threat vocalization.

21. YAWN Tilting the head back, opening the mouth wide and exposing the canine teeth.

22. DISPLAY Vigorously jumping, lunging and shaking the cage.

23. GIRN A whimper-like voralization.

24. COO A distress vocalization.

In Figure 10, Behavioral Observation Scoring Sheet, Form $A$, the first row of numbers $(.5,1,1.5, \ldots 7.5,8.0)$ indicates the number of minutes from the entrance of the test animal into the runway. The second row of numbers counts the number of thirty second blocks or intervals. The heavy black vertical line separates the first minute of observation, when all keylights were off, from the possible seven minutes of observation time when the test animal could release the stimulus animal.

If the stimulus animal was released, the two observers recorded the social behaviors of both subjects for 10 minutes. One observer used Behavioral Observation Scoring Sheet, Form B (Figure 11), while the other used Form $C$ (Figure 12). The recorded behaviors for Form $B$ consisted of the following:

1. PRES Present: same as A. 7.

2. F.G. Fear grimace: same as A. 10.

3. SHOW NECK Same as A. 13. 
TEST ANIMAL

STIMULUS ANIMAL

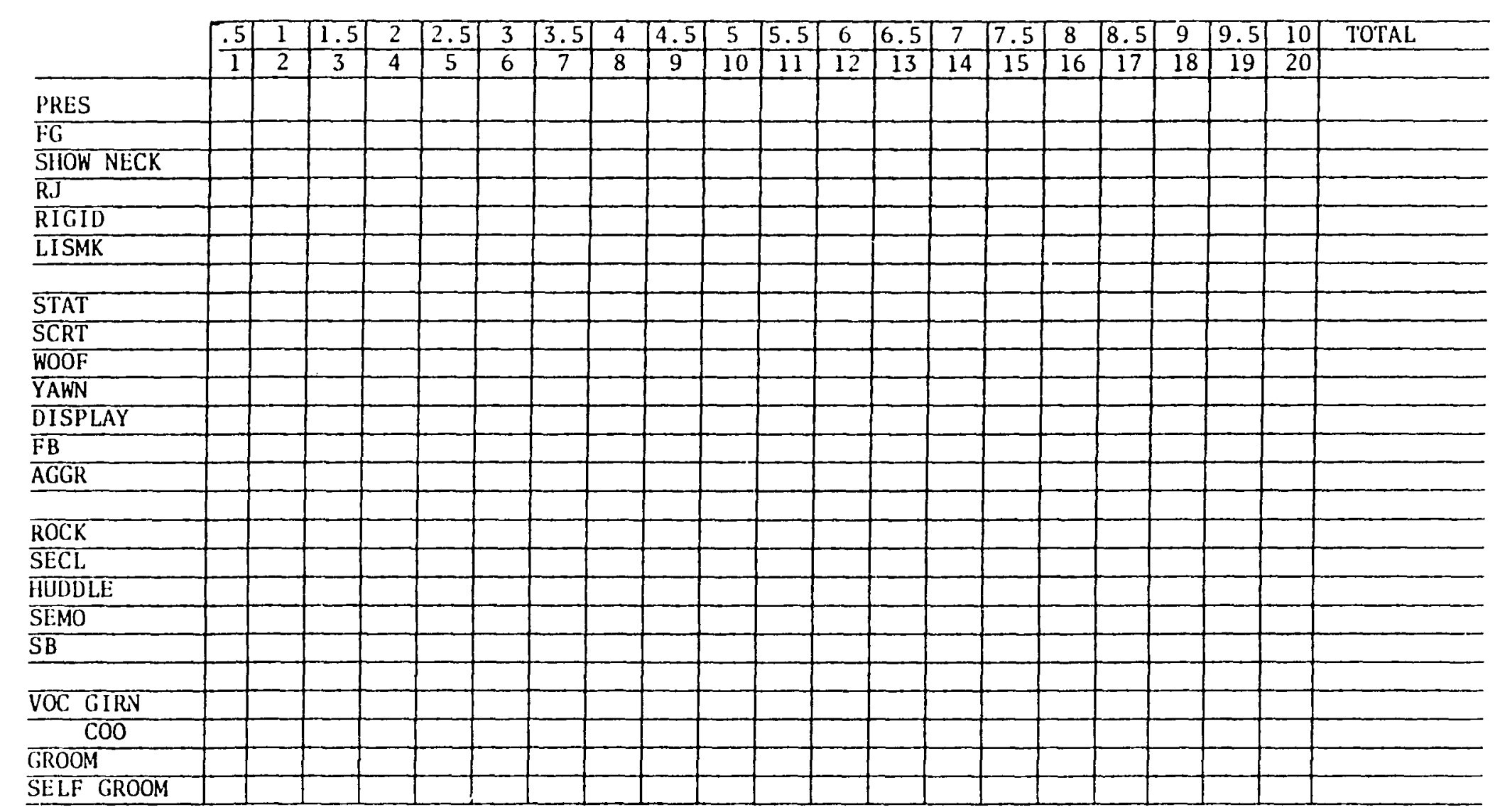

Figure 11. Behavioral observational scoring sheet, Form $B$.

DATE

TIME

ROUND ROBIN \#

DAY \# 
TEST ANIMAL

ROUND ROBIN \#

DAY \#

DATE

TIME

STIMULUS ANIMAL

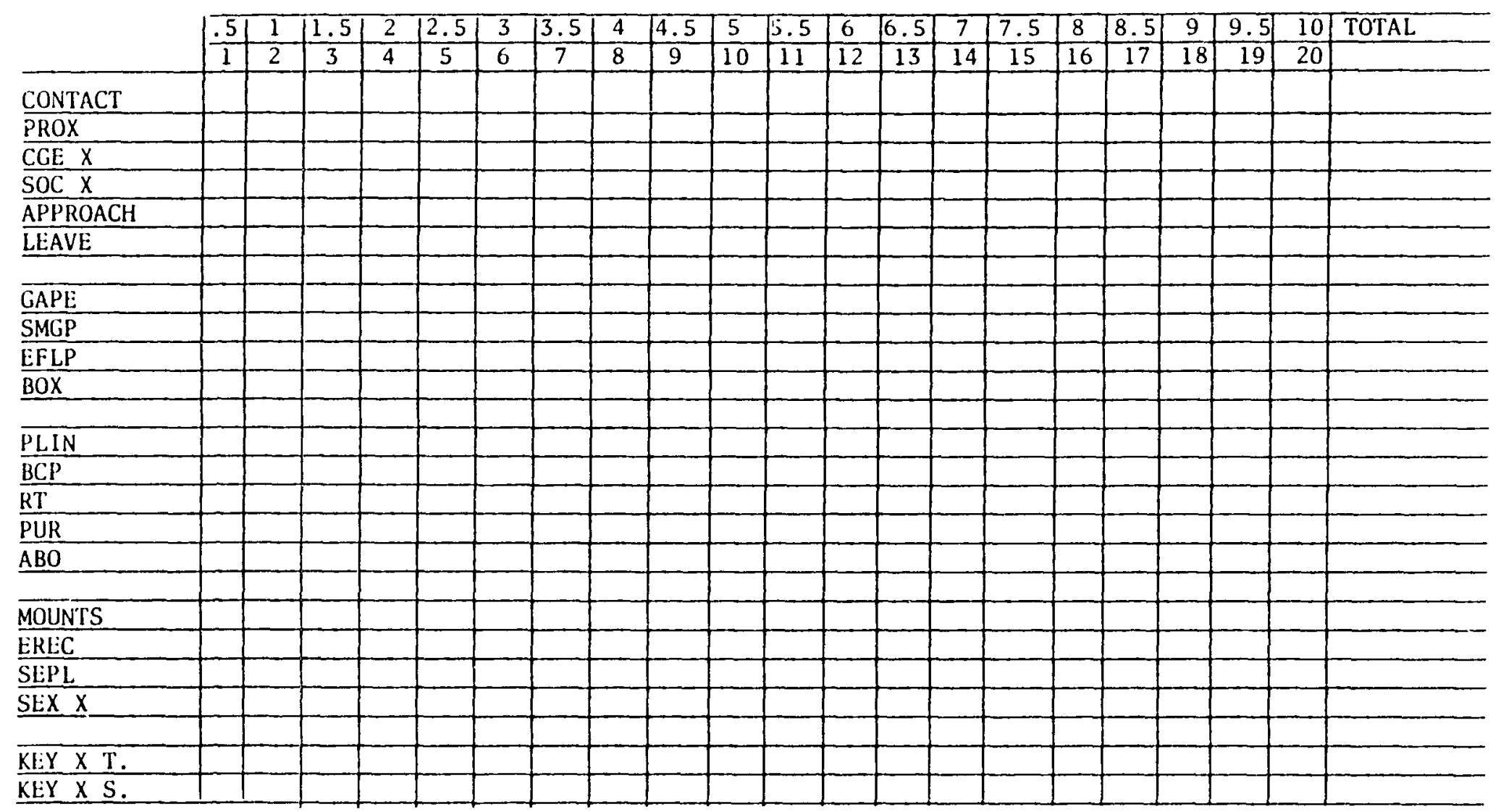

Figure 12. Behavioral observational scoring sheet, form $C$. 

4. R.J.
Reject jerk: spasmodically jerking the body - an annoyance gesture.
5. L.ISMK
Lipsmack: same as A. 14 .
6. STAT
Stare threat: same as A. 18 .
7. SCRT
Screech threat: same as A. 19.
8. WOOF
Same as A. 20.
9. YAWN
Same as A. 21.
10. DISPLAY
Same as A. 22.
11. F.B.
Fur bite: biting and pulling out another animal's fur.
12. AGGR
Aggression: a physical attack, including biting and shaking.
13. ROCK
Animal rocking itself, a self-stimulatory, disturbed behavior.
14. SECL
Self-clasp: animal wraping its hands, arms, or legs about itself, and holding itself. A disturbed behavior.
15. HUDDLE
Same as A. 12 .
16. SEMO
Self-mouth: animal sucking some part of its own anatomy such as a thumb, toe, or fingers. A disturbed behavior.
17. S.B.
Self-bite: animal biting itself, aggressive behavior toward itself.
18. GIRN Same as A. 23.
19. COO Same as A. 24.
20. GROOM Manually picking through the fur of the social partner, usually accompanied by lipsmacking.
21. SELF-GROOM Animal manually picking through its own fur while lipsmacking.
Behaviors scored on Form $C$ included the following:
1. CONTACT Any physical contact with another animal 
not scored under another category.

2. PROX

Approaching and remaining within $30 \mathrm{~cm}$ of the social partner for at least five seconds.

3. CGEX

Same as A. 4.

4. $\operatorname{soc} x$

Social exploration: sniffing or gently touching another animal's face, head or body.

5. APPROACH Moving to within $60 \mathrm{~cm}$ of the social partner.

6. LEAVE Moving away from the social partner.

7. GAPE Same as A. 15.

8. SMGP Same as A. 16 .

9. EFLP Same as A. 17 .

10. BOX

A short, quick lunge ending in an open mouth contact with another animal.

11. PLIN

Play initiation: scored for the animal which clearly initiates a bout of BCP or RT (see below) with a gape, earflip, box, or approach. (Not determinable in all instances of play.)

12. $B C P$

Brief contact play: gentle play including mouthing and wrestling, with animals primarily sitting face to face.

13. R.T.

Rough and tumble play: play including mouthing and wrestling but rougher than $B C P$, with animals standing up and rolling over.

14. PUR

Pursuit: play chase, scored for animal which does the chasing (pursuit). Both pursuit and avoidance (below) are scored only when the chase is immediately preceded or followed by another play behavior, such as a box, BCP, RT, gape, or earflip.

15. AVO

Avoidance: play chase, scored for the animal which leads the chase, or is chased after. 
16. MOUNTS

Sexual behavior comprised of any form of mount including:

D.F.C.: Double foot clasp - grasping the partner's hips with the hands and clasping the partner's ankles or calves with both feet.

S.F.C.: Single foot clasp.

N.F.C.: No foot clasp.

S.T.S.: Stand to side.

S.T.H.: Stand to head.

(The last two positions are immature and incomplete mounting positions.)

17. EREC Erection: male's penis is erect.

18. SEPL Self play: Same as A. 11.

19. SEX X Sexual exploration: making a visual, olifactory or manual examination of another animal's genital region.

20. KEY X T Key exploration by the Test Animal: biting, sniffing, holding, touching or manipulation of an inactivated key by the test animal.

21. KEY XS Key exploration (as above) by the Stimulus Animal.

Data sheets $B$ and $C$ are both divided into 30 second intervals for a total duration of ten minutes of observation time, beginning with the release of the stimulus animal. In Figures 11 and 12 (Sample of the Behavioral Observation Scoring Sheet, Forms $B$ and $C$ ), the first row of numbers $(.5,1,1.5, \ldots 9,9.5,10)$ gives the number of minutes elapsed from release of the stimulus animal. The second row of numbers $(1,2,3, \ldots 19,20)$ simply indexes the thirty-second blocks from one to twenty.

The two observers sat directly in front of the runway. For each test, both observers separately recorded behavioral responses on data sheet A. If the stimulus animal was released, one observer recorded behaviors on data sheet $B$, while the other recorded those on data 
sheet $C$. During inter-observer reliability test sessions, each observer scored behavioral responses on all three data sheets independent of one another. No verbalizations were exchanged during these test sessions.

The social partners for Phase $V$ consisted of intra-group test pairs (animals within the same social group). Each member of a social group was paired with every other member of the group. One complete set of such pairings was referred to as a Round Robin. For the social group SPARCE, one Round Robin consisted of 30 test pairs; for the social group SIMPL, one Round Robin consisted of 20 test pairs. A total of three Round Robins was conducted for each social group. The stimulus animal could be placed behind any one of three possible doors for each test animal-stimulus animal pairing. The door sequence was ordered so that each stimulus animal was rotated through these three possible door positions.

The sequence of pairings is given in Figures 13 and 14 (intragroup test pairs SPARCE and intra-group test pairs SIMPL). The first letter represents the test animal's initial, the second letter represents the stimulus animal's initial, and the number in brackets indicates the door position to which the stimulus animal was assigned for that test pair. For instance, C P (2), indicates that the test animal was Charlie, the stimulus animal was Peter, and that the stimulus animal was placed behind door number two. R.R. \#1, 2 , or 3 refer to the three Round Robins. The number of testing days appears horizontally from left to right above the animal pairing information. The numbers in a colum (one through three) to the left of the pair 
INTRO GROUP TEST PAIRS "SPARCE"

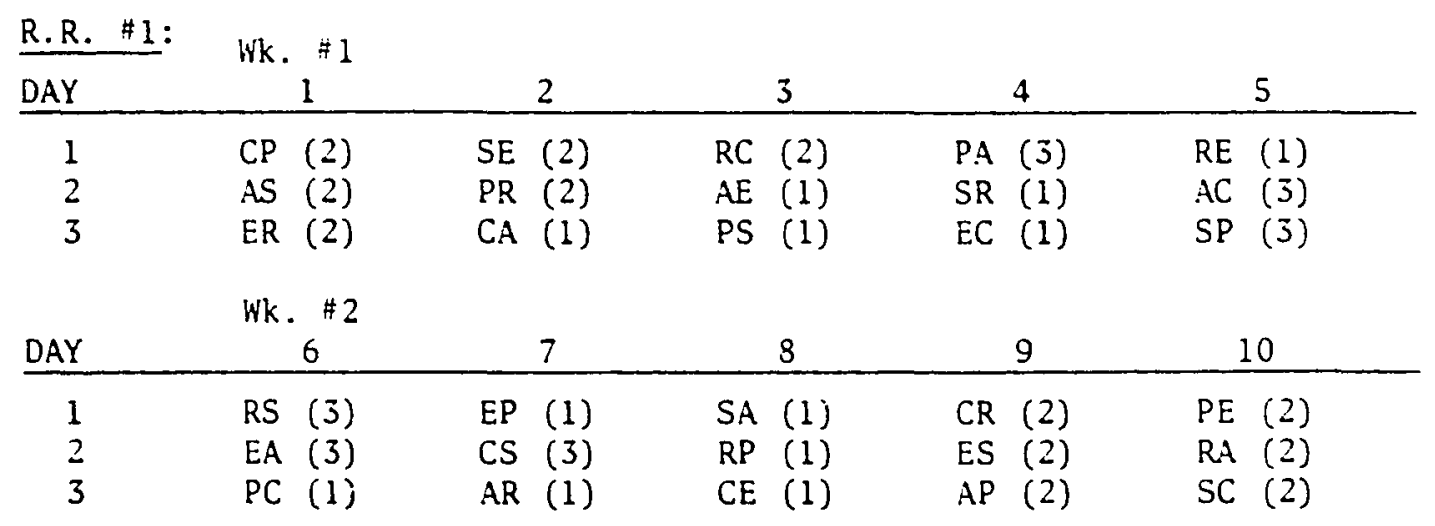

R.R. \#2:

\begin{tabular}{|c|c|c|c|c|c|}
\hline DAY & 11 & 12 & 13 & 14 & 15 \\
\hline 1 & PC (5) & $A R \quad(3)$ & $\mathrm{CA}$ (2) & ER (3) & PA (3) \\
\hline 2 & RS (3) & EP (2) & SE (3) & $C P(3)$ & EC (1) \\
\hline 3 & EA (j) & $\operatorname{cs}(3)$ & PR (2) & AS (2) & SR (2) \\
\hline
\end{tabular}

wk. \#4

\begin{tabular}{cccccc} 
DAY & 16 & 17 & 18 & 19 & 20 \\
\hline 1 & SP (3) & AP (1) & CE (3) & PS (1) & SC (3) \\
2 & RE (2) & CR (1) & SA (1) & RC (1) & PE (3) \\
3 & AC (3) & ES (3) & RP (3) & AE (3) & RA (3)
\end{tabular}

\begin{tabular}{cccccc} 
R.R. \#3: & Wk. $\# 5$ & & & & \\
DAY & 21 & 22 & 23 & 24 & 25 \\
\hline 1 & RP (2) & AC (2) & CR (1) & EA (1) & PR (1) \\
2 & CE (2) & SP (1) & EX (2) & PC (2) & CA (2) \\
3 & SA (2) & RE (1) & AP (1) & RS (2) & SE (2)
\end{tabular}

\begin{tabular}{cccccc}
\multicolumn{5}{c}{ Wk. \#6 } & \multicolumn{2}{l}{2} & \\
DAY & 26 & 27 & 28 & 29 & 30 \\
\hline 1 & SR (1) & CS (1) & AE (1) & RA (3) & AS (3) \\
2 & EC (2) & AR (2) & PS (1) & SC (3) & ER (3) \\
3 & PA (2) & EP (1) & RC (1) & PE (3) & CP (3)
\end{tabular}

DOOR SEQUENCE FOR STIMULUS ANIMALS:
R. R. \#1
$\begin{array}{lllll}2 & 1 & 3 & 1 & 2\end{array}$
R. R. \#2
$\begin{array}{lllll}3 & 2 & 3 & 1 & 3\end{array}$
R.R. \# 3
$\begin{array}{lllll}2 & 1 & 2 & 1 & 3\end{array}$

Figure 13. Figure sequence of pairings, Test Pairs SPARCE. 
INTRA GROUP TEST PAIRS "SIMPL"

\begin{tabular}{|c|c|c|c|c|c|}
\hline DAY & 1 & 2 & 3 & 4 & 5 \\
\hline $\begin{array}{l}1 \\
2\end{array}$ & $\begin{array}{l}\text { IL (2) } \\
\text { MS (2) }\end{array}$ & $\begin{array}{ll}\text { PI } & (2) \\
\text { SL } & (2)\end{array}$ & $\begin{array}{l}\text { LP (2) } \\
\text { IM (1) }\end{array}$ & $\begin{array}{l}\text { SM (1) } \\
\text { LI (1) }\end{array}$ & $\begin{array}{l}\text { ML (1) } \\
\text { PS (1) }\end{array}$ \\
\hline DAY & Wk. ${ }_{6}^{\# 2}$ & 7 & 8 & 9 & 10 \\
\hline $\begin{array}{l}1 \\
2\end{array}$ & $\begin{array}{ll}S I & (3) \\
M P & (3)\end{array}$ & $\begin{array}{l}\text { IP (3) } \\
\text { LM (1) }\end{array}$ & $\begin{array}{l}\text { PL (3) } \\
\text { IS (1) }\end{array}$ & $\begin{array}{ll}M I & (1) \\
\text { SP } & (1)\end{array}$ & $\begin{array}{l}\text { LS (1) } \\
\text { PM (1) }\end{array}$ \\
\hline
\end{tabular}

\begin{tabular}{llllll} 
R.R. \#2: & Wk. \#3 & \multicolumn{1}{l}{} & & \\
DAY & 11 & 12 & 13 & 14 & 15 \\
\hline 1 & SL (2) & IM (2) & MS (2) & PM (3) & LI (2) \\
2 & PI (2) & LP (2) & IL (3) & LS (3) & SM (3)
\end{tabular}

\begin{tabular}{cccccc}
\multicolumn{9}{c}{ Wk. \#4 } & \multicolumn{1}{c}{10} \\
\hline DAY & 16 & 17 & 18 & 19 & 20 \\
\hline 1 & PS (2) & IS (2) & SP (2) & LM (3) & MP (3) \\
2 & ML (3) & PL (3) & MI (2) & IP (3) & SI (3)
\end{tabular}

\begin{tabular}{|c|c|c|c|c|c|}
\hline DAY & $\begin{array}{c}m \times \\
21 \\
\end{array}$ & 22 & 23 & 24 & 25 \\
\hline $\begin{array}{l}1 \\
2\end{array}$ & $\begin{array}{l}\text { SM (1) } \\
\text { LI (1) }\end{array}$ & $\begin{array}{l}\text { ML (1) } \\
\text { PS (1) }\end{array}$ & $\begin{array}{l}\operatorname{IM}(1) \\
\operatorname{LP}(3)\end{array}$ & $\begin{array}{l}\text { PI (3) } \\
\text { SL (3) }\end{array}$ & $\begin{array}{l}\text { IL (3) } \\
\text { MS (3) }\end{array}$ \\
\hline
\end{tabular}

\begin{tabular}{|c|c|c|c|c|c|}
\hline DAY & $\begin{array}{c}\text { Wk. } \# 6 \\
26 \\
\end{array}$ & 27 & 28 & 29 & 30 \\
\hline $\begin{array}{l}1 \\
2\end{array}$ & $\begin{array}{ll}M P & (2) \\
\text { SI } & (2)\end{array}$ & $\begin{array}{l}\text { IP }(2) \\
\text { LS (2) }\end{array}$ & $\begin{array}{l}\text { PL (2) } \\
\text { MI (1) }\end{array}$ & $\begin{array}{l}L M \quad(1) \\
S P \quad(1)\end{array}$ & $\begin{array}{l}\text { PM (1) } \\
\text { IS (1) }\end{array}$ \\
\hline
\end{tabular}

DOOR SEQUENCE FOR STIMULUS ANIMALS:
R.R. \# 1
R.R. \#2
R.R. \# 3
2131
2323
1321

Figure 14. Figure sequence of pairings, Test Pairs SIMPL. 
data denote whether a pair was the first, second, or third test pair of the day.

At the bottom of the page appears the key for the rotation of the stimulus animals through the three possible door positions for each Round Robin. For instance, 21312 reveals that the first time a stimulus animal is paired with a test animal, the choice chamber door behind which the stimulus animal was housed was \#2; the second time that same stimulus animal was paired with another animal, it was placed behind choice chamber door $\# 1$, and so on. 
CHAPTER IV

\section{RESULTS AND DISCUSSION}

\section{Habituation: Phases I and II}

Phases I and I I were designed to gradually and progressively habituate the subjects to the test chamber. The deficient animals, like malnourished animals in other studies, showed neophobia in new test settings. This procedure therefore attempted to minimize differences due to neophobia by equalizing the degree of habituation for all animals according to a series of behavioral criteria.

The latency to enter the runway, the latency to retrieve each reinforcer, and the number of trials to criterion were all recorded. For the latency data, graphs revealed no appreciable difference in performance between the deficient and control groups. Formal statistical analyses therefore were not done. For the number of trials to criterion a Mann-Whitney u test was used to compare the deficient and control groups. Based on prior observations with these subjects it was predicted that the protein-deficient animals would take longer to habituate. Therefore a one-tailed test was used.

For Phase I, habituation to the selection chamber, the difference in number of trials to criterion between the two groups did did not reach statistical significance $(u=12, p=.331)$ despite the apparent difference seen on the graphic representation of the data (Figure 15.). One explanation for this is the small number of 


\section{$\square$ Control \\ Protein Deficient}

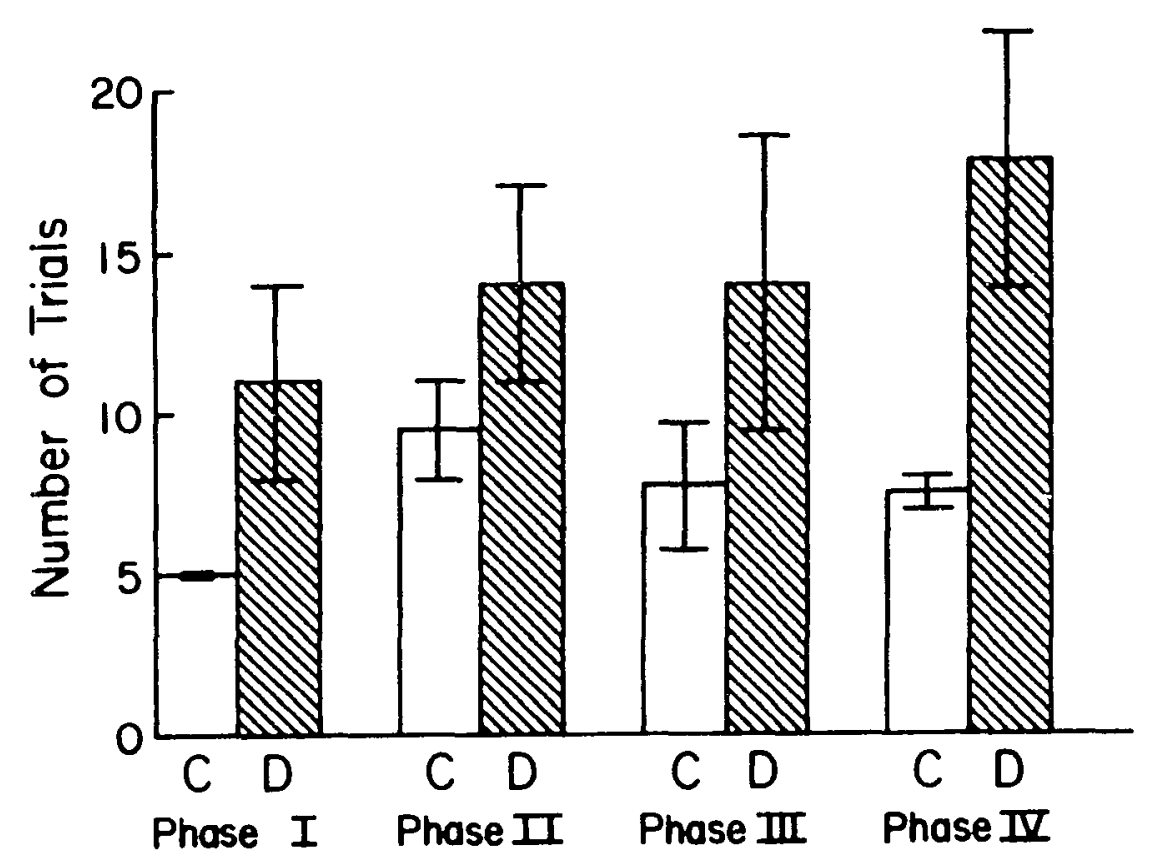

Figure 15. Habituation to the Selection Chamber, Phases I - IV Trials to Criterion for Each Phase (Mean Plus and Minus S.E.). 
subjects and the large number of ties which reduce the possibility of significance with the Mann-Whitney test.

In Phase II, habituation to the selection chamber doors, there was also no significant difference between groups $(u=9, p=.165)$. The variability between individual members of the same diet condition was greater among the protein-deficient subjects than the control subjects.

Phase III - Shaping thie Key Press

For Phase III, shaping the key press, the number of trials to criterion was compared between groups. A Mann-Whitney test again demonstrated no significant difference $(p=.165)$. One simple measure of learning, acquisition of a keypress, therefore was not affected by postnatal protein deprivation. This is consistent with the learning data cited in the review of the literature. Protein-deficient animals tend to show deficits only in complex discrimination learning tasks. In addition, this study employed a food reward which may have had the effect of maximizing performance in the deficient animals (Smart and Dobbing, 1972).

\section{Phase IV - Generalization of the Key Pressing Response}

In this phase the task demands were expanded from responding to one key with its associated keylight (discriminative stimulus) to discriminating and responding differentially to three keys and three discriminative stimuli. A difference in acquisition rate for the two groups became apparent. The number of trials required to attain criterion by deficient subjects was significantly greater than that 
needed by the controls. (Mann-Whitney test, $u=3, p=.015$ ). Proteindeprived subjects therefore took longer to apply a behavioral response learned in one setting to another setting with slightly more complex environmental contingencies. Once again, this supports the contention that deficits come to the fore when the task is more complex. The underlying mechanism for this finding, however, is not understood. As previously mentioned in the literature review, neophobia or attentional changes may explain apparent deficits in learning.

Phase V-Release Data

Phase $V$ was designed to experimentally test the assertion that deficient monkeys seek social interactions less than do normal, wellfed monkeys. It was predicted that the protein-deficient monkeys would release a social partner less frequently than the control monkeys. An examination of Figure 16 shows that there is an overall trend for the control animals to release partners more often than the deficient animals, especially in unlike diet group pairings, that is, control-deficient or deficient-control pairs. A Wilcoxin matchedpairs signed-rank statistic (one-tailed) was computed for unlike diet group pairings and demonstrated that diet condition influences the likelihood of one animal releasing another $(N=13, t=4, p=.005)$.

An ANOVA (two-factor mixed design with repeated measures on one factor) was computed to assess the interaction of test animal diet condition and stimulus animal diet condition. Four possible combinations existed: a control subject had the opportunity to release another control subject (like-diet pair); a control subject had the opportunity to release a protein-deficient subject 


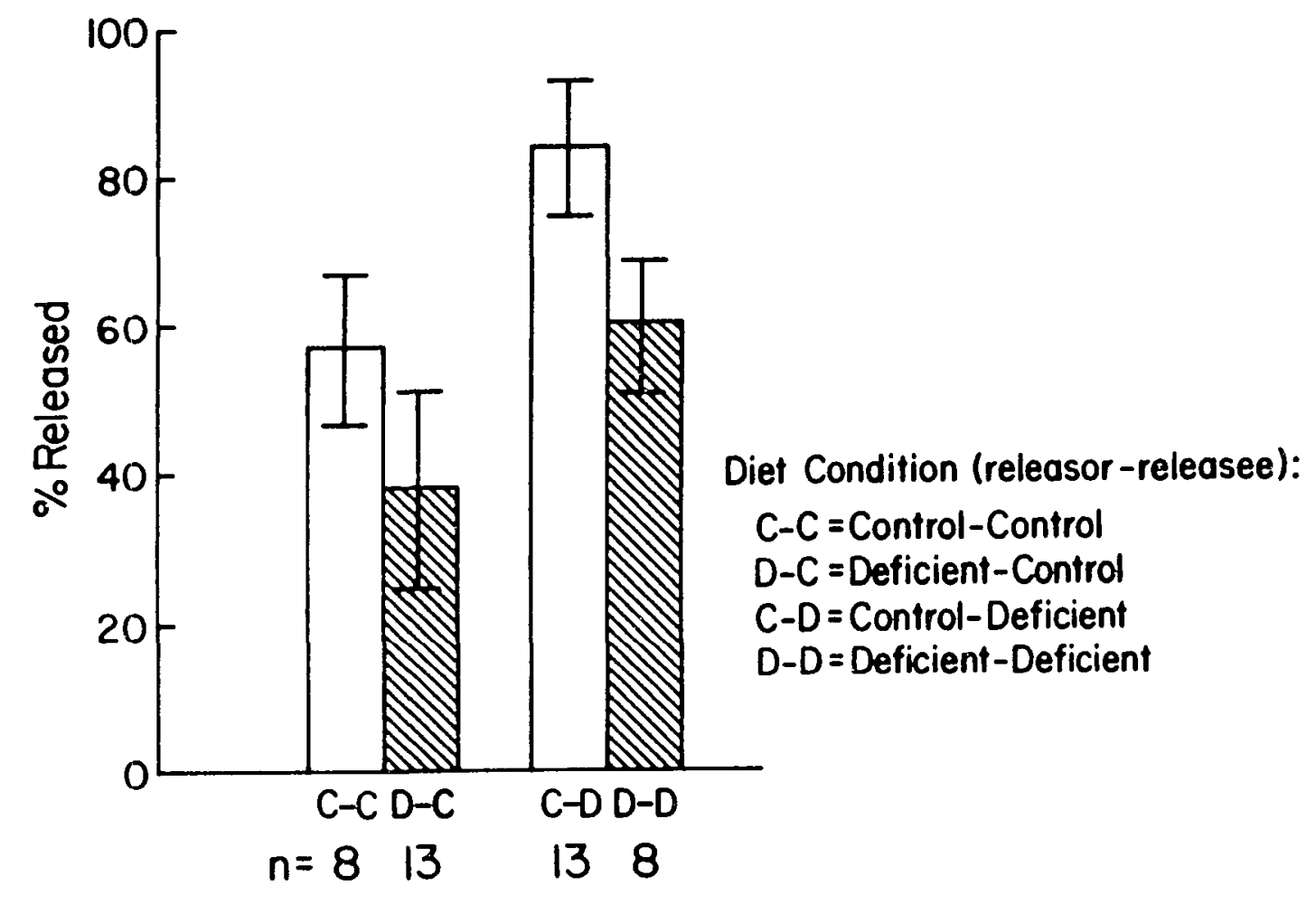

Figure 16. Effect of Diet Condition on Frequency of Release (Mean Plus and Minus S.E.). 
(unlike-diet pair); a protein deficient subject had the opportunity to release another protein-deficient subject (like-diet pair); or a protein-deficient subject had the opportunity to release a control subject (unlike-diet pair). Figure 16 reveals that for like-diet pairings both the control and protein-deficient subjects tended to release approximately 60 per cent of their partners. However, the control animals were far more likely to release a dissimilar diet partner ( 84 per cent probability) than were the protein-deficient subjects ( 39 per cent probability).

Findings from the ANOVA (Table V) show that diet condition of the releasor (test animal) had a significant effect ( $p$ (.05), whereas the effect of diet condition of the releasee (stimulus animal) reached a borderline value $(p<.10)$. The interaction effect of test animal diet condition with stimulus animal diet condition, however, was not significant. Although differences due to the diet condition of the releasee did not attain traditionally acceptable significance, one must consider that the number of subjects was very small and therefore an effect must have been very large to achieve significance. Under circumstances such as these it would not be wise to dismiss the role that the diet condition of the releasee might play. In summary, however, the findings from the ANOVA confirm that diet condition is a determinant of the probability of ene animal releasing another. Unfortunately, there are a number of variables which could obscure these findings. For instance, subjects were housed in adjoining pairs of cages (see Figure 3) which allowed close visual and auditory communication between pairs. It is possible that these 
TABLE $V$

ANOVA: RELEASOR - RELEASEE DIET CONDITIONS

\begin{tabular}{|c|c|c|c|c|c|}
\hline SOURCE & SS & $\mathrm{dF}$ & MS & $F$ & $\mathrm{p}$ \\
\hline Total & 1.533 & 19 & & & \\
\hline Between subjects & 0.7235 & 9 & & & \\
\hline (A) Releasor diet & 0.296 & 1 & 0.296 & 5.585 & $<0.05$ \\
\hline Error $b$ & 0.4275 & 8 & 0.053 & & \\
\hline Within subjects & 0.8095 & 10 & & & \\
\hline (B) Releasee diet & 0.296 & 1 & 0.296 & 4.66 & $<0.1$ \\
\hline$A \times B$ interaction & 0.0056 & 1 & 0.0056 & 0.088 & ns \\
\hline Error within & 0.5077 & 8 & 0.0635 & & \\
\hline
\end{tabular}


home-cage pairings, and not the diet condition per se, account for the primary difference in release rates. All home-cage pairs, therefore, were deleted from the data in order to determine whether the apparent effect of diet was an artifact of home-cage conditions. Figure 17 demonstrates that a difference in release rates between control and protein-deficient subjects persists. A Wilcoxin matched-pairs signedrank statistic was computed for the unlike diet-group pairings minus any home-cage pairs. The difference between diet groups remained highly significant $(n=9, t=1.5, p=.005$, one-tailed). Therefore, the exclusion or inclusion of home-cage pairs did not alter the nature or direction of the difference in release rates between control and deficient animals.

An ANOVA (two-factor mixed design with repeated measures on one factor) was also re-calculated, with the home-cage pairs deleted (Table VI). Once again, diet condition of the releasor was found to have a significant effect $(p<.05)$, whereas diet condition of the releasee had a marginal effect $(p<.10)$, and the interaction between releasor and releasee diet conditions was nonsignificant. Deletion of home-cage pairs did not alter the original results. This analysis thus confirms that housing conditions did not contaminate the findings.

Another variable that needs to be examined in order to assess its impact on the findings is the sex of the subject. Figure 18 provides graphic representation of release data as a function of both sex and diet condition. It is obvious that a significant difference on the basis of sex is unlikely given the large standard error. There 


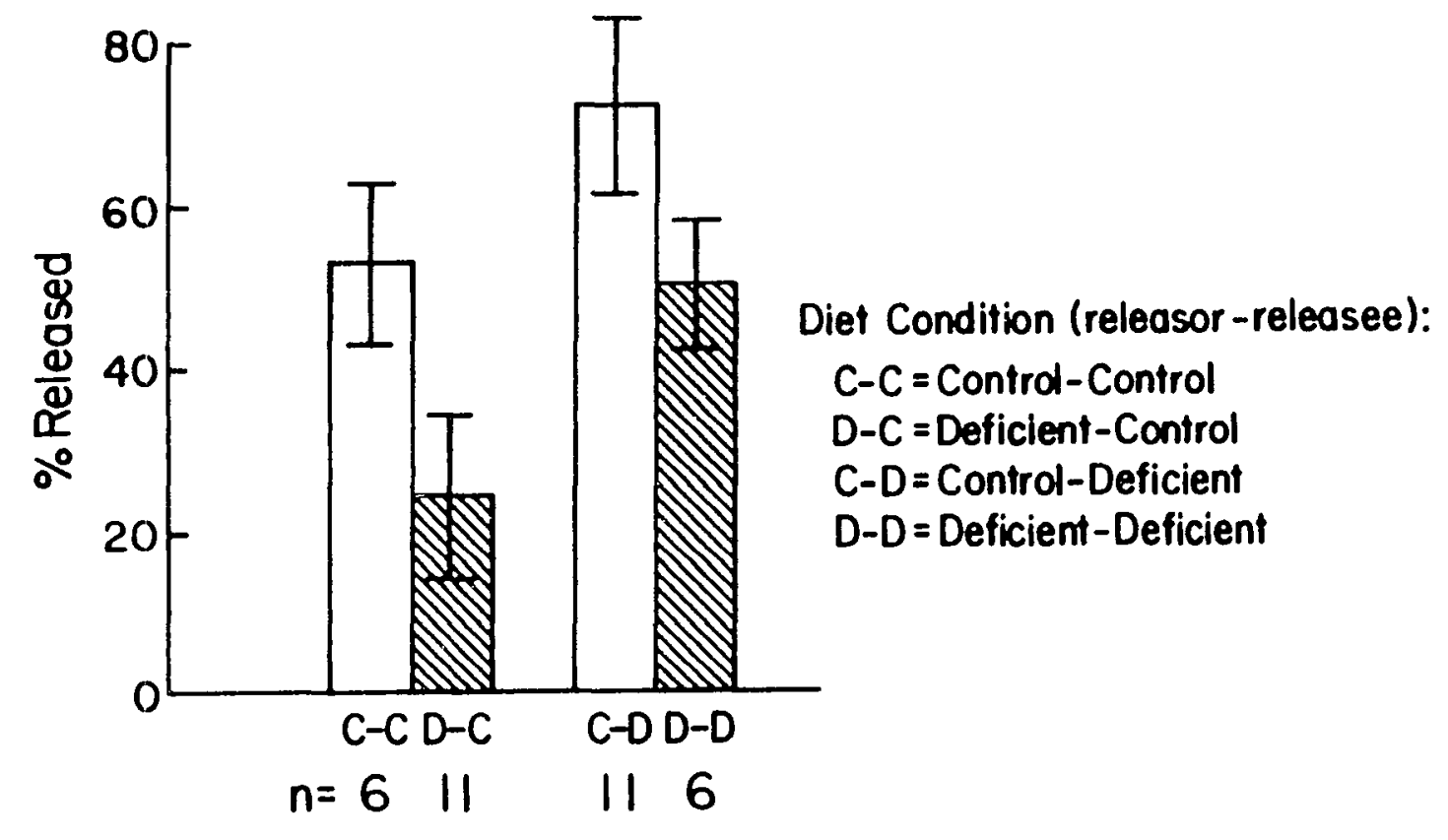

Figure 17. Frequency of Release with Home Cage Partners Omitted (Mean Plus and Minus S.E.). 
TABLE VI

ANOVA: RELEASOR - RELEASEE DIET CONDITIONS

(CONTROL DIET VERSUS PROTEIN-DEFICIENT DIET)

WITH HOME CAGE PARTNER PAIRS DELETED

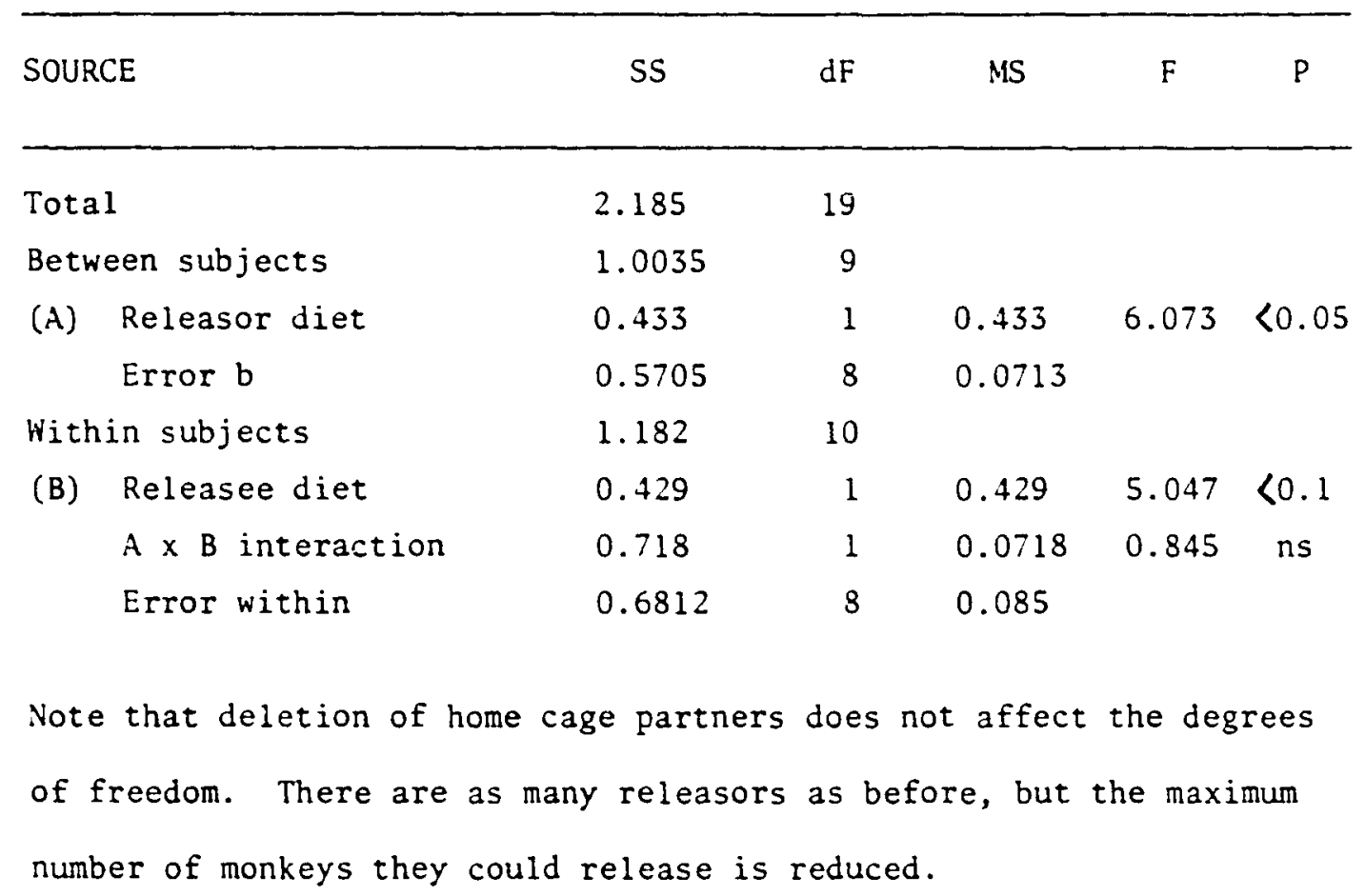




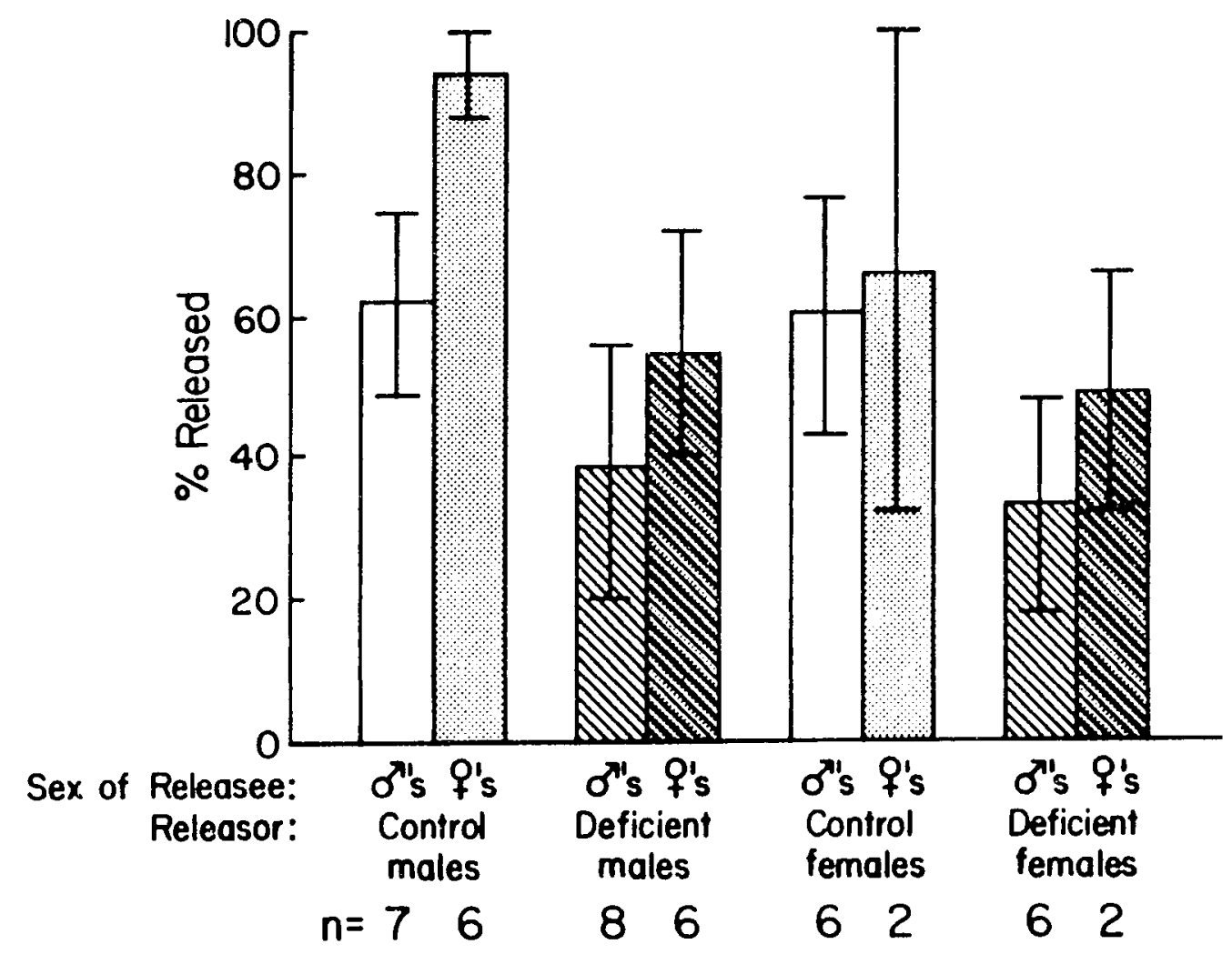

Figure 18. Effect of Diet Condition and Sex on Frequency of Release (Mean Plus and Minus S. E.). 
does seem to be a slight tendency for males of both diet groups to release females more frequently than they release other males.

An ANOVA [three factors with repeated measures on one factor (sex of releasee)] was computed for these data (Table VII). All of the possible interaction effects were nonsignificant. The only effects that approached significance were those of diet condition of the releasor and sex of the releasee (both $\mathrm{p}<0.10)$. The previous analyses indicated a statistically significant effect $(p<.05)$ of diet condition of the releasor. It fails to attain significance in this analysis because the degrees of freedom are small, yielding a very low-powered test. The same may hold true for sex of the releasee. The most important finding, however, is the fact that none of the interaction effects came close to being significant. This alleviates the concern that sex of the animal plays a confounding role in the data.

The next factor examined was that of body weight. As previously mentioned, the control animals outweighed the deficient animals despite attempts to offset this imbalance by feeding the proteindeficient subjects more calories (Figures 1 and 2 ). It is possible, therefore, that differences in releasing a social partner could be principally due to body weight. Larger and heavier animals were more likely to release lighter, smaller ones than vice versa (Figure 19). This is not a simple relationship, however, since body weight, diet condition and frequency of release are all strongly interrelated. Indeed, diet condition and body weight are highly correlated, as demonstrated by a point biserial correlation of +0.82 ( $p<01$ for a 
TABLE VII

ANOVA: THREE FACTORS

(DIET $X$ SEX OF RELEASOR $X$ SEX OF RELEASEE)

WITH REPEATED MEASURES ON ONE FACTOR

\begin{tabular}{llrlll}
\hline SOURCE & SS & dF & MS & F & P \\
& & & & & \\
\hline & 1.249 & 19 & & & \\
Total & 0.996 & 9 & & & \\
Between subjects & 0.06425 & 1 & 0.06425 & 0.7895 & $\mathrm{~ns}$ \\
(A) Sex of releasor & 0.431 & 1 & 0.431 & 5.295 & 0.10 \\
(B) Diet contition: releasor & 0.0123 & 1 & 0.0123 & 0.151 & $\mathrm{~ns}$ \\
$\quad$ A X B interaction & 0.4885 & 6 & 0.0814 & & \\
$\quad$ Error b & 0.253 & 10 & & 3.977 & \\
Within subjects & 0.0851 & 1 & 0.0851 & 3.977 & 0.1 \\
(C) Sex of releasee & 0.0065 & 1 & 0.0065 & 0.304 & $\mathrm{~ns}$ \\
$\quad$ A x C interaction & 0.0009 & 1 & 0.0009 & 0.042 & $\mathrm{~ns}$ \\
B x C interaction & 0.0238 & 1 & 0.0238 & 1.112 & $\mathrm{~ns}$ \\
$\quad$ A x B x C interaction & 0.12845 & 6 & 0.021408 & & \\
Error withhin & & & & &
\end{tabular}




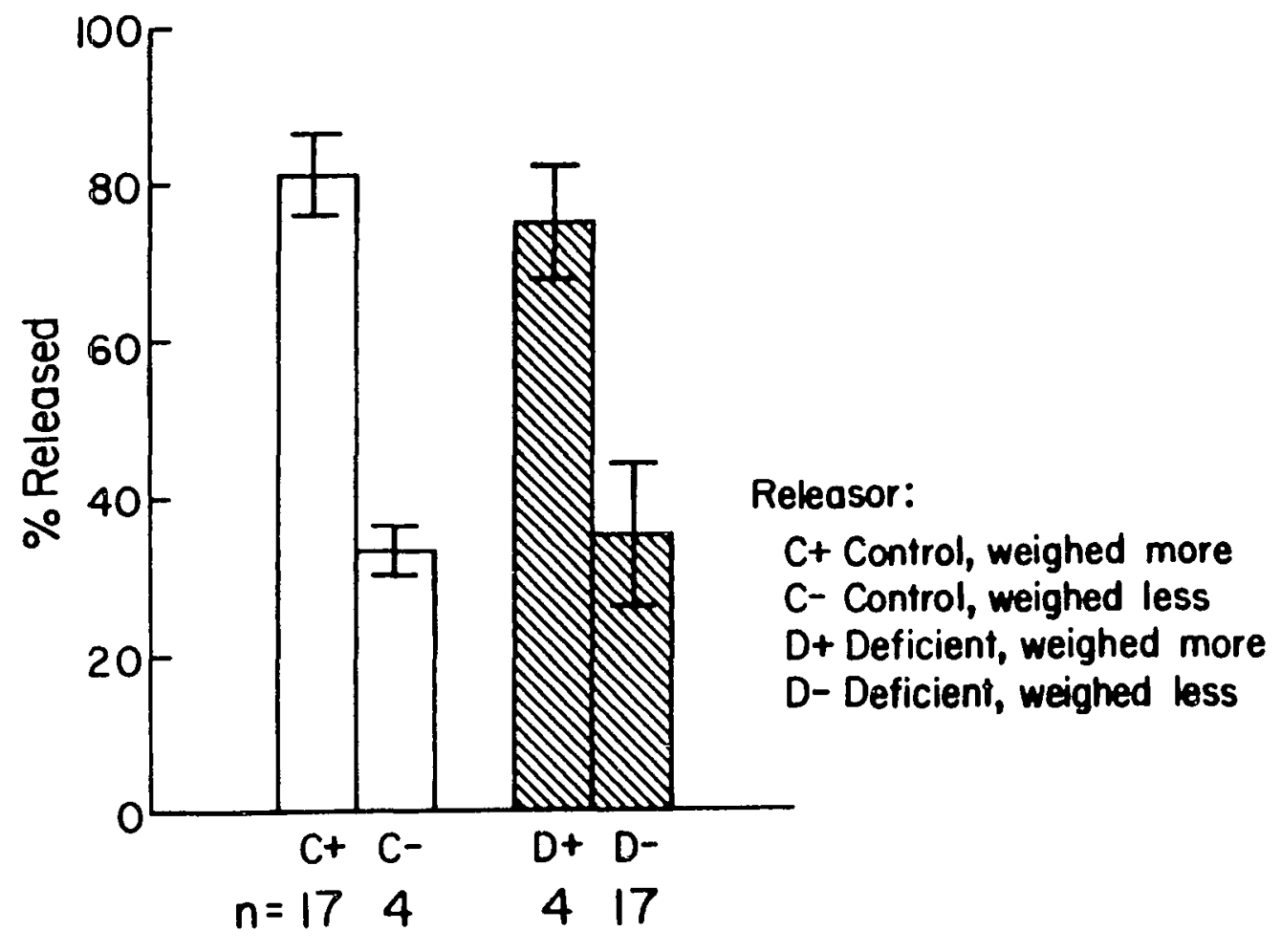

Flgure 19. Effect of Body Weight on Frequency of Release (Mean Plus and Minus S. E.). 
two-tailed t-test, $n=10$ ). The question that needs to be answered is whether or not body weight has an effect above and beyond diet condition.

One way to address this issue indirectly is to look solely at control-control and deficient-deficient pairings. A Spearman rank order correlation was computed in which both the percentage released and body weight were ranked. This yielded a Rho of $+0.006 \quad(n=8)$, which was not significant. Body weight for like-diet pairs is not correlated with frequency of release; therefore, body weight alone is not the sole contributing factor in predicting the probability of release.

Other calculations can help to further clarify the true role of body weight when unlike-diet pairs are included. The Pearson productmoment correlation coefficient between body weight and the percentage released was $r=+0.583$ which was significant $(p<.05$ for a one-tailed t-test, $n-10$ ). In addition, a point biserial correlation between diet condition and the percentage released was $r_{p b}=+0.60$, which is significant ( $p<.05$ for a one-tailed t-test, $n=10)$. The partial correlation between body weight and frequency of release with the relational effects of diet condition partialed out is +0.193 . Thus $\mathrm{r}_{\mathrm{ab}}=+0.583$ is reduced to +0.193 when the mutual relationships of the variables with diet are partialed out. Conversely, the partial correlation between diet condition and frequency of release with the relational effects of body weight partialed out is +0.27 . Thus $r_{a b}=+0.60$ (for diet condition with frequency of release) is reduced to +0.27 . This indicates that body weight clearly has a role, but 
one which is less significant than diet condition. There is, however, an obvious nonstatistical rationale for believing that diet causes weight differences and not vice versa. Therefore, controlling for diet condition in assessing the separate, additional contribution of weight is appropriate. All of the above data suggests that body weight alone does not determine frequency of release, and that diet condition is a significant variable.

The subjects in this experiment had long-term previous social group experience and therefore had an established social dominance hierarchy. Data on the dominance relationships between pairs had been recorded. Dominance status, therefore, is another factor that may have determined the frequency of release. An examination of Figure 20 shows that a relationship exists between dominance within each pair and the likelihood of release. A Wilcoxin matched-pairs signed-rank test for unlike diet pairs indicated that the dominant member of a pair was significantly more likely to release its partner than vice versa $(p=.01$, two-tailed, $n=12)$.

Once again, however, this is not a straightforward relationship since dominance, body weight, and diet condition are intercorrelated. As with body weight, several analyses can be utilized here to help tease apart these inter-relationships.

The Pearson product-moment correlation coefficient between dominance rank and body weight was +0.67 (p<.01, two-tailed t-test, $\mathrm{n}=10$ ). The point biserial correlation for dominance rank and diet condition was +0.65 ( $p<.05$, two-tailed t-test, $n-10)$. In addition, a sign test showed that the control animal was dominant to the 


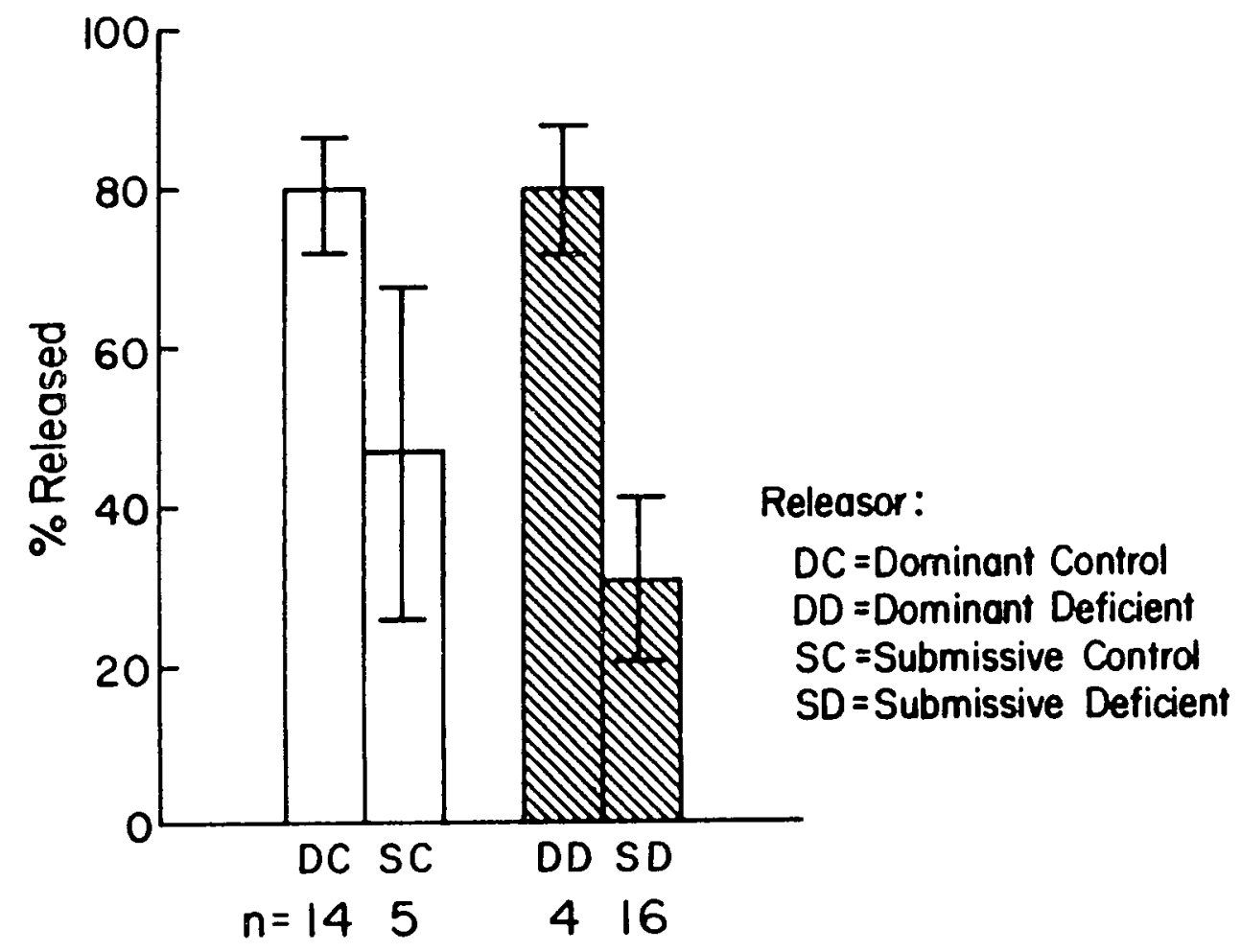

Figure 20. Effect of Dominance on Frequency of Release (Mean Plus and Minus S.E.). 
deficlent subject in 11 out of 12 unlike diet pairs ( .003$)$. Thus signiftcant correlations exist for both sets of relationships. Dominance rank is correlated with both body weight and diet condition. This is not surprising considering that body weight and diet condition are significantly correlated. Control animals weigh more, animals which weigh more tend to be more dominant, and animals which weigh more and are more dominant tend to release other animals more frequently.

Once again, in order to separate these interrelated factors, a partial correlation with the three variables was computed. The purpose of this analysis was to provide a correlation measure between dominance rank and body weight with the relational effects of diet condition removed. The correlation of dominance rank with body weight is reduced to +.31 when the relationships with diet are partialled out. Therefore the interrelationship of dominance and body weight is clearly mediated by diet condition to a large extent.

A final set of relationships needs to be explored. A Pearson product-moment correlation for dominance rank and frequency of release for all pairs yields $\mathrm{r}=+0.45, \mathrm{n}=10$, which was not significant. As previously reported, the point biserial correlation between diet condition and frequency of release was +0.60 , and the point biserial correlation between dominance rank and diet was +0.65 . The partial correlation with these three variables permits a determination of the relationship of dominance ranking to the frequency of release where the effect of diet condition is partialled out. This partial correlation is +0.11 , indicating that dominance rank by itself shows 
only a very weak correlation with the likelihood of one subject releasing another. In addition, the partial correlation between diet condition and frequency of release with the effect of dominance partialled out is +0.45 . Therefore, the correlation between diet and release of +0.60 is only reduced to +0.45 when the impact of dominance is separated out. Once again, diet condition plays the most important mediating role.

\section{Phase V-Social Behaviors}

Social behavior data were collected throughout Phase $V$ for the test and stimulus animals both prior to and following a release. It is beyond the scope of this thesis to provide an extensive analysis of all the behavioral data obtained. Only a generalized summary of major trends noted for post-release interactions will be presented.

The individual behaviors defined in the Methods section were grouped into seven categories. The category of dominant behaviors, for instance, included aggression, woof, yawn, stare threat, fur bite and display behaviors. Submissive behaviors were subdivided into primary submisstve behaviors -- fear grimace, rigid, present and withdraw -- and secondary submissive behaviors -- show neck, screech, leave and lipsmack. A social contact category was comprised of social exploration, sexual exploration, proximity, groom, approach and contact behaviors. A play category included play initiate, pursuit, avoid, box, gape, small-mouth gape, earflip, rough and tumble, and brief contact play. Self-clasp, huddle, self-mouth, self-bite, coo and girn behaviors were defined as a disturbed behavior cluster. Sexual behaviors included sexual exploration, self-play, erection and 
mounts. Finally, cage exploration, key exploration, and ineffective presses (pressing the key post-release) were grouped as exploratory behaviors.

Figure 21 suggests a tendency for controls to exhibit more dominant behaviors than the deficient animals. This trend was not statistically significant, however. On the other hand, a significant discrepancy between the two groups is revealed when primary submissive behaviors (Figure 21) are compared (Mann-Whitney $u=1, p=.008$ ). Secondary submissive behaviors, in contrast, were equally distributed between the control and protein-deficient groups (Mann-Whitney $u=15$, $\mathrm{p}=0.579$ ). Figure 22 suggests a tendency for the control animals to engage in more social contact, play, and sexual behaviors, but none of these differences was statistically significant $(p=0.155$ for social contact, $p=0.345$ for play behaviors, and $p=0.345$ for sexual behaviors, Mann-Whitney u test). For both groups of animals, sexual actions were almost nonexistent and play behaviors were rare.

The two areas in which the control and protein-deficient subject subjects deviated most dramatically from one another were disturbed behaviors and exploration (Figure 23). The protein-deprived animals tended to engage in self-stimulatory, withdrawn, autistic-like behaviors (self-clasping, huddling, rocking, sucking body parts and making disturbed vocalizations such as coos and girns) whereas the control animals spent more time exploring (biting, sniffing, and manipulating) their environment. In fact, the experimental subjects engaged in disturbed behaviors significantly more than did controls (Mann-Whitney $u=j, p=.028$ ), whereas the control subjects interacted 


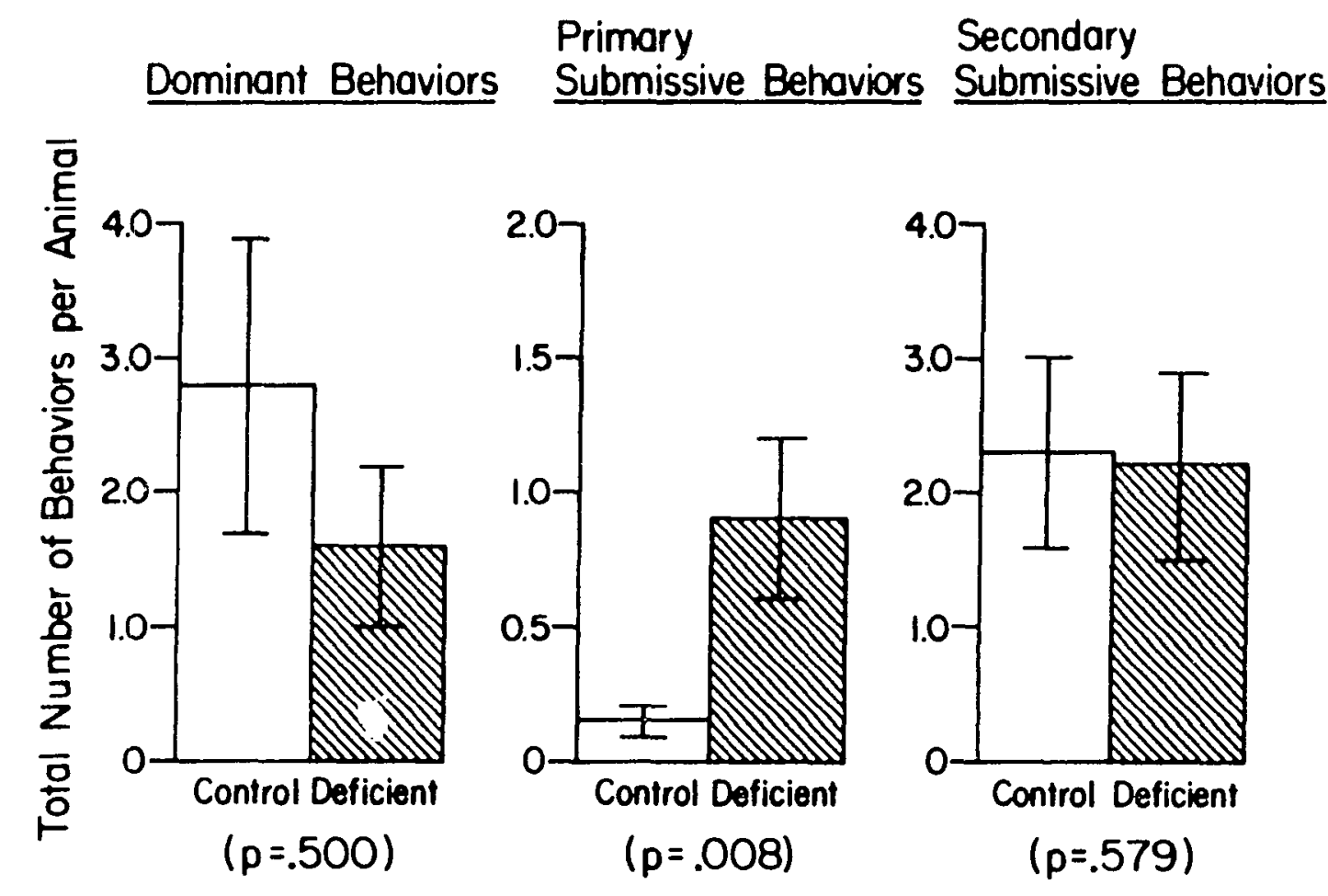

Figure 21. Effect of Diet Condition on Frequency of Dominant and Submissive Behaviors (Mean Plus and Minus S.E.). 

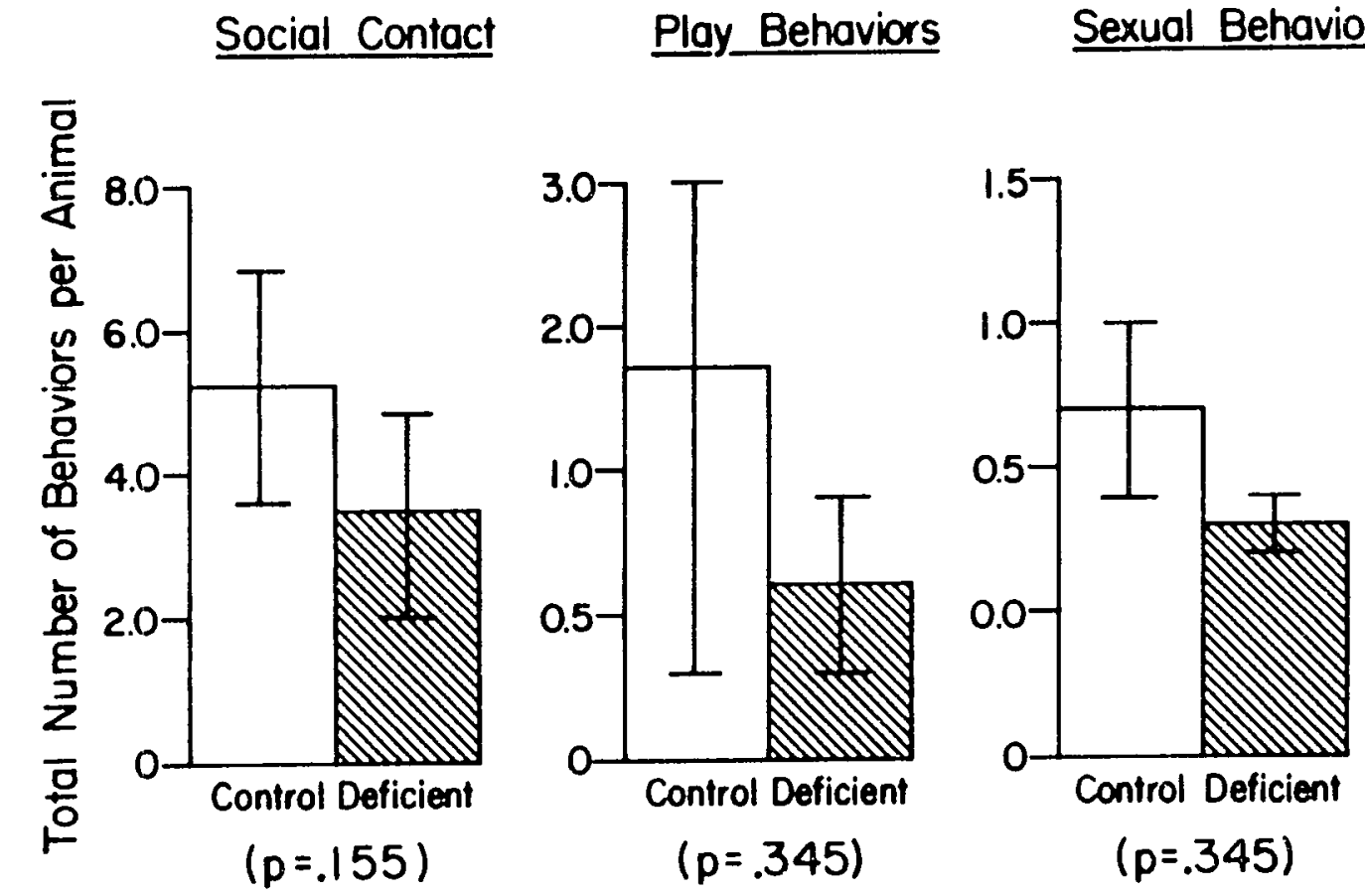

Figure 22. Effect of Diet Condition on Frequency of Social Contact, Play and Sexual Behaviors (Mean Plus and Minus S.E.). 

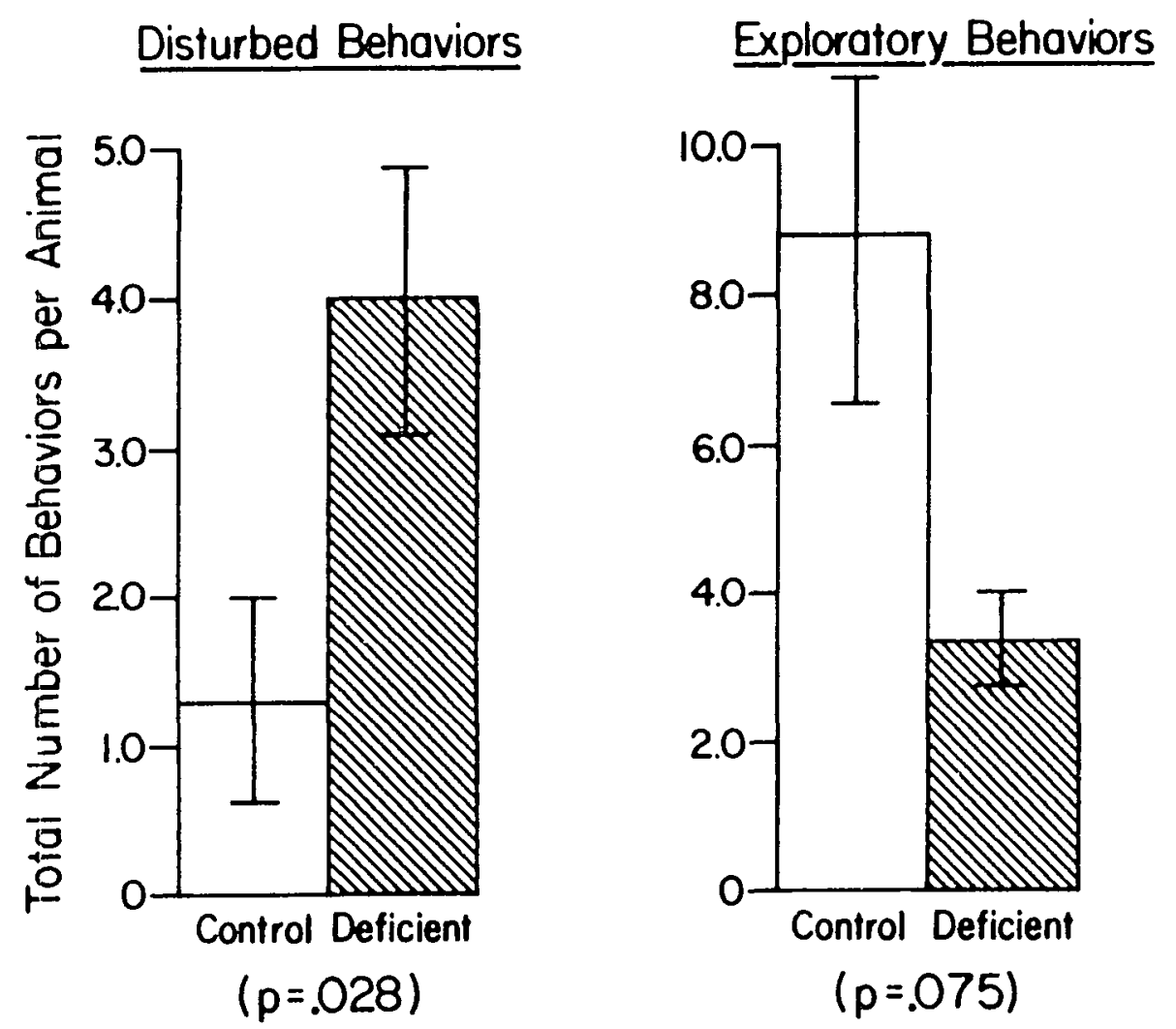

Figure 23. Effect of Diet Condition on Frequency of Disturbed and Exploratory Behaviors (Mean Plus and Minus S.E.). 
with their environment more often than deficient animals (Mann-Whitney $u-5, p=.075$, borderline significance).

\section{Conclusion}

As previously stated in the introduction of this paper, several investigators have proposed that the physical and behavioral consequences of early malnutrition may serve to limit the appropriate development and expression of social interaction in later life (Latham, 1969 and Sussman, 1972). To date, these conjectures have been based primarily on inference and indirect experimental observation. The research undertaken in this study was intended to test experfmentally the hypothesis that postnatal malnutrition interferes with normal social motivation. In this study, the performance of an operant response wis used as an objective measure to the tendency to seek out social interaction. The present research provides behavioral observations made during social group interactions. In these previous studies, the animals could not choose whether to be placed together.

As predicted, the protein-deficient animals released soctal partners less frequently than did their controls. Findings from the ANOVA demonstrate that the diet condition of the test animal (releasor) was the critical determining factor. Other posstble confounding variables such as housing conditions and sex of the pair members were ruled out.

A closer examination of the data reveals some interesting trends. The control animals were far more likely to release an unlike-diet partner than were the protein-deficient animals. It is possible that 
overt physical characteristics such as scant body hair and reduced body size, as well as behavioral characteristics such as submissive and self-stimulatory behaviors, could have served as cues for deficient animals to identify a physical and behavioral peer. The physical appearance and behavior of the control animals may have made them more threatening stimulus animals, so that the deficient animals were less willing to commit themselves to a social encounter with them.

Two additional and possibly confounding factors entailed in this analysis are body weight and dominance rank. The data show that neither factor alone exerts an effect beyond that of diet condition, or conversely that diet condition mediates both dominance and body weight. Diet condition therefore is the key critical variable, accounting for both the behavioral and physical changes mentioned above.

Protein-deprived subjects are less motivated to seek out an opportunity to interact socially with another animal. Even when such animals do release a social partner, their behavioral interactions are abnormal. In general, the deficient diet served to depress social and exploratory behaviors. Increases were found only in disturbed and self-stimulatory behaviors. As stated in the introduction, actively engaging or encountering one's environment is a basic prerequisite for acquiring adaptive, survival-oriented knowledge. The deprived subjects' neophobia curtailed their ability to respond to and interact with their environment. In addition, these animals withdrew from social interactions. By such behaviors, 
these animals tended to isolate themselves from their surroundings and limit their experiences. It is not surprising, therefore, their behavior resembled that of animals raised in social isolation. Among both control and protein-deficient animals, sexual behaviors were almost nonexistent and play was rare. In contrast, Geist, et al. (1972) and Zimmermann (1970), found reductions in play and sexuality solely in the protein-deficient subjects. The paucity of play behaviors in the present study might be accounted for as a product of maturation; that is, adult animals simply drop play from their mature repertoire of behaviors. The lack of appropriate sexual behavior indicates that these animals could not reproduce. It is probable that despite a history of social group interactions early in life, these animals failed to develop appropriate sexual behaviors due to a lack of older adult models as well as the generally unstimulating environment of caged experimental animals.

Social isolates have been characterized as developmentally delayed or immature. Both sexual behaviors and play are depressed in comparison to laboratory-reared controls (Zimmermann and Zimmermann, 1972) and Harlow (1965). In these two areas of play and sexual behaviors, both groups in this study behaviorally mimic social isolate monkeys.

The protein-deficient subjects showed more behavioral abnormalities than did the controls. They had fewer social interactions; they were neophobic and showed reduced exploratory behaviors; they were more fearful and submissive toward other monkeys; they engaged in more disturbed behaviors. The protein-deficient 
animals therefore are even more like social isolates. Zimmermann, Geist and Wise (1970), for instance, found that social isolates overreacted to and avoided novel stimuli and engaged in fewer investigatory behaviors. These isolate monkeys were less social in the sense that they initiated fewer social interactions, did not reciprocate social overture and avolded soctal contact. However, when social interactions did occur, these animals were far more aggressive than the control monkeys. The protein-deficient monkeys in this study displayed no sign of such hyper-aggression. Instead, they were quite fearful, engaging in may more fear and submissive behaviors.

Harlow (1965 and 1966) found that his total social isolates did not make social approaches, failed to respond to such advances, showed low object exploration, had heightened fear reactions and spent the majority of their time in autistic or self-stimulatory behaviors such as rocking back and forth, self-clasping, screaming, and self-mouthing.

The behavioral changes resulting from protein deficiency are almost identical to those induced by social isolation. The combination of a low protein diet with restricted social and environmental stimulation (inherent to the laboratory setting) creates an animal which is almost indistinguishable from one raised under extreme social deprivation. Peer group social experience early in life did not offset these behavioral abnormalities. This study shows that there are differences in social and exploratory behaviors between control and protein-deficient monkeys when they are all raised in a relatively impoverished environment; it is not known 
whether these differences would occur among animals reared in a richer, more socially normal environment. An interaction between diet and social isolation seems likely, however. It is possible, for instance, that the effects of diet and social isolation are additive. In addition, similar mechanisms may underlie both conditions. Proteindeficiency and social isolation both give rise to neophobia. This neophobia curtails exploration and socialization which in turn delays the animals maturational development and social experience. A vicious cycle ensues in which the animal continues to avoid the very experience needed to develop mature social behaviors.

An alternative hypothesis is that both social isolation and protein-deficiency produce attentional deficits; and it is these attentional deficits (for example, failure to attend to and thereby respond appropriately to social cues) which lead to ever compounding behavioral abnormalities. Verification of such underlying mechanisms awaits future research.

In summary, this study found that diet per se can produce pronounced behavioral and emotional deviations. These deviations persisted and were not ameliorated merely by maturation. This study demonstrates that chronic malnutrition gives rise to persistent inadequacies in social behavior. The results from this study support and extend previous findings from social group observations and studies of exploratory behavior. These previous studies found that:

a. malnourished monkeys are less likely to look at other monkeys (Zimmermann, et al., 1972);

b. malnourished monkeys are more likely to rebuff social overtures (Kerr, et al., 1970 and Zimmermann, 1970); 
c. malnourished animals initiate fewer social encounters (Frankova, 1973);

d. malnourished monkeys show high levels of withdrawal and self-stimulatory behaviors (Zimmermann, et al., 1972 and 1970).

A study such as this is useful insofar as it helps to clearly define the consequences of protein deprivation per se. Human studies could never achieve this clarity because the type and degree of nutritional deprivation can never be known precisely, and because there are so many other potentially confounding variables, such as the role of environment in behavioral development, which cannot be controlled. Animal models therefore are essential to separate out the effects of nutritional deprivation in and of itself. This study demonstrates that long-term postnatal protein malnutrition alters the course of normal social development. Although it is always risky to generalize from animal models to human behavior, one can speculate that the consequences of protein malnutrition could only be detrimental to a human populace. The same children who experience malnutrition usually are also subjected to impoverished and unstimulating environments. Therefore, if these two factors interact to produce behavioral deficits, these children would be especially vulnerable. It is possible that chronic malnutrition may create a set of socially disadvantaged person, who are only able to marginally interact with others. Such as effect would seem to have the potential for far-reaching limitations in all domains of behavior. 


\section{BIBLIOGRAPHY}

Anderson, J. E. and Smith, A. H. The effect of quantitative stunting upon maze learning in the white rat. Journal of Comparative Psychology, 6, pp. 337-359, 1926.

Barnes, R. H. Behavioral abnormalities resulting from early malnutrition in rats and pigs. In: Protein, Metabolism and Biological Function, Bianchi, P. C. and Russell H. (Eds.), New Brunswick, N. J.: Rutgers University Press, 1970.

Barnes, R. H., Moore; 2. V.; and Pond, W. G. Behavioral abnormalities in young adult pigs caused by malnutrition in early life. Journal of Nutrition, 100:149-155, 1970.

Barnes, R. H.; Cunnold, S.; Zimmermann, R.; Simons, H.; MacLeod, R.; and krock, $L$. The influence of nutritional deprivation in early life on learning behavior of rats as measured by performance in a water maze. Journal of Nutrition, 89, p. 399, 1966.

Barnes, R. H.; Moore, Z. V.; Reid, I. M.; and Pond, W. G. Effect of food deprivation on behavioral patterns. In: Malnutrition, Learning, and Behavior. Scrimshaw, N.S. and Gordon, J. E. (Eds.), Cambridge, Massachusetts: M.I.T. Press, 1967.

Barnes, R. H. Experimental studies in animals: physiologic and behavioral correlates of malnutrition. In: Nutrition, Growth and Development of North American Indian Children, Moore, W. M.; Silverberg, M. M.; and Reid, M. S. (Eds.). DHEW Publication No. (NIH) 72-76. Washington, D.C., 1973.

Behar, M. Prevalence of malnutrition among preschool children of developing countries. In: Malnutrition, Learning, and Behavior, Scrimshaw, N. S. and Gordon, J. E. (Eds.), Cambridge, Massachusetts: M.I.T. Press, 1968.

Bernhardt, K. S. Protein deficiency and learning in rats. Journal of Comparative Physiological Psychology, 22, pp. 269-272, 1936.

Butler, R. A. Discrimination learning by rhesus monkeys to visual exploration. Journal of Comparative and Physiological Psychology, 46, pp. 95-99, 1953.

Brockman, L. N. and Ricciut1, H. N. Severe protein-calorie malnutrition and cognitive development in infancy and early childhood. Developmental Psychology, 4, pp. 312-319, 1971. 
Cabak, V. and Najdanvik, R. Effects of undernutrition in early life on physical and mental development. Archives Disabled Childhood, 40, pp. 532-534, 1965.

Caldwell, D. F. and Churchhill, J. A. Learning ability in the progeny of rats administered a protein deficient diet during the second half of gestation. Neurology, 17, pp. 95-99, 1967.

Champakan, S.; Srikantia, S. G.; and Gopalan, C. Kwashiorkor and mental development. American Journal of Clintcal Nutrition, 21 , pp. 844-852, 1968.

Chase, H. P.; Dorsey, J.; and McKhann, G. M. Malnutrition and the synthesis of myelin. Pediatrics, 40, pp. 551-559, 1967.

Chase, H. P. and Martin, H. P. Undernutrition and child development. New England Journal of Medicine, 282, pp. 933-939, 1970.

Cheek, D. B.; Holt, A. B.; and Mellits, E. D. Malnutrition and the nervous system, In: Malnutrition in early life and subsequent development of function, 2nd conference, pp. 9-15, January, 1972.

Chow, B. In: Malnutrition, Learning and Behavior. Scrimshaw, N.S. and Gordon, J. E. (Eds.), Cambridge, Massachusetts: M.I.T. Press, pp. 228-229, 1968.

Cobos, F. and Guevara L. Assessment of cognitive development in deprivation and malnutrition. In: Nutritional Development and Social Behavior, Kallen, D., pp. 173-189, 1973.

Cowley, J. J. and Griesel, R. F. Low protein diet and emotionality in the albino rat. Journal of Genetic Psychology, 104:89-98, 1964.

Cravioto, J.; Delicardie, E. R.; and Birch, H. G. Nutrition, growth, and neuro-integrative development: an experimental and ecologic study. Pediatrics, 38, pp. 319-372, 1966.

Dobbing, J. and Widdowson, E. M. The effect of undernutrition and subsequent rehabilitation on myelination of rat brain as measured by its composition. Brain, 88, pp. 357-366, 1965.

Dobbing, J. and Path M. N. Development of the nervous system. In: Malnutrition, Learning and Behavior, Scrimshaw, N. S. and Gordon, J. E. (Eds.), Cambridge, Massachusetts: M.I.T. Press, pp. 181$202,1968$.

Dobbing, J. Undernutrition and the developing brain: the relevance of animal models to the human problem. American Journal of the Disabled Child, 120, pp. 411-415, 1970.

Dobbing, J. and Sands, J. Vulnerability of developing brain: the 
effect of nutritional growth retardation on the timing of the brain growth spurt. Biological Neonate, 19, pp. 363-378, 1971.

Elias, M. F. and Samonds, K. W. Exploratory behavior and activity of infant monkeys during nutritional and rearing restriction. American Journal of Clinical Nutrition, 27, pp. 458-463, 1974.

Elias, M. F. and Samonds, K. W. Protein and calorie malnutrition in infant Cebus monkeys: growth and behavioral development during deprivation and rehabilitation. American Journal of Clinical Nutrition, 30:355-366, 1977.

Frankova, S. and Barnes, R. Effect of malnutrition in early life on avoidance conditioning and behavior of adult rats. Journal of Nutrition, 96 , pp. 485-493, 1968.

Frankova, S. and Barnes, R. Influence of malnutrition in early life on exploratory behavior of rats. Journal of Nutrition, 96 , pp. 477-484, 1968 (b).

Frankova, S. Effect of early dietary and sensoric reduction on behavior of adult rats. Activitas Nervosa Super., 14:1, 1972.

Frankova, S. Effects of protein-calorie malnutrition on the development of social behavior in rats. Developmental Psychology, 6 (1), pp. 33-43, 1973.

Frankova, S. Relationship between nutrition during lactation and maternal behavior of rats. Activas Nervosa Superior, 13:1-8, 1971.

Geist, C. R.; Wells, A. M.; and Zimermann, R. R. Influence of environment and nutritional factors on problem solving in the rat. Perceptual and Motor Skills, 35, pp. 235-244, 1972.

Geist, C. R.; Zimmermann, R. R.; and Strobel, D. A. Effect of proteincalorie malnutrition on food comsumption, weight gain, serum proteins, and activity in the developing rhesus monkey (Macaca mulatta). Laboratory Animal Science, 22, pp. 369-377, 1972.

Gerber, M. and Dean, R. F. The psychological changes accomanying. kwashiorkor. Courrier, 6:3, 1956.

Guthrie, H. A. Severe undernutrition in early infancy and behavior in albino rats. Physiological Behavior, 3, pp. 619-623, 1968.

Griffiths, W. J. and Senter, R. U. The effects of protein deficiency on maze performance of domestic norway rats. Journal of Comparative and Physiological Psychology, 47, PP. 41-43, 1954.

Hansen, E. W. The development of maternal and infant behavior in the 
Rhesus monkey. Behavior, 27, Pp. 107-149, 1966.

Harlow, H. F.; Blazek, N. C.; and McClearn, G. E. Manipulatory motivation in the infant rhesus monkey. Journal of Comparative and Physiological Psychology, 49, Pp. 444-448, 1956.

Harlow, H. F. and Harlow, M. K. The effect of rearing conditions on behavior. Bulletin of the Menninger Clinic, Vol. 26, No. 15, pp. $213,1962$.

Harlow, H. F. The effects of early social deprivation on primates. Tire a Part, Symposium Bel Air II, Desafferentiation Experimentales at Cliniques. George and Company, Geneva, Switzerland. 66-77, 1965 .

Harlow, H. F.; Dodsworth, R. O.; and Harlow, M. K. Total social isolation in monkeys. Proceedings Nattonal Academy of Science, 54, pp. 90-7, 1965.

Harlow, H. F.; Mitche11, G. D.; Raymond, E. L.; and Ruppentha1, G. C. Long-term effects of total social isolation upon behavior of Rhesus monkeys. Psychological Reports, 18, PP. 567-580, 1966.

Harlow, M. K.; Harlow, H. F.; Chamroe, A. S.; Deets, A. C.; Kerr, G. R.; and Waisman, H. A. Effects of malnutrition on the learning of Rhesus monkeys. Meetings of American Association for Advancement of Science, 1969.

Howard, E. and Granoff, D. M. Effect of neonatal food restriction in mice on brain growth, D.N.A., and cholesterol and on adult delayed response learning. Journal of Nutrition, 95, pp. 111-121, 1968.

Kallen, D. J. (Ed.,), Nutrition, Development and Social Behavior. U.S. Department of Health, Education and Welfare, Publication $\# 73-\overline{242}$.

Kanw1t, M. The influence of nutritional and environmental variations on the behavior of the rat. Unpublished senior honors thests, Reed College, 1976.

Kerr, G. R.; Allen, J. R.; Scheffler, G.; and Waisman, H. A. Malnutr1tion studies in the rhesus monkey, American Journal of Clinical Nutrition, 23, Pp. 739-748, 1970.

Kerr, G. R.; Waisman, H. A.; Allen, J.A.; Wallace, J.; and Scheffler, G. Malnutrition studies in Macaca mulatta II, the effect on organ size and skeletal growth. American Journal of Clinical Nutrition, 26, pp. 620-629, 1973.

Klein, R. E.; Gilbert, O.; Canosa, C.; and DeLeon, R. Performance of malnourished in comparison to adequately nourished chlldren (Guatemala). Paper for the American Assoclation for Advancement 
of Science, Boston, Massachusetts, 1969.

Klein, R. E.; Habricht, J. P.; and Yarbrough, C. Effects of proteincalorie malnutrition on mental development. Advances in Pediatrics, 18, pp. 75-91, 1971.

Lat, J. E.; Widdowson, and McCance, R. A. Some effects of accelerating growth, III. Behavior and Nervous Activity, Proceedings Royal Society (Biology), 193:347-356, 1960 .

Latham, M. C. International nutrition and later learning assoctation for childhood educational international. p. 34, 1969.

Levitsky, D. A. and Barnes R. H. Effects of early protein-calorie malnutrition of animal behavior, Paper read at meeting of American Assoctation for Advancement of Science, December, 1969.

Levitsky, D. A. and Barnes R. H. Effect of early malnutrition on the reaction of adult rats to aversive stimuli. Nature 255, pp. 468$469,1970$.

Levitsky, D. A. and Barnes, R. H. Nutritional and envioronmental interactions in the behavioral development of the rat: Long-term effects. Science 176, pp. 68-71, 1972.

Mason, W. A. and Davenport, R. K. Early experience and the social development of monkeys. Early experience and behavior. Newton, G. and Levin, S. (Eds.), Springfield, Illinois, 1968.

Mason, W. A. and Green, P. H. The effects of social restriction on the behavior of Rhesus monkeys. Journal of Comparative Psyciological Psychology, 55, pp. 363-368, 1962 .

Massaro, T.; Levitsky, D.; and Barnes, R. Protein malnutrition in the rat: its effects on maternal behavior and pup development. Developmental Psychobiology, 7, pp. 551-555, 1972.

McKay, H. E.; McKay, A.; and Sinisterra, L. Behavioral intervention studies with malnourished children: a review of experiences. In: Nutrition, Development and Social Behavior, Kallen, D. (Ed.), pp. 121-145, 1972 .

Melzak, R. The genesis of emotional behavior - an experimental study of the dog. Journal of Comparative Physiological Psychology, 47, pp. 166-168, 1954 .

Melzak, R. Effects of early experience on behavior: experimental and conceptual considerations. In: Disorders of Perception, Hock, P. H. and Zubin, J. (Eds.), New York: Grune and Stratton, 1965.

Monckeberg, F. Effect of early marasmic malnutrition on subsequent physical and psychological development. In: Malnutrition, 
Learning, and Behavior, Scrimshaw, N. S. and Gordon, J. E. Cambridge, Massachusetts: M.I.T. Press, pp. 269-78, 1967.

Neuringer, M. D. Behavioral effects of early malnutrition in monkeys. NICHD Research Grant HD-07649, 1977.

Neuringer, M. D. Behavioral effects of malnutrition in monkeys. NICHD Research Grant, unpublished, 1978.

Ordy, J.; Samorajski, T.; and Hershberger, T. Brain vulnerability to postnatal protein-calorle deficiency in infant Rhesus monkeys. Proceedings Social Experimental Biological Medicine, 135, pp. 680684,1970 .

Pettus, J. P.; Geist, C. R.; and Schultze, G. E. Recovery from ma1nutrition food preference and neophobia. Perceptual Motor Skills, 38 (3), pp. 767-773, 1974.

Platt, B. S.; Heard, C. R.; and Stewart, R. J. Experimental proteincalorie deficiency. In: Mammalian Protein Metabolism. Academic Press, Vol. II, Chapter 21, New York, 1964.

Pilgrim, F. J.; Zabarenko, L. M.; and Patton, R. A. The role of amino acid supplementation and dietary protein level in serial. learning performance of rats. Journal of Comparative Physiological Psychology, 44, pp. 26-36, 1951 .

Pollftt, E. Behavior correlates of severe malnutrition in man. In: Nutrition, Growth and Development of North American Indian Children. Moore, W. M.; Silverberg, M. M.; Read, M. S. (Eds.), 1972 .

Portman, O. W.; Alexander, M.; and Illingsworth, D. R. Changes in brain and sciatic nerve composition with development of the Rhesus monkey. Brain Research, 43, pp. 197, 1972.

Portman, O. W.; Neuringer, M.; Illingsworth, D. R.; and Alexander, M. Developmental changes in the brain of the Rhesus monkey: The role of diet. Primate News, 10 (3), p. 5, 1972.

Ramalingaswamf, V.; Deo, M. G.; and Sood, S. K. Protein deficiency in the Rhesus monkey. In: Meeting Protein Needs of Infants and Children. Publication 843, National Academic Science, National Research Council, pp. 365-375, 1961.

Scrimshaw, N. S. and Behar, M. Protein malnutrition in young children. Science, 133, pp. 2039-2047, 1961.

Scrimshaw, Nevin Malnutrition, learning and behavior. American Journal of Clinical Nutrition, 5, p. 493, 1967. 
Simonson, M.; Hanson, H.: Herriott, R. M.; Stephan, J. K.; and Chan, B. $F$. Open field studies in offspring of underfed mother rats. Federal Proceedings, 28, p. 552, 1969.

Smart, J. Long lasting effects of early nutritional deprivation on the behavior of rodents. Psychiatra Neurologia, 74, p. 443, 1971.

Smart, J. and Dobbing, J. Vulnerability of developing brain. Passive avoidance behavior in young rats following maternal undernutrition. Developmental Psychobiology, 5, p. 129, 1972.

Smart, J. Activity and exploratory behavior of adult offspring of undernourished mother rats. Developmental Psychobiology, 7, p. $315,1974$.

Stein, Z.; Susser, M.; Saenger, G.; and Marolla, F. Famine and Human Development: the Dutch Hunger Winter of 1945-46. New York: Oxford University Press, 1975.

Stewart, R. J. and Platt, B. S. Nervous damage in experimental proteincalorie deficiency. In: Malnutrition, Learning and Development, Scrimshaw, N.S. and Gordon, J.E. (Eds.), Cambridge, Massachusetts: M.I.T. Press, pp. 168-180, 1967.

Stoch, M. B. and Smythe, P. M. Does undernutrition during infancy inhibit brain growth and subsequent intellectual development? Archives Diseases of Childhood, 38, pp. 546-552, 1963.

Stoch, M. and Smythe, P. Undernutrition during infancy and subsequent brain growth and intellectual development. In: Malnutrition, Learning, and Behavior, Scrimshaw, $\mathrm{N}$ and Gordon, J. (Eds.), Cambridge, Massachusetts: M.I.T. Press, p. 278, 1968.

Stollnitz, F. Spatial variables, observing response and discrimination learning sets. Psych. Review, 72, pp. 247-261, 1965.

Sulzer, J. L. Behavioral data from the Tulane nutrition study. Symposium malnutrition and learning in chlldren within U.S.A. American Association for the Advancement of Science, Boston, Massachusetts, 1969.

Sussman, M. B. Competence and options: a theoretical essay, implications for nutritional research. In: Nutrition, Development, Social Behavior. Kallen, D. (Ed.), DEHW Publication \#(NIH) 73242, pp. 251-275, 1972.

Trowell, H. C.; Davies, J. P.; and Dean, R. A. Kwashiorkor. First edition, London: Edward Arnold Publishers, Ltd., 1954.

Warren, J. M. and Maroney, R. J. Competitive sociai interaction between monkeys, Journal of Social Psychology, 48, pp. 223-233, 1958. 
Waterlow, J. C; Cravioto, J. and Stephen, J. M. L. Protein malnutrition in man. Advance. Protein Chem., 15:131, 1960.

Wells, A. M.; Geist, C. R.; Zimmerman, R. R. Influence of environment and nutritional factors on problem solving in the rat. Perceptual Motor Skills, 35, p. 235, 1972.

Whatson, T.; Smart, J.; Dobbing, J. Social interactions among adult male rats after early undernutrition. British Journal of Nutrition, 32, p. 413, 1974.

Whatson, T.; Smart, J.; and Dobbing, J. Dominance relationships among previously undernourished and well fed male rats. Physiology and Behavior, 14, p. 425, 1975.

Wiener, G. The ralationship of birth weight and length of gestation to intellectual development at ages 8 to 10 years. Journal of Pediatrics, 76, pp. 694-699, 1970.

Winick, M. and Noble, A. Cellular response in rats during malnutrition at various ages. Journal of Nutrition, 89, p. 300, 1966.

Winick, M. Nutrition and nerve cell growth. Federation Proceedings, 29, p. 1510, 1970 .

Winick, M. Mutrition and mental development. Medical Clinics of North America, 54, p. 1413, 1970.

Winick, M. and Rosso, P. The effect of severe early malnutrition on cellular growth of the human brain. Pediatric Research, 3, p. 181-184, 1969.

Witkop, C. J. Auditory memory span and oral stereodiagnosis in children recovered from Kwashiorkor. In: Second Symposium on Oral Sensation and Perception, Bosma, J. S. (Ed.), Springfield, Illinois, 1970.

Zimmermann, R. R. Effects of age, experience and malnourishment on object retention in learning set. Perceptual and Motor Skills, 28, p. 867,1970 .

Zimmermann, R. R.; Strobel, D. A.; and Maguire, D. Neophobic reactions in protein malnourished infant monkeys. Proceedings of the American Psychological Association. p. $1 \overline{97,} 1970$.

Zimmermann, R. R. and Strobel, D. A. Effects of protein malnutrition on visual curiosity, manipulation and social behavior in the infant Rhesus monkey. Proceedings of the Amertcan Psychological Association, pp. 197-198, 1970 .

Zimmermann, R. R.; Geist, C. R.; and Wise, L. A. Behavioral 
development, environmental deprivation, and malnutrition. In: Advances in Psychoblology, Vol. 2., Newton, G. and Riesan, A. H. (Eds.), John Wiley and Sons, Inc., pp. 133-392, 1970.

Zimmermann, R. R. and Wells, A. M. Performance of malnourished rats on the Hebb-Willians Closed-Field Maze Learning Task. Perceptual and Motor Sk11ls, 33, pp. 1043-1050, 1971.

Zimmermann, R. R. and Zimmermann, S. J. Responses of protein malnourished rats to novel objects. Perceptual and Motor Skills, 35 , p. 319,1972 .

Zimmermann, R. R.; Steeve, P. L.; Strobel, D. A.; and Hom, H. L. Abnormal soclal development of protein-malnourished Rhesus monkeys. Journal of Abnormai Psychology, 80, pp. 129-131, 1972.

Zimmermann, R. R.; Gelst, C. R.; Strobel, D. A.; and Cleveland, T. J. Attention defictencles in malnourished monkeys. In: Early Malnutrition and Behavioral Development. Carvioto, J.; Hambraeus, L.; and Vahlquist B. (Eds.), Stockholm, Sweden, 1974

Zimmermann, R. R.; Strobel, D. Z.; Steere, P.; and Ge1st, C. R. Behavior and malnutrition in the Rhesus monkey. In: Primate Behavior, Developments in Field and Laboratory Research, Rosenblum, L. A. (Ed.), New York: Academlc Press, 1975. 


\section{BIOCHEMISTRY BIBLIOGRAPHY}

Arroyave, G. The estimation of relative nutrient intake and nutritional status by blochemical methods: Proteins. American Journal of Clinical Nutrition, 11, p. 447, 1962.

Cohen, J. and Hansen, D. L. Metabolism of albumin and globulin in Kwashiorkor. Clinical Science, 23, pp. 351-359, 1963.

Deo, M. G.; Phan, V.; and Ramalingaswamt Metabolism of albumin and body Eluid compartments in protein deficiency. An experimental study in the Rhesus monkey. Department of Pathology, All India Institute of Medical Sclences, New nelh1.

Gitlin, D.; Cravioto, J.; Frank, S.; Montano, E. L.; Gomez, F.; and Janeway, C. A. Albumin metabolism in children with protein malnutrition. Journal of Clinical Invest., 37, p. 682, 1958.

Guyton, A. C. Textbook of Medical Physiology. Philadelphia, Pennsylvania: W. B. Saunders Company, 1971.

Hall, A. S. Keynote address: A clinical evaluation of the hematologic and blood chemical profiles of primates. Presented: Technicon International Congress, November, 1970.

K1rsch, R.; Frith, L.; Black, E.; and Hoffenberg. Regulation of Albumin synthesis and catabolism by alteration of dietary protein, Nature, $217: 578,1968$.

Kumar, Vifay; Chase, P. H.; Hammond, K.; and O'Brien, D. Alterations in blood biochemical tests. In: Progressive Protein Malnutrition. Pediatrics, Vol. 49, 1972.

LaJtha, A. Protein metabolism of the nervous system. In: International Review of Neuroblology. Pfeiffer, C. C. and Smythies, J. R. (Eds.), Vol. 6, New York: Academic Press, pp. 97-98, 1964 .

Munro, H. N. and Allison, J. B. Mammalian Protein Metabolism, Vol. I, New York: Academic Press, 1964.

Ordy, J. M.; Samorajski, T.; Zimmermann, R. R.; and Rady, P. M. Effects of postnatal protein deficiency on weight gain, serum proteins, enzymes, cholesterol, and liver ultrastructure in a subhuman primate (Macaca Mulatta). American Journal of Pathology, 48, pp. 769-791, 1966. 
Scrimshaw, N. S. and Behar, M. Malnutrition in underdeveloped countries. New England Journal of Medicine, 272:137, p. 193, 1965.

Ramanathan, M. K. Biochemical changes in the serum in nutritional oedema syndrome (Kwashiordor). Ind. Journal of Medical Research, 43, pp. 517-523, 1955.

Wannemacher, R. W.; Russe11, T. J.; and Allison, J. B. Serum and liver protein metabolism in protein-depleted dogs. Journal of Nutrition. 80, pp. 320-325, 1963. 
APPENDIX A

BLOOD BIOCHEMISTRY DATA

\section{Background}

The formation of cellular proteins is the basis of life itself. Guyton (1971) sums up the essential value of proteins with this description:

Three-fourths of body solids are proteins: structural proteins, enzymes, genes, proteins that transport oxygen, proteins of the muscle that cause contraction, and many other types that perform both intracellular and extracellular metabolic functions.

All proteins consist of unique combinations of the twenty-one different amino acids. There are eleven non-essential amino acids which are normally present in animal proteins and are readily synthesized by the cells. The ten essential amino acids are either produced in such miniscule amounts that they fail to meet bodily requirements, or cannot be synthesized at all. This second group must be provided in the diet for protein formation to take place in the body.

The organism attempts to maintain a steady state of equilibrium between plasma and tissue proteins. A constant state of flux ensues in which amino acids are transported, synthesized, degraded in order to maintain a constant ratio of total tissue proteins to total plasma proteins. Immediately following a meal the concentration of amino acids in the blood increases slightly. Protein digestion and 
absorption extend over a two to three hour period, permitting a gradual release of amino acids into the blood stream. The concentration of plasma proteins drops whenever the supply of amino acids is reduced, thereby limiting the amount of protein available to the cells and tissues of the body.

The body preferentially employs carbohydrates over fats and proteins as the energy source for its metabolic functions. When supplies of carbohydrates and/or fats are depleted, however, (as is true in the case of siarvation) the body draws upon its circulating supply of plasma proteins; when this source is exhausted, body tissues are broken down to supply proteins and their constituent amino acids for essential body functions ind for energy. In short, the body cannabalizes its own tissues.

One would expect a dietary regime deficient in protein to result in the depletion of proteins and amino acids in the blood, followed by the degradation of body tissue proteins which ultimately could lead to the deterioration of cellular functions. Lack of adequate dietary protein in the immature human or animal results in retarded growth and reduced weight gain.

Method

Throughout the duration of the experiment blood samples were drawn and the levels of several blood constituents were determined every three or four months. This provided a simple, direct, and objective assessment of the animals' nutritional status. The biochemical determinations included:

Total Serum Protein, by the Biuret procedure. 
Serum Albumin and Globulins, by the cellulose acetate electrophoresis method.

Serum Glucose, by the photometric method of Nelson.

Blood Urea Nitrogen, by the Berthrol reaction using urease.

Hemoglobin, determined from the optical density of a $1: 250$

dilution of blood and Drabkins solution with a $540 \mathrm{mu}$ filter on a Klett-Summerson colorimeter.

All Blood samples were collected before the morning feeding.

\section{Results and Discussion}

Total Serum Proteln. Plasma is the extracellular fluid present in the circulatory system of the body. It contains the proteins albumin, globulins, and fibrinogen. Numerous authors have noted decline in total serum proteins in kwashiorkor (Munro and Allison, 1964; Trowell, et al., 1954; and Scrimshaw, et al., 1965). A decrease in both total serum protein and albumin was found in human infants (Cohen and Hansen, 1963), young adult rhesus monkeys (Ramalingaswami, et a1., 1961; Ordy, et al., 1966), dogs (Wannemacher, et al., 1963), and pigs (Platt, Heard and Stewart, 1964) following protein deprivation. Lajtha (1964) found notable decreases in soluble proteins and amino acid pools following post natal protein deprivation. Kumar, et al., (1972) determined that total serum protein and albumin levels reflect long-term, progressive protein deprivation. These measures therefore serve as an index of the extent and severity of protein deficiency.

Total serum protein values obtained in this study confirm these previous findings of significant decreases as a consequence of long term post natal protein deficiency, in this case, extending into adulthood (Figure 24). 


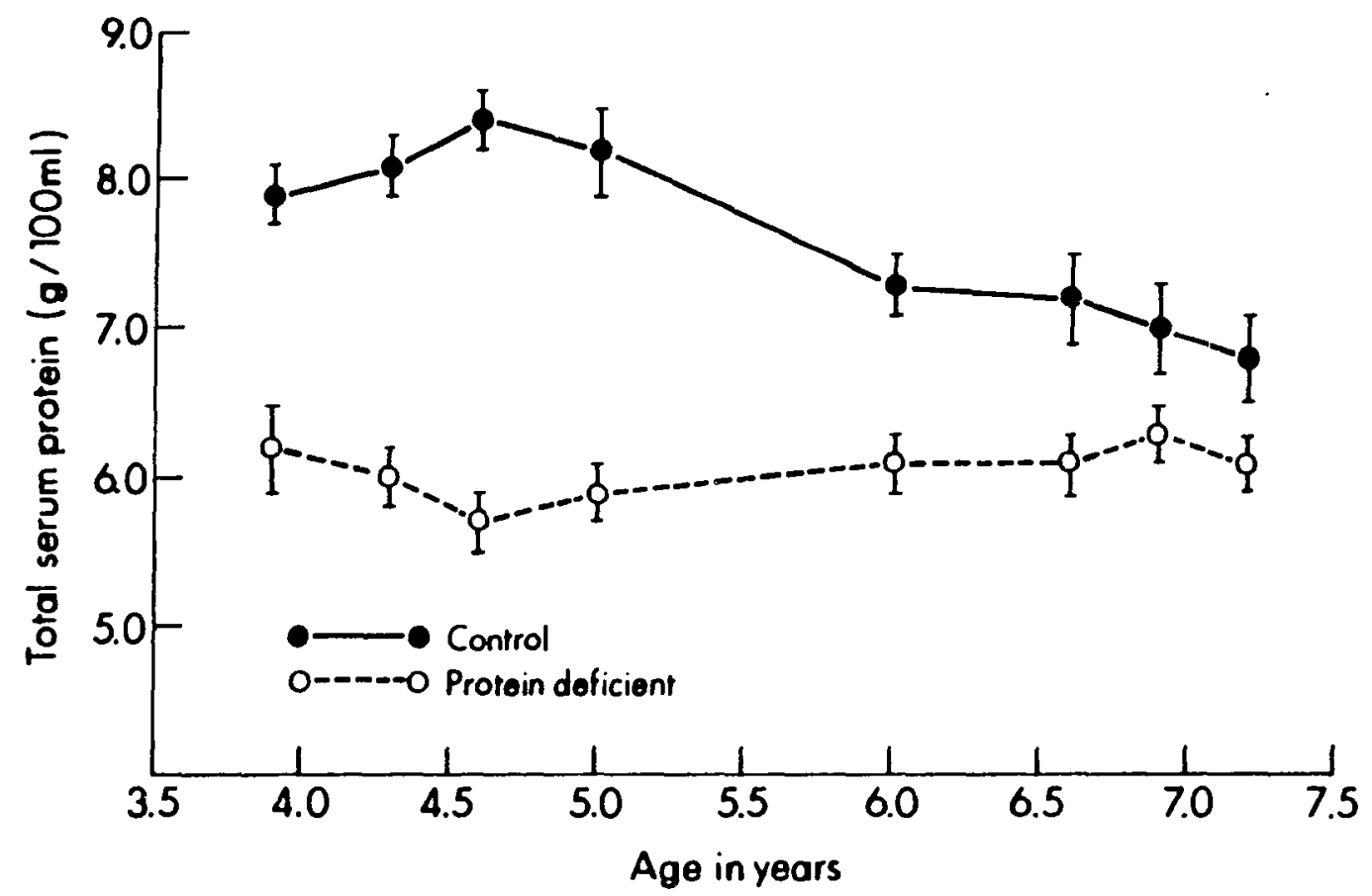

Figure 24. Effect of Dlet Condition on Serum Proteln Levels (Mean Plus and Minus S.E.). 
Albumin is a simple water-soluble protein which makes up the major portion of the plasma. One primary function is to provide colloid osmotic pressure which prevents plasma loss from the capillaries. Lowered levels of plasma albumin have been consistently reported in kwashiorkor (Trowell, et al., 1954; Scrimshaw, et al., 1961; Kumar, et al., 1972; Munro and Allison, 1964). In addition, a protein-deficient diet results in reduced plasma albumin levels in man (Scrimshaw and Behar, 1961; Arroyave, 1962), rhesus monkeys (Ordy, et a1., 1966), dogs (Munro and Allison, 1964), and rats (Wannemacher, 1961). This is thought to result from slower synthesis of albumin in the liver (Gitlin, et al., 1958; Wannemacher, 1961). Similar findings were obtained in this study (Figure 25).

Globulins are simple proteins that are poorly soluble in water but which will dissolve in a salt solution. Like albumin, they form a major portion of the plasma protein content. Globulins perform numerous enzymatic functions in the plasma; however, their primary functional role resides in the formation of antibodies. They are responsible for the organism's natural and acquired immunity against infections.

It is a well esti - shed fact that protein insufficiency reduces the body's natural resistance to disease processes (Guyton, 1971; Kumar, 1972; and Munro and Allison, 1964). These findings explain the observation in this study of greater incidence of shigellosls and other illnesses among the low protein animals than the control subjects. Globulin production should increase with bacterial infections, whereas albumin and total protein should 


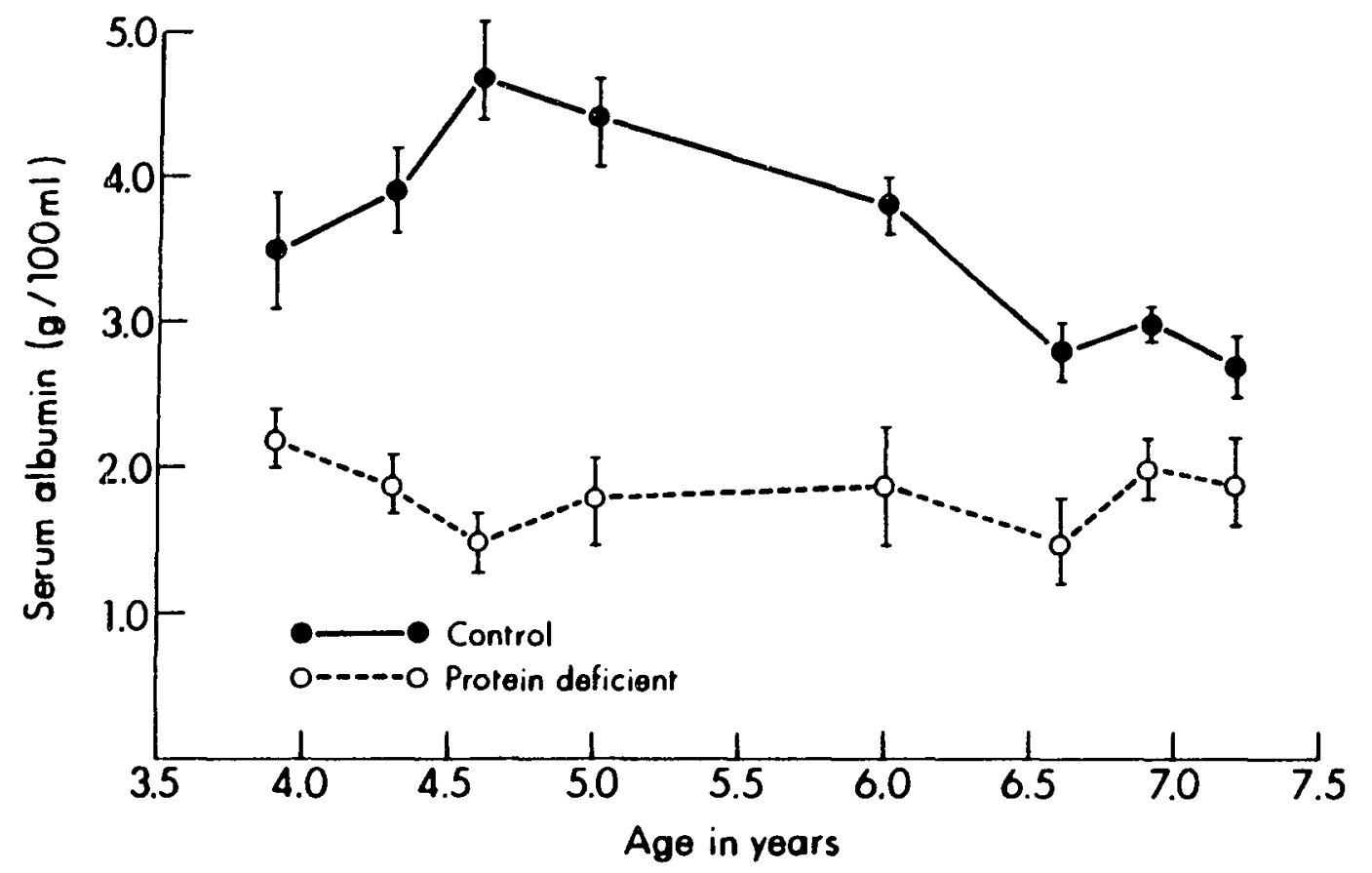

Figure 25. Effect of Diet Condition on Serum Albumin Levels (Mean Plus and Minus S.E.). 
decrease.

Globulin production has been reported to increase with protein deficlency in primates and man (Ordy, et al., 1966; Cohen and Hansen, 1963). However, other investigators reported no change in rhesus macaques (Kumar, et a1., 1972) or in pigs (Platt, Heard and Stewart, 1964) and small decrements in rats (Kirsh, et al., 1968) and humans (Ramanthan, 1955). This study demonstrated no change in gamma globulin levels (Figure 26).

Blood Urea Nitrogen (BUN) refers to the non-protein waste products resulting from protein metabolism. Urea must be removed from the body to insure continued protein metabolism in cells. Blood urea nitrogen is highly sensitive to disease. Infections produce a rapid loss of plasma protein which then shows up as increased BUN levels. Blood urea nitrogen levels also increase when renal blood flow is reduced by dehydration (as in more severe cases of shigellosis). Decreases in BUN levels produced by low dietary protein have been experimentally documented in humans (Ramanthan, 1955). Kumar, et al., 1972) determined that BUN reflects an immediate (acute) protein deprivation and therefore could be utilized as an early indicator of an organism's nutritional status. Unfortunately, as noted above, infections tend to compromise blood urea nitrogen data. In general, blood urea nitrogen levels were consistently lower for the protein deprived animals in this study (Figure 27).

Glucose is produced from carbohydrates and fats as well as amino acids via the mechantsm of gluconeogenesis. Serum glucose levels drop as a consequence of malnutrition. The low protein animals in this 


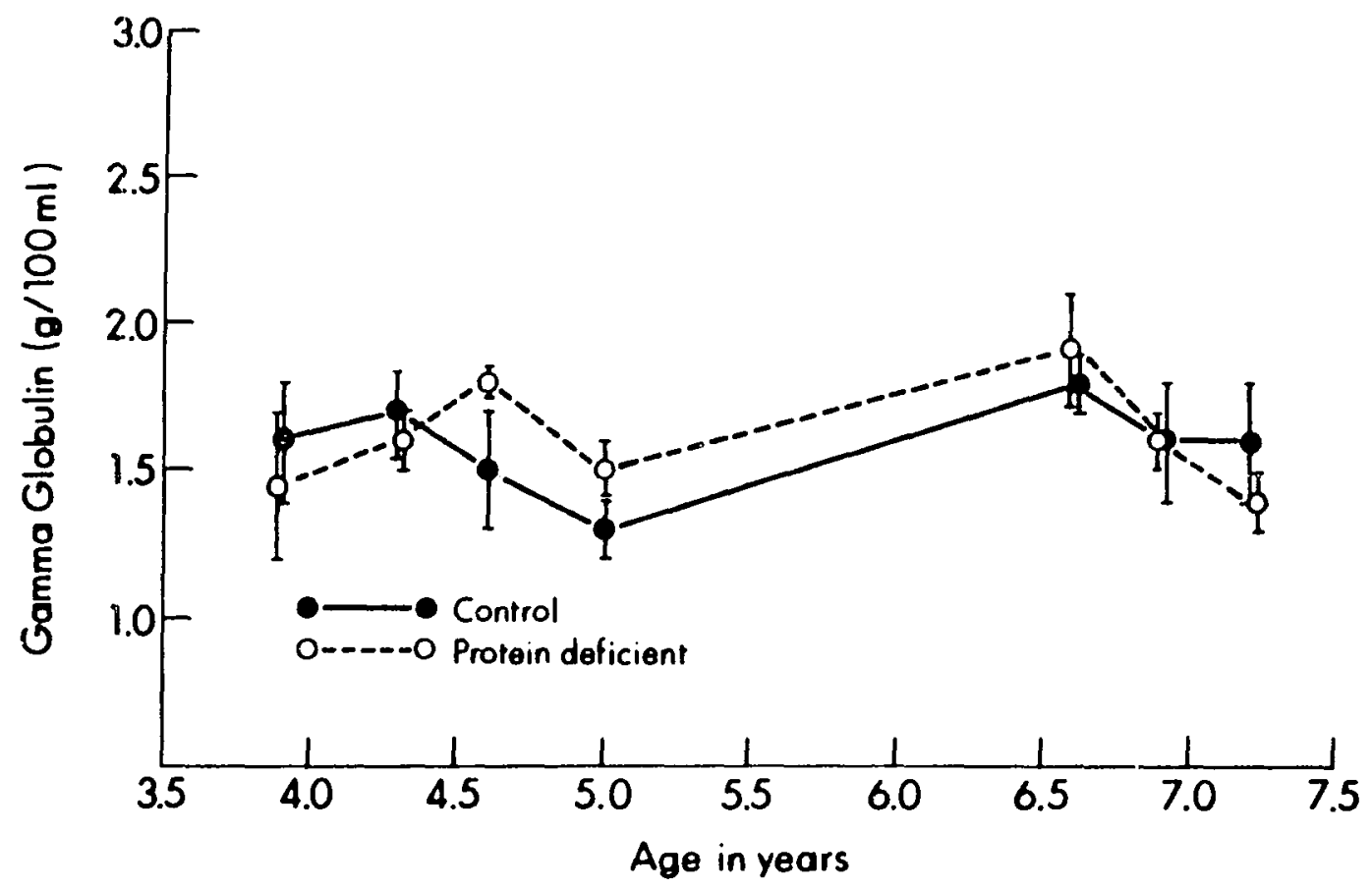

Figure 26. Effect of Diet Cond1tion on Gamma Globulin Levels (Mean Plus and Minus S.E.). 


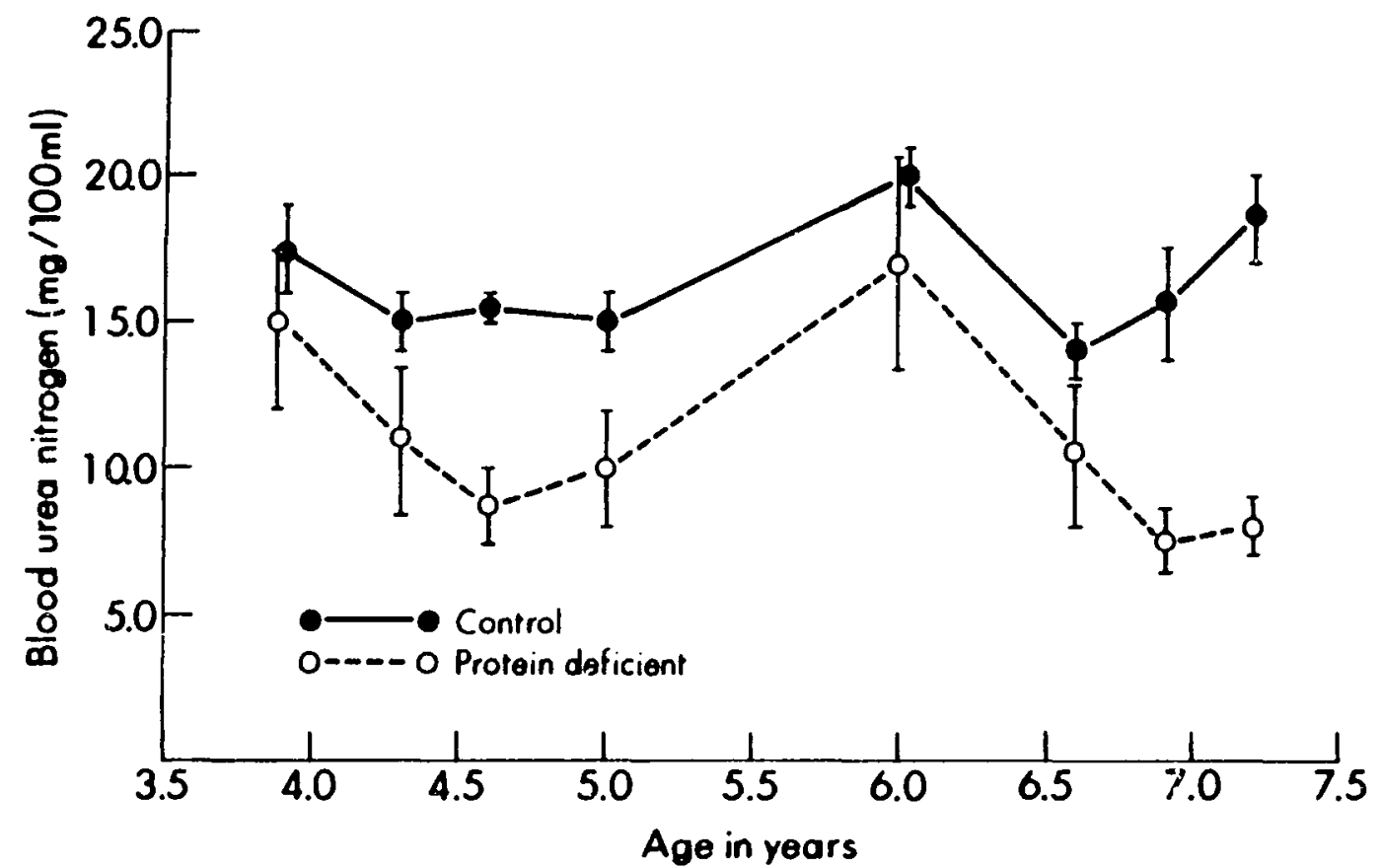

Figure 27. Effect of Diet Condition on Blood Urea Nitrogen Levels (Mean Plus and Minus S.E.). 
study received more calories and more sugar than did the control subjects; despite this, glucose levels for the low protein subjects were frequently well below those for the control group (Figure 28). Hemoglobin is a protein formed directly from amino acids and iron. It is found in red blood cells and performs the essential function of transporting oxygen from the lungs to the tissues. Reduced levels of hemoglobin and red blood cells result in anemia. Red blood cell production is stimulated by the body's demand; that is, if the amount of oxygen being carried to the tissues falls below the actual levels being utilized, production is triggered. However, production is limited by the supply of necessary amino acids, and therefore may be curtailed by insufficient availability of proteins. In this study, lowered hemoglobin levels were found in the low protein animals (Figure 29 ). 


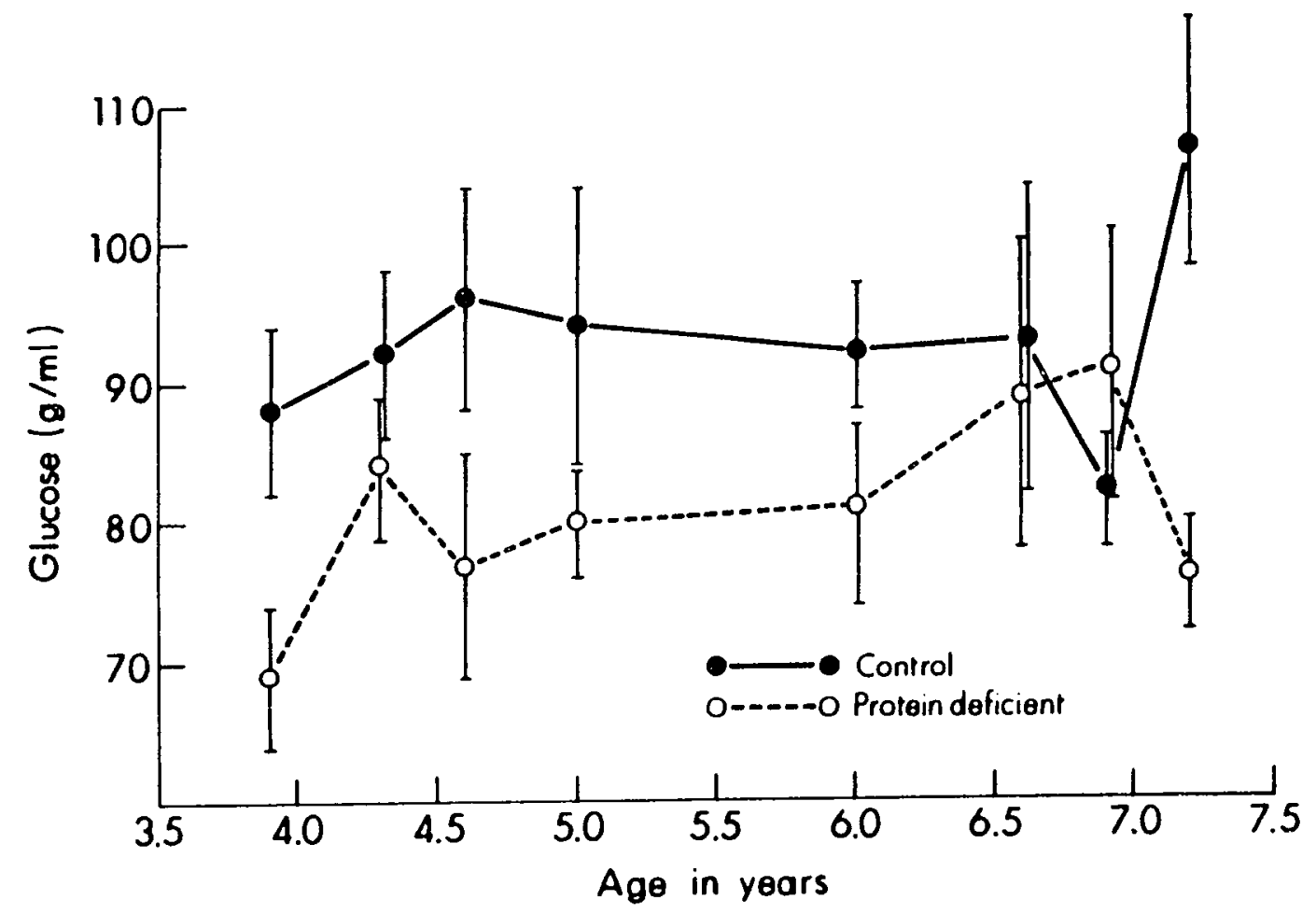

Figure 28. Effect of Diet Condition on Serum Glucose Levels (Mean Plus and Minus S.E.). 


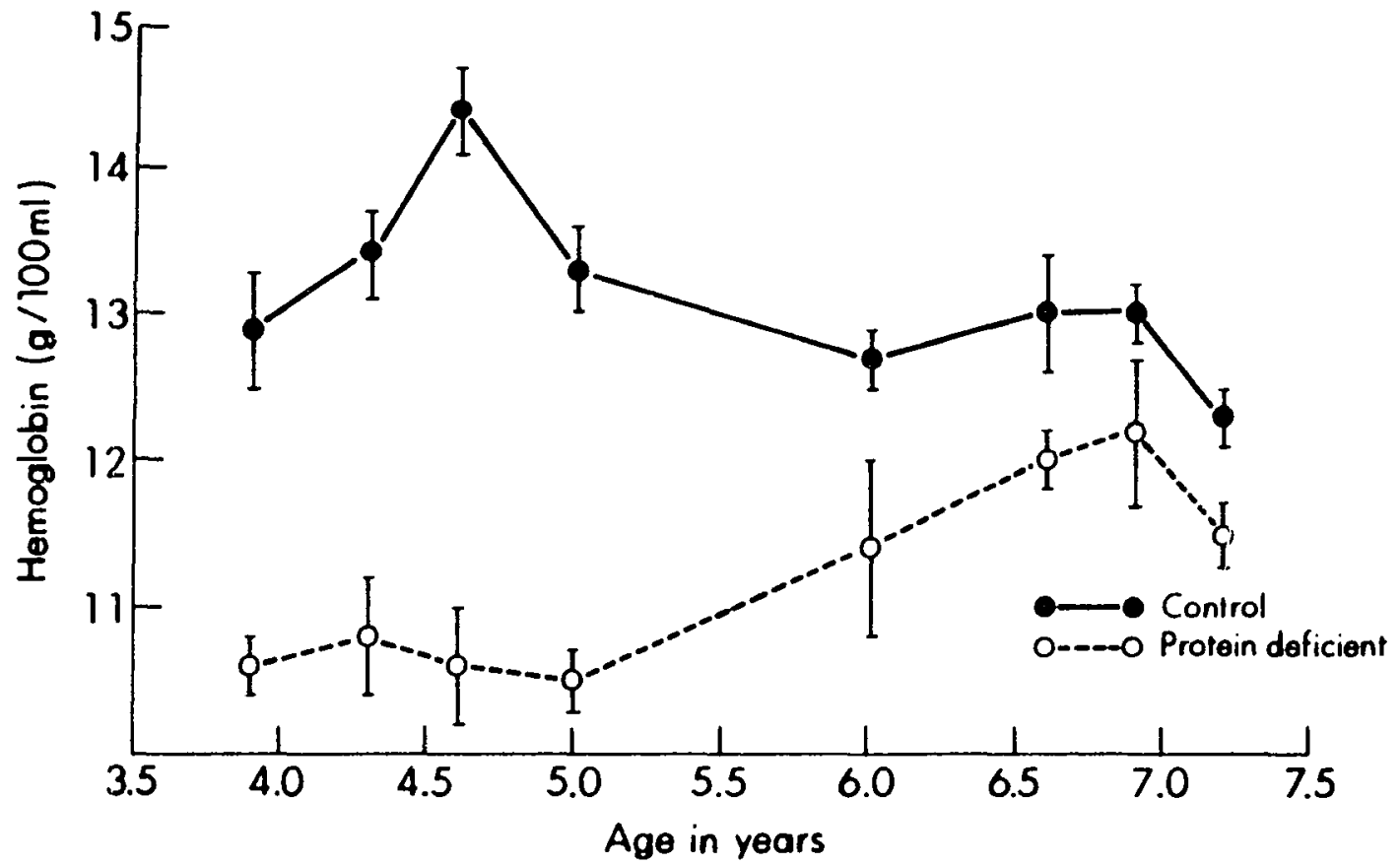

Flgure 29. Ef fect of Diet Condition on Hemoglobin Levels (Mean Plus and Minus S.E.). 


\section{APPENDIX B}

\section{EXPERIMENTAL HISTORIES}

\section{General Activity Levels}

General activity levels were measured by photo-electric units attached to the animal's home cage. An electromechanical counter recorded each time the animal passed through the beam of the electric eye. The sensitivity of the snoto-electric units was adjusted so that a gross motor movement was required to trigger the count. As previously mentioned, the overall activity levels between the two groups were identical.

\section{Visual Exploration}

A Butler box consists of a four unit cage, identical to the animal's home cage which has sheets of stainless steel metal instead of the usual wire mesh sides and ceiling. An animal housed inside this unit therefore has absolutely no visual contact to the outside world. The only means by which an animal could gain visual access outside its cage was to manually lift and hold open a small hinged door. An electromagnetic switch was activated by every opening of the door, which in turn cperated a counter and timer. In this fashion, the number of times an animal opened the door as well as a cumulative recording of the duration of time the door was held open was obtained per a given time period. The Butler box was positioned to face a concrete wall or to face another four unit cage housing 
other monkeys. The number of door openings was the same for both groups during baseline data collection (facing a concrete wall). However, the percentage increase over baseline was greater for the control versus low protein animal when provided with a view of other monkeys. The control subjects therefore manifested greater visual curiosity or exploration than did the protein deficient subjects.

\section{Puzzle Board Manipulation}

An automated puzzle board consisting of several hooks and hasps was placed in each subject's home cage. Recordings were made of the number of contacts with the puzzle board and the number of times the hooks and hasps were moved. The control group's performance exceeded that of the experimental group. Thus, the protein-deprived subjects utilized in this study had reduced interactions with their external environment both visually and tactually, despite equal levels of overall gross motor activity.

\section{Food Preferences}

When given a choice between two small color-coded bites of diet, the low protein subjects consistently preferred the control diet (green) over their usual deficient diet (yellow) whereas the control subjects evidenced no clear preference. The deficient animals also preferred a novel protein-deficient diet (dyed blue) in striking contrast to their neophobia in all other realms.

\section{Food Competition}

In food competition tests between pairs of subjects, control monkeys demonstrated dominance more often than protein-deprived ones. 
The control subjects were dominant in 78 per cent of the pairs of subjects from the same social group and in 57 percent of unfamiliar pairs, with subjects from different social groups.

\section{Dominance Hierarchies}

Subjects sharing a similar nutritional history were paired with one another, that is, controls with controls and protein-deficient with protein-deficient animals. The deficient group demonstrated fewer clear dominance relationships among one another than did the control group.

\section{Previous Attempts at Operant Conditioning}

Prior to this study, an attempt was made to teach these subjects a simple operant response in the form of a keypress. Operant conditioning was severly hampered by the deficient animals' neophobic reaction to the experimental chamber. The monkeys were obviously fearful and displayed the full repertoire of disturbed behaviors, including defecating, shrieking, huddling in the corner, self-clasping, self-mouthing, and rocking. Habituation sessions to adapt the low protein subjects to the chamber were conducted unsuccessfully for an entire year. Only one deficient subject acquired the response, whereas all the control animals habituated to the chamber and learned the instrumental response. 